\title{
Essays about Prerequisites for the Regulation of Risk Communication in Supply Chains with Respect to the European Community Regulation on Chemicals REACH (EC) No 1907/2006
}

\author{
Dissertation \\ zur Erlangung des wirtschaftswissenschaftlichen Doktorgrades \\ der Wirtschaftswissenschaftlichen Fakultät \\ der Universität Göttingen
}

vorgelegt von

Stephan Hensel, Diplom-Volkswirt aus Hannover

Göttingen, 2016 
$$
\text { Back to table of contents }
$$

Erstgutachter: Prof. Dr. Kilian Bizer
Zweitgutachter: Prof. Dr. Gerhard Rübel
Tag der mündlichen Prüfung: 24.10 .2016

Erstgutachter: Prof. Dr. Kilian Bizer
Zweitgutachter: Prof. Dr. Gerhard Rübel
Tag der mündlichen Prüfung: 24.10 .2016

Erstgutachter: Prof. Dr. Kilian Bizer
Zweitgutachter: Prof. Dr. Gerhard Rübel
Tag der mündlichen Prüfung: 24.10 .2016

Back to table of contents

Erstgutachter: Prof. Dr. Kilian Bizer
Zweitgutachter: Prof. Dr. Gerhard Rübel
Tag der mündlichen Prüfung: 24.10 .2016

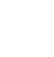

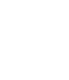




\title{
Table of contents
}

\author{
Introduction
}

\section{Part A}

The European Community Regulation on Chemicals REACH (EC) No 1907/2006

Considerations on the relation between positions and downstream risk communication within supply chains from the perspective of game theory

\section{Part B}

The European Community Regulation on Chemicals REACH (EC) No 1907/2006

Incentives for upstream risk communication within supply chains - considerations from the perspective of game theory

\section{Part C}

Smart regulation of downstream communication in a supply chain - experimental evidence (With Kilian Bizer; main author Stephan Hensel; Kilian Bizer contributed by interpreting the results through offering an explanation titled 'compensation for possible cognitive dissonances')

\section{Affirmation in lieu of an oath}




\section{Introduction}

The European Community Regulation on Chemicals (REACH) is supposed to be a modern and intelligent regulation. It entered into effect on June 1, 2007 and remains in its implementation phase. The modern and intelligent aspects primarily lie in the way in which self-responsible action on the part of the norm addressees should be linked with sovereign elements of the European Commission and the member states of the European Union. Especially given that many experiences have been collected since the beginning of the $\mathrm{REACH}$ implementation in 2007, it is worth focusing on some aspects in further detail now, especially with respect to the ambitious aims and expectations associated with this regulation.

"The purpose of this Regulation is to ensure a high level of protection of human health and the environment, including the promotion of alternative methods for assessment of hazards of substances, as well as the free circulation of substances on the international market while enhancing competitiveness and innovation. [...] This Regulation is based on the principle that it is for manufacturers, importers and downstream users to ensure that they manufacture, place on the market or use such substances that do not adversely affect human health or the environment. [...]" (Article 1 REACH-Regulation). In order to contribute to better regulation particularly within the European legislation - many means and procedures have been invented and established. The umbrella term under which all of these efforts can be merged is named Regulatory Impact Assessment (RIA). The work in hand applies some means of the RIA toolbox to study aspects of the REACH-Regulation in depth. Collectively, three papers focus on prerequisites for the regulation of risk communication in supply chains with respect to the REACH-Regulation. The considerations and results presented in this work have been acquired under the Responsive Regulation of Innovation Behavior for Sustainability research project, funded by the German Federal Ministry of Education and Research (Bundesministerium für Bildung und Forschung (BMBF)). According to the three papers, the structure of the work in hand has three parts, $A, B$ and $C$.

"The European Community Regulation on Chemicals REACH (EC) No 1907/2006: Considerations on the relation between positions and downstream risk communication within supply chains from the perspective of game theory" is the title of the first paper which constitute part A. As the title already suggests, in this paper game theory is used as an RIA tool to study the way in which positions in a supply chain influence the shape of downstream risk communication. Under the research hypothesis "The respective position within a supply chain influences the form of downstream risk communication", it is shown that stable downstream risk communication in the form of equilibria emerges and that the quality of the 
emerging downstream risk communication is sensitive to the different positions in the supply chain that are analyzed here.

In order to change the viewing direction from downstream to upstream risk communication, part B contains a paper entitled "The European Community Regulation on Chemicals REACH (EC) No 1907/2006: Incentives for upstream risk communication within supply chains - considerations from the perspective of game theory". Again, game theory is used as an RIA tool to explore the hypothesis "There exists no incentive for upstream risk communication in compliance with REACH within the supply chain". The results from the equilibrium analysis demonstrate that the normative requirements set forth by $\mathrm{REACH}$ in this context could be met under certain conditions. Especially this paper derives its importance through the fact that elaborations on the functioning of upstream risk communication are difficult to find, in comparison to reflections on downstream risk communication. However, one key element of REACH is the implementation of risk communication that works in both directions, upstream and downstream.

Alongside game theory, the means of experimental economics are also appropriate in the context of RIA. Besides risk communication up and down the supply chain, self-responsible action on the part of norm addressees is another key element of REACH. Accordingly, part $\mathrm{C}$ of the work in hand addresses issues of self-responsible behavior on part of the norm addressees. Under the title "Smart regulation of downstream communication in a supply chain - experimental evidence", prerequisites and factors are studied that self-responsible behavior - in compliance with the normative requirements set forth by $\mathrm{REACH}$ - may help to happen. This is achieved by exploring the two hypotheses "If they are not sanctioned for noncompliant behavior, the actors will choose the form of downstream communication that brings them the highest cooperation gain possible, even if this form is not conformable to law" and "If non-compliant behavior is not sanctioned, the way of dividing the cooperation gain made through a form of downstream communication between two norm addressees is independent of whether this form is conformable to law". The results show that selfresponsible norm-compliant behavior does not emerge automatically and reveal factors that seem to be crucial in this context. This third paper is jointly work together with Kilian Bizer, who contributed to this paper by interpreting the results through offering an explanation titled 'compensation for possible cognitive dissonances'.

All three papers presented in the parts $A$ to $C$ constitute the cumulative dissertation of Stephan Hensel, who is grateful to all persons who contributed to prepare this work in hand. 
$$
\text { Back to table of contents }
$$

Part A

Part A

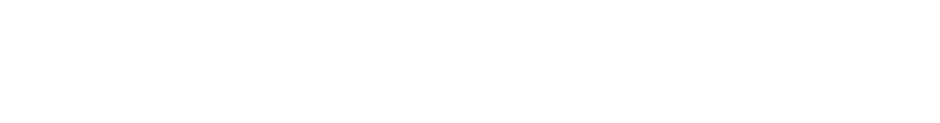

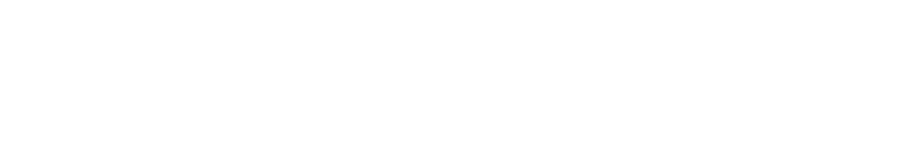




\title{
The European Community Regulation on Chemicals REACH (EC) No 1907/2006 \\ Considerations on the relation between positions and downstream risk communication within supply chains from the perspective of game theory
}

\author{
Stephan Hensel ${ }^{a}{ }^{\dagger}$ \\ ${ }^{a}$ Chair of Economic Policy and SME Research, Faculty of Economic Sciences, University of Göttingen, Platz der Göttinger \\ Sieben 3, 37073 Göttingen, Germany
}

\begin{abstract}
This paper is concerned with the European Community Regulation on Chemicals REACH. It seeks to theoretically model the forms that the transfer of information may take relatively at the beginning and end of a supply chain, respectively, from the perspective of game theory. One central aim of REACH - among others - is to establish high standards for passing on information within the entire supply chain to ensure a functioning downstream risk communication. REACH uses an approach of regulation based on control theory. This approach combines sovereign regulation with self-responsible action on the part of norm addressees. In consideration of the normative purposes of REACH, the game theoretical approach serves as a basis for further inquiry into the question concerning at which points a failure to act in accordance with the regulation's aims may be considered as a rational choice on the part of the norm addressee. Finally, this paper aims to underscore game theory's claim as an important method and tool for the purpose of Regulatory Impact Assessment.
\end{abstract}

KEYWORDS: Environmental Law and Economics, Risk Communication, Self-Responsibility, Game Theory, Perfect Bayesian Equilibrium, Regulatory Impact Assessment

JEL classifications C70, K32

\section{Acknowledgements}

The author is grateful for the support of Richard Forsythe and Nikolas Helm, who helped to prepare the English version of this paper. The Federal Ministry of Education and Research (Bundesministerium für Bildung und Forschung (BMBF)) enabled the considerations reported here by funding the research project "Responsive Regulation of Innovation Behavior for Sustainability”.

${ }^{\dagger}$ Corresponding author Stephan Hensel

E-mail address: Stephan.Hensel@wiwi.uni-goettingen.de 


\section{Part A}

\section{Introduction}

On June 1, 2007, the regulation (EC) No 1907/2006 on Registration, Evaluation, Authorisation and Restriction of Chemicals came into effect (REACH-Regulation). "This Regulation is based on the principle that it is for manufacturers, importers and downstream users to ensure that they manufacture, place on the market or use such substances that do not adversely affect human health or the environment. [...]" [Art. 1 (3) REACH-Regulation]. At several points throughout the regulation, it is suggested that norm addressees along the entire supply chain have a responsibility ${ }^{1}$ to transfer information regarding chemicals among each other to ensure the safe handling of substances or preparations. This is what the regulation refers to as the chain of responsibility ${ }^{2}$, pointing to its basis in control theory, an approach that seeks to combine sovereign regulation with self-responsible ${ }^{3}$ action on the part of norm addressees ${ }^{4}$. From the perspective of the regulator, rational and self-responsible downstream risk communication on the part of norm addressees has the advantage that it emerges in the course of the pursuit to maximise utility. This can cause communication to stabilise and thus create a situation in which no norm addressee may have reasons to one-sidedly depart from the status quo. Game theory analyzes such stable states by using equilibrium concepts and thus is used as the methodology in this paper. By means of Regulatory Impact Assessment (RIA), ${ }^{5}$ it should attempt to ascertain whether the theoretically-occurring risk communication meets the normative requirements of $\mathrm{REACH}^{6}$. The regulation sets forth uniform requirements for downstream risk communication within an abstract supply chain ${ }^{7}$. One important requirement is the use of a tool referred to as a safety data sheet throughout the entire supply chain. As surveys on the quality of safety data sheets prove, the level of refinement of safety data sheets often varies (e.g. European Commission (COM (2013) 49 final) 2013; European Chemicals Agency (ECHA) 2011; Nationaler Normenkontrollrat 2012; Mayer-Figge 2013; Bunke, Rühl 2011). This causes downstream risk communication to assume various different shapes in everyday practical use. In fact, a supply chain often comprises several different actors who occupy different positions along the supply chain. For instance, the manufacturers and/or importers of substances or preparations are located at the beginning of the supply chain, whereas the last downstream user before the end user marks the end of the supply chain. In this paper, I analyze the influence of positions within the supply chain regarding the shape of downstream risk communication. For this purpose, I will compare the shape that the transfer of information takes relatively at the beginning and end of a supply chain from the perspective of game theory. The shape of downstream risk communication will be assessed according to whether the information was transferred by means of a detailed or relatively less detailed safety data sheet. My research hypothesis is: The respective position within a supply chain influences the form of downstream risk communication! For this purpose, I will briefly summarise the information stated by REACH on the various actors and positions, the requirements to be met regarding downstream risk communication in the supply chain and regarding the safety data sheet (chapter 2). These considerations act as a starting point for game theoretical modelling and a subsequent equilibrium analysis. I have deliberately chosen a more extensive form of modelling as this will enable a more substantial

\footnotetext{
1 “ $[\ldots]$ This important responsibility should also apply throughout the supply chain to enable all actors to meet their responsibility in relation to management of risks arising from the use of substances.” (Recital 56 REACH-Regulation)

${ }^{2}$ See Recital 58 REACH-Regulation.

${ }^{3}$ General considerations on strengths and weaknesses of regulatory approaches including self-responsibility on part of norm addresses are given in Krarup 2001 and Börzel, Risse 2010.

${ }^{4}$ Further information on this regulatory approach with respect to European chemicals policy can be found in Führ, Bizer 2007 and Hey et al. 2007.

${ }^{5}$ Hensel et al. 2010 contains an actual overview about the application of regulatory impact assessment in practice and recent developments.

${ }^{6}$ Incentives and constraints with respect to REACH are analyzed by Führ 2010.

${ }^{7}$ REACH-Regulation defines in Article 3, No. 17: "For the purposes of this Regulation: [...] actors in the supply chain: means all manufacturers and/or importers and/or downstream users in a supply chain;".
} 
discussion of possible determining factors against the background of the aforementioned hypothesis. Hereunto the player's payoffs will be decompiled into utility components. The results of the analysis will be discussed regarding both form and content (chapter 3). Within the concluding remarks (chapter 4), the results will be evaluated against the background of REACH's regulatory framework. Furthermore, this paper seeks to stimulate the use of game theory (Gibbons 1997) in the context of RIA. ${ }^{8}$

\section{Positions and forms of downstream risk communication within the supply chain - normative requirements set forth by REACH}

\subsection{Positions within the supply chain}

The great variety of different processes within the chemical industry is reflected by the states of affair that prevail in supply chains. Accordingly, one may identify differences concerning the dimension and length of different supply chains, as well as the number of actors, the frequency and the duration of contacts within a supply chain, the kind of substance or preparation or the kind of manufacturing processes. This short list is most likely not even exhaustive. In Article 3 No. 17 of REACH, the regulation text states "actors in the supply chain: means all manufacturers ${ }^{9}$ and/or importers ${ }^{10}$ and/or downstream users ${ }^{11}$ in a supply chain”. Figure 1 illustrates the different groups of actors and their accustomed positions within the supply chain.

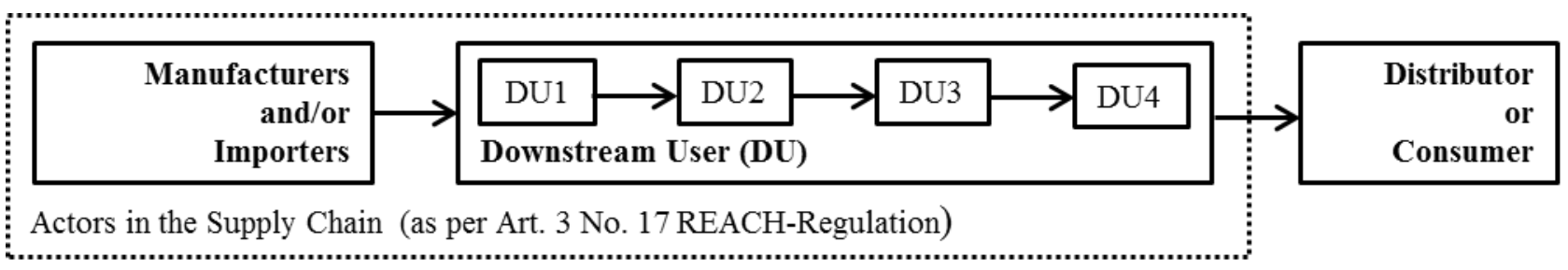

\section{FIGURE 1 ACTORS IN THE SUPPLY CHAIN}

\subsection{Downstream risk communication - normative requirements set forth by REACH}

The recitals to REACH contain various hints ${ }^{12}$ concerning how communication between actors within the supply chain pertaining to substance-related risks should be conducted. Alongside the often-repeated stress on the self-

\footnotetext{
${ }^{8}$ An evaluation of the quality of impact assessment in the European Union is given by Cecot et al. 2008.

${ }^{9}$ Defined in Art. 3 No. 9 REACH-Regulation: "manufacturer: means any natural or legal person established within the Community who manufactures a substance within the Community;".

${ }^{10}$ Defined in Art. 3 No. 11 REACH-Regulation: "importer: means any natural or legal person established within the Community who is responsible for import;".

${ }^{11}$ Defined in Art. 3 No. 13 REACH-Regulation: "downstream user: means any natural or legal person established within the Community, other than the manufacturer or the importer, who uses a substance, either on its own or in preparation, in the course of his industrial or professional activities. A distributor or a consumer is not a downstream user. [...]."

${ }^{12}$ Amongst others. "[...] This Regulation is based on the principle that industry should manufacture, import or use substances or place them out the market with such responsibility and care as may be required to ensure that, under reasonably foreseeable conditions, human health and the environment are not adversely affected." (Recital 16); "[...] recommendations about risk management measures should systematically be conveyed through supply chains, as reasonably necessary, to prevent adverse effects on human health and the environment. [...]". (Recital 17); "Responsibility for the management of the risks or substances should lie with the natural or legal persons that manufacture, import, place on the market or use these substances. [...]." (Recital 18); "The responsibility to assess the risks and hazards of substances should be given, in the first place, to the natural or legal persons that manufacture or import substances, [...]. Natural or legal persons handling chemicals should take the necessary risk management measures in accordance with the assessment of the risks of substances and pass on relevant recommendations along the supply chain. This should include describing, documenting and notifying in an appropriate and transparent fashion the risks stemming from production, use and disposal of each substance." (Recital 25); "Part of the responsibility of manufacturers or importers for the management of the risks of substances is the communication of information on these substances to other professionals such as downstream users or distributors. [...]. This important responsibility should also apply throughout the supply chain to enable all actors to meet their responsibility in relation to management of risks arising from the use of substances." (Recital 56); "In order to have a chain of responsibilities, downstream users should be responsible for assessing the risks arising from their uses of substances if those uses are not covered by a safety data sheet received from their suppliers, unless the downstream user concerned
} 
responsibility of actors, emphasis is placed upon the safety data sheet as a means by which communication within the supply chain may be conducted: "As the existing data sheet is already being used as a communication tool within the supply chain of substances and preparations, it is appropriate to develop it further and make it an integral part of the system established by this Regulation" (Recital 57).

\subsubsection{The safety data sheet - a communication tool}

The safety data sheet (SDS) is an important communication tool within supply chains. It is supposed to ensure accurate handling of substances by means of transferring safety-related information. ${ }^{13}$ It is primarily addressed to professional users of substances and preparations and is supposed to help them to take all necessary precautions to guarantee safety, as well as upholding standards for the protection of health and the environment in the workplace (Bundesanstalt für Arbeitsschutz und Arbeitsmedizin (BAuA) 2008). The practice of SDSs predates REACH, although since the latter's coming into effect the SDS has also come to be legally based on it and now provides specific information demanded by REACH. According to Article 31 (1) REACH-Regulation, the supplier ${ }^{14}$ of a substance or preparation shall provide the recipient with a data sheet, where a substance or preparation meets the criteria for classification as dangerous, where a substance is persistent, bioaccumulative and toxic or very persistent and very bioaccumulative and where a substance is included in the list ${ }^{15}$ established in accordance with Article 59 (1) for reasons other than those referred to before. In ANNEX II "Guide to the compilation of safety data sheets" of the regulation, quality criteria for the creation of a SDS are stated and its composition is explained. There are safety-related details to be given under sixteen ${ }^{16}$ headings. According to ANNEX II, the SDS should be compiled by a competent person and the details should be given in "a clear and concise manner". The notion of what exactly constitutes "a clear and concise manner" appears to be relative to the substance or preparation in question and thus needs to be specifically interpreted for each case. Moreover, the sixteen headings of the SDS differ regarding their respective input requirements. Thus, on the one hand, the amount of time spent on the work on a heading depends on the amount of information required, while on the other hand, the input requirements are of differing kinds; for instance, some headings possess the character of command fulfilment obligations, while others are more like target fulfilment obligations (Hensel 2011). The difference between these two types of obligations is that in the case of a command fulfilment obligation, it is precisely stated what is required to the fulfilment of the obligation. In the case of a target fulfilment obligation, the aim is also stated, albeit not the way in which the obligation may be fulfilled. For example, heading 9 "Physical and chemical properties" on the SDS principally corresponds more to a command fulfilment obligation. This is because the input requirement is comparatively clearly defined here, e.g. appearance, $\mathrm{pH}$, boiling point/boiling range vapour pressure [...]. By contrast, headings 4 "first-aid-measures" and 12 "ecological information" possess characteristics that are more like target fulfilment obligations. Accordingly, under heading

takes more protective measures than those recommended by his supplier or unless his supplier was not required to assess those risks or provide him with information on those risks. [...]." (Recital 58).

${ }^{13}$ The most relevant information pertaining to this issue is given under TITLE IV and V of the REACH-Regulation. A precise guideline concerning the creation of a safety data sheet is given in ANNEX II of the REACH-Regulation "Guide to the compilation of safety data sheets".

${ }^{14}$ Defined in Art. 3 No. 32 REACH-Regulation: "supplier of a substance or a preparation: means any manufacturer, importer, downstream user or distributor placing on the market a substance, on its own or in a preparation, or a preparation;".

${ }^{15}$ This list names substances which cannot be used without restrictions from a special point in time (sunset-date). After this date a special authorisation is required. The list is also known by the expression "candidate-list".

${ }^{16}$ Defined in Art. 31 No. 6 REACH-Regulation: "The safety data sheet shall contain the following headings: 1. identification of the substance/preparation and of the company/undertaking; 2. hazards identification; 3. composition/information on ingredients; 4. first-aid measures; 5. fire-fighting measures; 6. accidental release measures; 7. handling and storage; 8 . exposure controls/personal protection; 9. physical and chemical properties; 10. stability and reactivity; 11. toxicological information; 12. ecological information; 13. disposal considerations; 14. transport information, 15. regulatory information, 16. other information." 
4 details are inter alia required "which shall be brief and easy to understand by the victim, bystanders and firstaiders." For heading 12, there results input requirement from ANNEX II to the extent that possible effects, behavior and the environmental fate of the substance or preparation in air, water and/or soil have to be described. This is also a reason why in practice there is a great variety of different SDSs, all of which differ regarding their intelligibility and detail. Therefore, it is plausible to suppose that downstream risk communication in practice may assume different forms. Differences in the form of downstream risk communication may thus generally be seen as being rooted in differing levels of refinement of the SDS. This is assumed in this paper.

\section{Positions and forms of downstream risk communication within a supply chain - considerations from the perspective of game theory}

The aim of this chapter is to translate the aforementioned practical aspects pertaining to positions in the supply chain and the requirements to be met by downstream risk communication into a theoretical framework. This will be achieved against the background of the previously-formulated research hypothesis that positions in the supply chain influence the shape of downstream risk communication.

\subsection{Basis game}

The game under consideration is a dynamic game with pure strategies and incomplete information (Gibbons 1992). There are two enterprises that may enter into a business relation with one another in the context of a supply chain. The enterprise that thereby assumes the role of seller is referred to as the upstream enterprise. The role of buyer is attributed to the downstream enterprise. The two enterprises will be referred to as player 1 and player 2. The basis game functions in the following way:

Stage 1: Nature draws a type $t_{i}$ of player 1 as the upstream enterprise in the supply chain from a set $\mathrm{T}=($ player $1_{\mathrm{t} 1}$; player $1_{\mathrm{t} 2}$ ). This may be an enterprise that is competent in its handling of chemicals and that either meets or exceeds the requirements set out by REACH (player $1_{t 1}$ ). The latter case means that this enterprise meets requirements that are stricter than necessary. The type of enterprise player $1_{\mathrm{t} 2}$ is characterised by less safe handling of chemicals in comparison to player $1_{\mathrm{t} 1} \cdot{ }^{17}$ Player $1_{\mathrm{t} 1}$ 's share of the population amounts to $\alpha$ and player $1_{\mathrm{t} 2}$ 's share is $1-\alpha$. After the initial draw of nature, the respective enterprise player 1 is aware of what type it is. Furthermore, all players have the same probability estimates regarding the draw of nature (common priors) and these are common knowledge. Furthermore, the following applies: $0<\alpha<1$. Stage 2: The upstream enterprise (player 1) - which in this game takes on the role of the sender - sends out a signal to the downstream enterprise (player 2) in the supply chain. In the context of the game, the signals correspond to differing levels of refinement of the SDS, which is regarded as an important tool for the purpose of downstream risk communication. ${ }^{18} \mathrm{~S}=$ $\left(\mathrm{SDS}_{\mathrm{g}} ; \mathrm{SDS}\right)$ defines the set of signals from which the sender may choose. $\mathrm{SDS}_{\mathrm{g}}$ stands for safety data sheet gold $^{19}$ and refers to a very extensive SDS. By contrast, SDS stands for a safety data sheet that is less extensive compared to $\mathrm{SDS}_{\mathrm{g} .}{ }^{20}$ Stage 3: The downstream enterprise (player 2) - which assumes the role of the receiver in

\footnotetext{
${ }^{17}$ This characteristic of player $1_{\mathrm{t} 2}$ may not be equated with the statement that player $1_{\mathrm{t} 2}$ does not fulfil the requirements set out by REACH, although the assumption of non-fulfilment of requirements set out by REACH does not run contrary to the characterisation made here.

${ }^{18}$ Hereunto see my elaborations in chapter 2.

${ }^{19}$ The subfix " $\mathrm{g}$ " labels this kind of safety data sheet. In addition this subfix has been chosen to set up the link to the term "gold plating" which is common in the language use of the European institutions, see European Commission.

${ }^{20}$ This characterisation of the data sheet with the level of refinement SDS may not be equated with the statement that the level of refinement SDS does not fulfil the requirements set out by REACH, although the assumption of non-fulfilment of requirements set out by REACH does not run contrary to the characterisation made here.
} 


\section{Part A}

this game - observes the signal sent by the upstream enterprise (player 1). However, player 2 cannot observe the type of the upstream enterprise of player 1, whereby in this respect it is confronted with uncertainty. As a result, player 2 must develop beliefs regarding the chances of what type of player 1 he might be confronted with after having observed a certain signal. The relevant decision nodes are marked as information sets in Figure 2 and are framed by a dashed line. This game contains two information sets that correspond to the sum of possible signals $\mathrm{S}=\left(\mathrm{SDS}_{\mathrm{g}} ; \mathrm{SDS}\right)$. The beliefs at the decision nodes within the information sets are labelled $\rho$ and $\psi .1-\rho$ and $1-\psi$ are the respective converse probabilities in a corresponding information set. After having observed a signal, player 2 can choose an action to react to it. The set of possible actions from which player 2 can choose is $\mathrm{A}=$

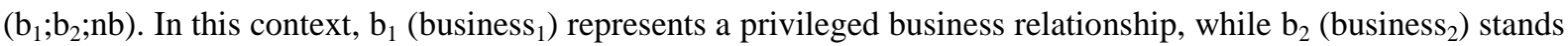
for a relationship with an upstream enterprise, which is equipped with relatively less favourable conditions in comparison to $b_{1}$. For instance, the privileged status of $b_{1}$ may comprise a longer contract duration ${ }^{21}$ or the purchase of greater amounts of substances or preparations. ${ }^{22}$ Of course, player 2 may also not enter a business relationship with the upstream enterprise at all. In this case, he chooses action nb (no business). The game finishes after player 2 has made his move.

\subsubsection{The payoffs of player 1 and player 2}

Player 1: The upstream enterprise within the supply chain achieves a utility component "W" if it happens to create the correct SDS in its case. In the present game, this case applies under the condition that player $1_{\mathrm{t} 1}$ creates an extensive data sheet $\operatorname{SDS}_{\mathrm{g}}$, while player $1_{\mathrm{t} 2}$ creates a data sheet that is less extensive compared to SDS . The first reason for this attribution of the utility component $\mathrm{W}$ is due to the avoided and unnecessary compliance efforts in the case of the creation of a SDS. The enterprises differ from one another regarding the way in which chemicals are being handled (for instance, the level of care, the collection and documentation of information pertaining to this, the human resources involved). This may make it either easier or more difficult for them to create a SDS with a certain level of extensiveness. In so far as they succeed in creating a SDS that possesses the level of extensiveness that is suitable in their case, they are able to avoid additional compliance efforts. In this case, the utility component $\mathrm{W}$ is to be interpreted as a utility increase by means of avoiding unnecessary compliance costs/efforts. A second reason is the psychological role played by a certain level of extensiveness of a SDS. In the case that an enterprise should use deception - for instance, through consciously omitting information or cheap talk - there is the danger of legal consequences. Furthermore, the enterprise's conscience (of course, given that such a thing exists in the first place) will be strained by the knowledge that a conscious attempt of deception has occurred. Likewise, the fear of the deception being discovered may cause psychological pressure, especially in the case of conscious deception. In this case, the utility component $\mathrm{W}$ must be interpreted as a utility increase caused by avoided conscious deception. Alongside the creation of the correct SDS, enterprise player 1 achieves a utility increase if a business relation materialises. In so far as this business relation poses as a privileged business relation $\mathrm{b}_{1}$, the utility increase amounts to " $\mathrm{X}_{1}$ ". However, in case this business relation poses as a less privileged business relation $\mathrm{b}_{2}$, the utility increase amounts to " $\mathrm{X}_{2}$ ". Furthermore, all utility components of player 1 are larger than zero: $\mathrm{W}>0, \mathrm{X}_{1}>0, \mathrm{X}_{2}>0$.

\footnotetext{
${ }^{21}$ This assumption can be justified by reference to transaction cost theory. Costs of finding new potential business associates can be reduced. ${ }^{22}$ Depending on the subsector, the supply chain itself and the respective position within the supply chain, there exist a multitude of further conditions, which in a specific supply chain may constitute a privilege.
} 


\section{Part A}

Player 2: The downstream enterprise achieves a utility increase of " $\mathrm{Y}$ " irrespective of which business relation materialises. Its participation in market action is the original purpose of an enterprise. In case that no business relation should materialise, at least some fixed costs will have to continue to be paid for a short time. For example, this would apply in the case of wages, fixed in employment contracts, or rents for facilities and infrastructure. Alongside the participation in market action, the choice of an upstream enterprise player 1 as a business associate has an impact upon the utility components of the downstream enterprise player 2, depending upon whether this upstream enterprise is of type player $1_{\mathrm{t} 1}$ or type player $1_{\mathrm{t} 2}$. The following consideration should make this clear. The downstream enterprise player 2 wants to build a reputation. At the same time, he seeks to protect himself from a potential loss of reputation. A reputation is usually built through prudent and sophisticated action within the supply chain. Player 2 builds a reputation by only entering into privileged business relationships with player $1_{\mathrm{t} 1}$. Player $1_{\mathrm{t} 1}$ is exactly the type of upstream enterprise that is competent in its handling of chemicals. It adequately fulfils the requirements set forth by REACH and even exceeds them. The same applies when player 2 enters a non-privileged business relationship $b_{2}$ with player $1_{\mathrm{t} 2}$. In contrast to upstream enterprise player $1_{\mathrm{t} 1}$, upstream enterprise player $1_{\mathrm{t} 2}$ is less competent in his handling of chemicals. In both cases, player 2 achieves a utility increase through the utility component " $\mathrm{Z}_{\mathrm{rep}}$ ", the building of a reputation. Business relationships that deviate from this pattern lead to a loss of reputation. Should downstream enterprise player 2 enter into a privileged business relationship $b_{1}$ with upstream enterprise player $1_{t 2}$, which - compared to player $1_{t 1}$ - is less competent in the handling of chemicals. Alternatively, should downstream enterprise player 2 enter into a less privileged business relationship $b_{2}$ with upstream enterprise player $1_{t 1}$, in accordance with the assumptions made here prudent action within the supply chain could not be ascertained. In both such cases, player 2 achieves a loss in utility through the negative utility component " $Z_{\mathrm{lor}}$ ", the loss of reputation. For the sake of clarity, I will henceforth refer to business relationships that help to build a reputation as correct business relationships. I shall refer to business relationships that lead to a loss of reputation on player 2's part as wrong business relationships.

Figure 2 depicts the progress of the basis game up to this point in the form of a game tree, as well as the respective utility components of players 1 and 2. Table 1 sums up the characterisations of players 1 and 2 with their respective utility components.

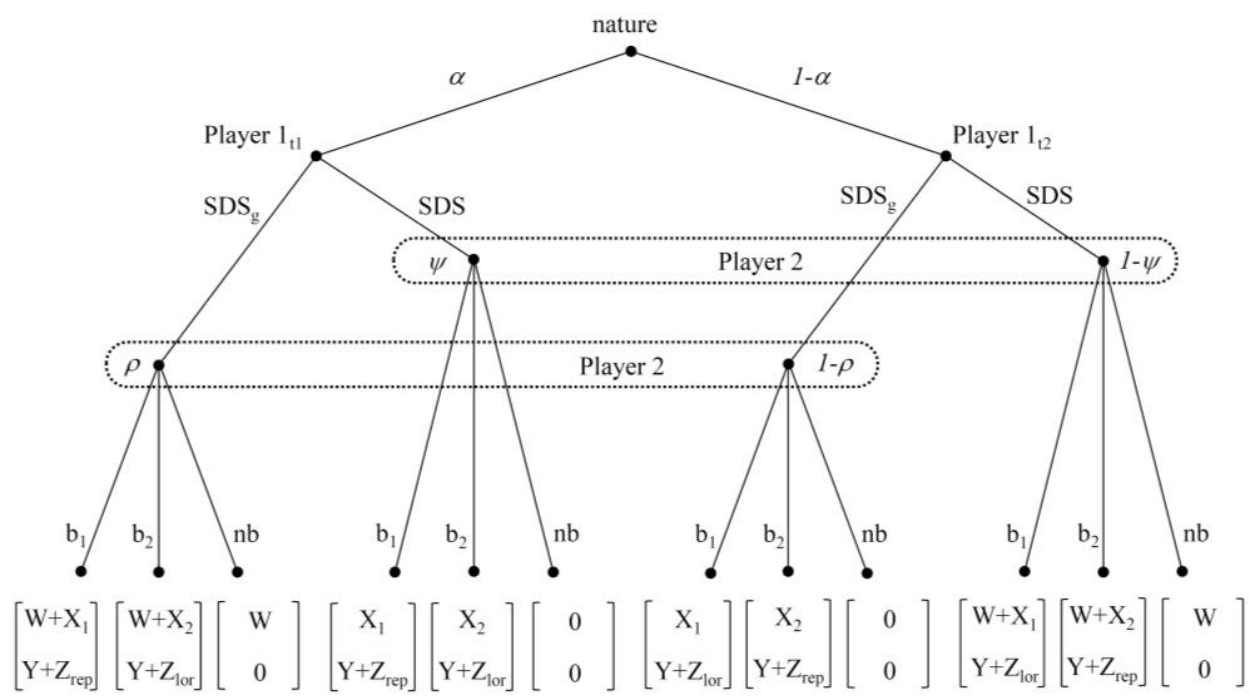


Part A

\begin{tabular}{|l|l|l|l|}
\hline \multicolumn{2}{|l|}{ Player 1 payoffs } & \multicolumn{2}{l|}{ Player 2 payoffs } \\
\hline $\mathrm{W}:$ & creation of the "correct" SDS & $\mathrm{Y}:$ & participation in market action \\
\hline $\mathrm{X}_{1}:$ & formation of $\mathrm{b}_{1}$ & $\mathrm{Z}_{\mathrm{rep}}:$ & formation of the "correct" business relationship \\
\hline $\mathrm{X}_{2}:$ & formation of $\mathrm{b}_{2}$ & $\mathrm{Z}_{\mathrm{lor}}:$ & formation of the "wrong" business relationship \\
\hline
\end{tabular}

TABLE 1 PAYOFFS PLAYER 1 AND 2

3.2 The basis game at different positions within the supply chain

Based on the basis game from chapter 3.1 and the research hypothesis "The respective position within a supply chain influences the form of downstream risk communication", I will now analyze different positions within the supply chain: two located relatively at the beginning and another two located relatively at the end of the supply chain. Figure 3 illustrates the analysis progress.

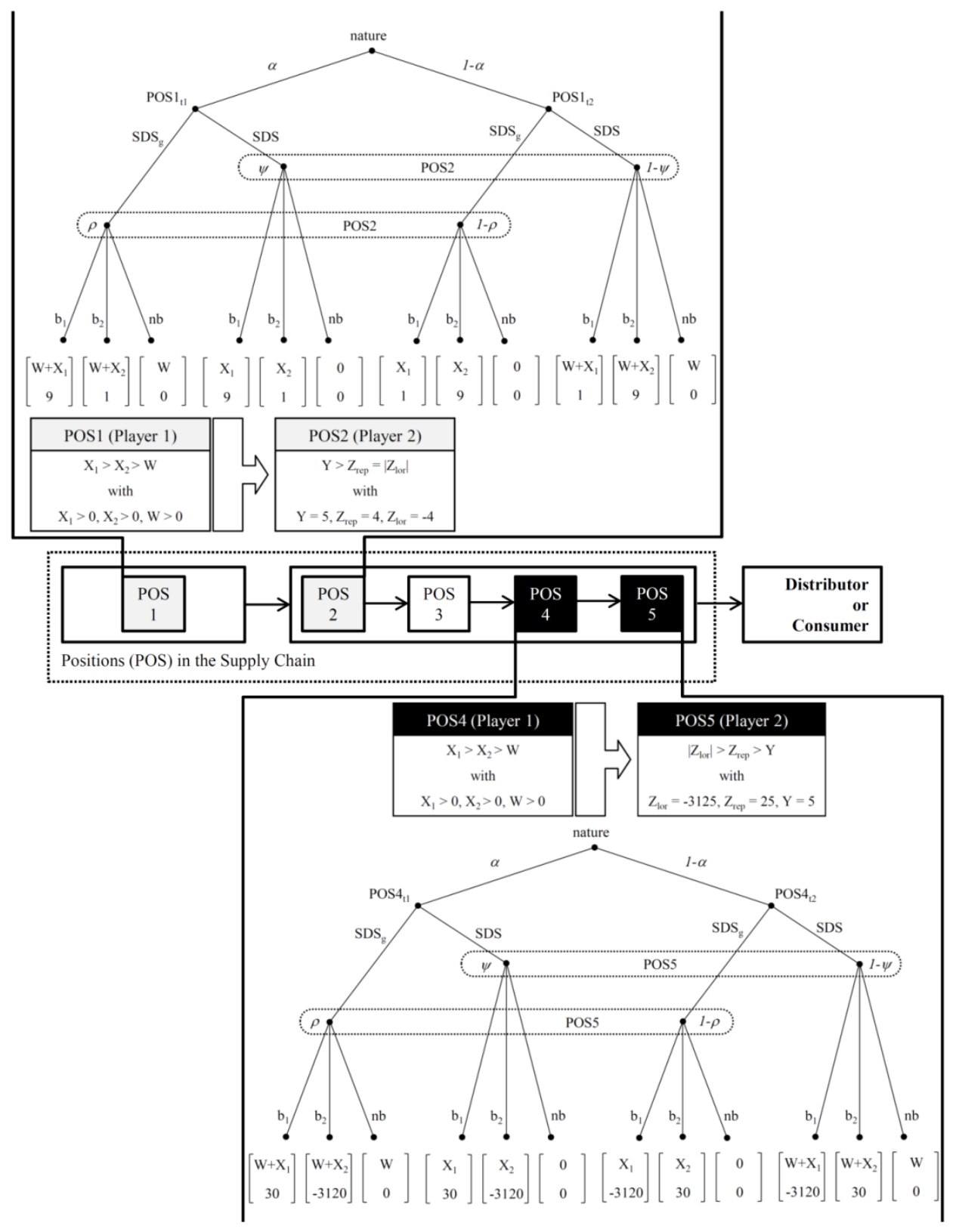

FIGURE 3 BASIS GAME AT DIFFERENT POSITIONS IN THE SUPPLY CHAIN 


\section{Part A}

Located in the middle of Figure 3 is the supply chain with its different elements. In chapter 2, I derived the individual elements from the legal definitions given in REACH. However, now they are neutral, which means that they are depicted as positions (POS) and not differentiated into different groups of actors. This neutral representation of the supply chain serves the purpose of keeping out variables that result from the partially different rights and duties of different actors within the supply chain, although it would exceed the scope and purpose of the present analysis. ${ }^{23}$ In our case, the supply chain contains five elements (POS1 until POS5). POS1 marks the beginning and POS5 the end. The game tree above the supply chain - which is shown in Figure 3 substantiates the basis game for POS1 and POS2 (relatively at the beginning of the supply chain), while the one beneath it elaborates on POS4 and POS5 (relatively at the end of the supply chain).

\subsubsection{Payoffs at different positions within the supply chain}

Within the context of this analysis, the players in positions POS1 and POS4 always assume the role of the upstream enterprise. In Figure 3, they have the role of player 1 in both game trees. As explained in the introduction to the basis game, the total payoff of player 1 comprises the utility components $\mathrm{X}_{1}, \mathrm{X}_{2}$ and W. Both types of player 1 achieve a utility increase when they avoid unnecessary compliance efforts in choosing a level of refinement for the SDS. Furthermore, their utility increases through their entering into a business relationship. It is assumed here that the utility increase - which results from the avoiding of unnecessary compliance efforts is the utility component that contributes the least to the total payoff. The utility increase that results from the formation of a business relationship is differentiated here regarding what kind of business relationship it results from. In the case of the formation of a privileged business relationship $b_{1}$, the utility increase is greater than when $a$ - in comparison to $b_{1}$ - less privileged business relationship $b_{2}$ is entered into. Here, this relationship is considered as identical relatively at the beginning and relatively at the end of the supply chain and is assumed to be constant in its weighting. As far as POS1 and POS4 are concerned, this means that $\mathrm{X}_{1}>\mathrm{X}_{2}>\mathrm{W}$ with $\mathrm{X}_{1}>0$, $\mathrm{X}_{2}>0, \mathrm{~W}>0$.

The players in position POS2 and POS5 assume the respective role of the downstream enterprise. In both game trees, they have the role of player 2. In analogy to the basis game, their total payoff comprises the utility components $\mathrm{Y}, \mathrm{Z}_{\text {rep }}$ and $\mathrm{Z}_{\mathrm{lor}}$. They achieve a utility increase from the emergence of a business relationship (Y) and their prudent actions in the context the formation of a contractual relationship with an upstream enterprise. A positive contribution to the total payoff may be achieved through the building of reputation $\left(Z_{\text {rep }}\right)$. This occurs when a privileged business relationship $b_{1}$ is being entered into with an enterprise (player $1_{t 1}$ ) that is competent in its handling of chemicals and risks. The entering into less privileged business relationship $b_{2}$ with an enterprise (player $1_{\mathrm{t} 2}$ ) that is relatively less competent in its handling of chemicals and risks compared to player $1_{\mathrm{t} 1}$ leads to an identical increase in reputation. Contractual relationships that deviate from these conditions in the case of POS2 and POS5 lead to a loss of reputation. In this case, the total payoff is reduced by $\mathrm{Z}_{\text {lor }}$.

What is important in the context of the comparative analysis of the positions located relatively at the beginning and relatively at the end of the supply chain is that the utility components $\mathrm{Y}, \mathrm{Z}_{\mathrm{lor}}$ and $\mathrm{Z}_{\text {rep }}$ of the respective downstream enterprises are position-dependent in their realisation. These dependencies may be depicted functionally and here are assumed and justified in the following way. The utility component $\mathrm{Y}$ is assumed to be a constant within the supply chain, which adopts the same numerical value for all positions. Nonetheless, as a

\footnotetext{
${ }^{23}$ With respect to the hypothesis explored in this paper, the partially different rights and duties of different groups of actors may be neglected.
} 
constant it is dependent on the number of elements within a supply chain. What is implicit here is the assumption that manufacturing processes become more complex depending on the depth of the supply chain, and that participation in more complex manufacturing processes potentially open up more possibilities and potentials in diverse ways. In our case of a supply chain comprising five elements, Y results from the sum of all elements in the supply chain and its realisation is five for all positions considered here. As concerning the utility components $\mathrm{Z}_{\text {rep }}$ and $\mathrm{Z}_{\mathrm{lor}}$, an exponential dependence on the position within the supply chain is assumed. Thereby, $\mathrm{Z}_{\text {rep }}$ overgrows the positions in such a way that the respective position within the supply chain is squared. On the other hand, $\mathrm{Z}_{\mathrm{lor}}$ exhibits negative exponential growth with the exponent of the respective position within the supply chain. The exponential dependencies assumed here are justified as follows. On the one hand, positions located relatively at the end of the supply chain are closer to the end consumer. Here, the conduct of businesses upon entering into contractual relationships is more likely to be perceived and either lauded or criticised as in the case of supply chain positions that lie at a distance to the market of the end consumer. The existence of institutions dedicated to the protection of the consumer make this assumption appear justified. Furthermore, it is plausible to assume that the building of a reputation as well as its loss do not progress in a linear fashion when observing institutions that also do not monitor the entire supply chain in the same linearly-phased fashion. On the other hand, the negative development of $\mathrm{Z}_{\mathrm{lor}}$ is modelled here as absolutely outweighing the positive development of $\mathrm{Z}_{\text {rep }}$, since reputation is most often more easily lost than earned. A summary of the functional dynamic sampling of the utility components $\mathrm{Y}, \mathrm{Z}_{\text {rep }}$ and $\mathrm{Z}_{\mathrm{lor}}$ is provided in Table 2 . An extensive representation of the payoff dynamics of player 2 is given in the appendix $\mathrm{A}^{24}$ of this paper.

\begin{tabular}{|l|c|}
\hline Utility components & dynamics as dependent on position (POS) \\
\hline $\mathrm{Y}$ & $\mathrm{Y}=$ constant = total amount of POS \\
\hline $\mathrm{Z}_{\text {rep }}$ & $\mathrm{Z}_{\text {rep }}\left(\mathrm{POS}_{\mathrm{i}}\right)=(\mathrm{i})^{2}$ \\
\hline $\mathrm{Z}_{\text {lor }}$ & $\mathrm{Z}_{\text {lor }}\left(\mathrm{POS}_{\mathrm{i}}\right)=(\mathrm{i})^{\mathrm{i}} *(-1)$ \\
\hline
\end{tabular}

TABLE 2 PAYOFF DYNAMICS PLAYER 2

Based on these conjectures, I have assigned concrete numerical values to the utility components of the respective downstream enterprises given in Figure 3 (POS2 in the upper game tree and POS5 in the lower one). A respective total payoff in the game trees in Figure 3 for player 2 results from the sum of the utility components as assumed in the basis game (see Figure 2). The weighting and specification of the payoffs for player 1 and player 2 - as depending on the position - are summarised below in Table 3. For POS1 and POS2, they are also given in Figure 3 underneath the upper game tree and above the lower game tree for POS4 and POS5.

\begin{tabular}{|l|l|}
\hline Position & Weighting and specification of utility components \\
\hline POS1 and POS4 (Player 1) & $\mathrm{X}_{1}>\mathrm{X}_{2}>\mathrm{W}$ with $\mathrm{X}_{1}>0, \mathrm{X}_{2}>0, \mathrm{~W}>0$ \\
\hline POS2 (Player 2) & $\mathrm{Y}>\mathrm{Z}_{\mathrm{rep}}=\left|\mathrm{Z}_{\mathrm{lor}}\right|$ with $\mathrm{Y}=5, \mathrm{Z}_{\mathrm{rep}}=4, \mathrm{Z}_{\mathrm{lor}}=-4$ \\
\hline POS5 (Player 2) & $\left|\mathrm{Z}_{\mathrm{lor}}\right|>\mathrm{Z}_{\mathrm{rep}}>\mathrm{Y}$ with, $\mathrm{Z}_{\mathrm{lor}}=-3125, \mathrm{Z}_{\mathrm{rep}}=25, \mathrm{Y}=5$ \\
\hline
\end{tabular}

TABLE 3 WEIGHTING AND SPECIFICATIONS OF UTILITY COMPONENTS FOR PLAYER 1 AND PLAYER 2 AS DEPENDING ON THE POSITION WITHIN THE SUPPLY CHAIN

\footnotetext{
${ }^{24}$ See in the appendix A (Payoff dynamics player 2) table A.1 "Absolute payoffs with respect to the position in the supply chain" and Figure A.1 "Graphic illustration of payoff development with respect to the position". Within figure A.1 the payoffs of player 2 are visualised decompiled into utility components (column a) and as sum of total payoffs (column b). Attention should be paid to the fact that player 2's payoffs materialise first at the second position (POS2), due to the assumption made here, that this is the first position of a downstream user within the supply chain.
} 


\section{Part A}

\subsection{Equilibrium analysis}

The solution concept ${ }^{25}$ applied here to identify the equilibrium structures of the basis game relatively at the beginning and end of the supply chain, respectively, is the perfect Bayesian equilibrium (PBE) ${ }^{26}$. The sender (player 1) possesses four and the receiver (player 2) nine pure strategies (see Table 4). The way in which the pure strategies are interpreted is elaborated based on two exemplary cases $\left(\left(\left[\operatorname{SDS}_{\mathrm{g}} \mid\right.\right.\right.$ Player $\left.1_{\mathrm{t} 1}\right] ;\left[\operatorname{SDS}_{\mathrm{g}} \mid\right.$ Player $\left.\left.1_{\mathrm{t} 2}\right]\right)$ and $\left.\left(\left[b_{1} \mid \operatorname{SDS}_{\mathrm{g}}\right] ;\left[\mathrm{b}_{1} \mid \mathrm{SDS}\right]\right)\right)$ in the footnotes. This reading applies equally to all strategies listed in the Table.

\begin{tabular}{|c|c|}
\hline Player & Pure strategies \\
\hline $\begin{array}{l}\text { Player } 1 \\
\text { (POS1 and POS4) }\end{array}$ & $\begin{array}{l}\left(\left[\text { SDS }_{\mathrm{g}} \mid \text { Player } 1_{\mathrm{t} 1}\right] ;\left[\text { SDS }_{\mathrm{g}} \mid \text { Player } 1_{\mathrm{t} 2}\right]\right)^{27} \\
\left(\left[\text { SDS }_{\mathrm{g}} \mid \text { Player } 1_{\mathrm{t} 1}\right] ;\left[\text { SDS } \mid \text { Player } 1_{\mathrm{t} 2}\right]\right), \\
\left(\left[\text { SDS } \mid \text { Player } 1_{\mathrm{t} 1}\right] ;[\text { SDS }\right. \\
\left.\left.\mathrm{g} \mid \text { Player } 1_{\mathrm{t} 2}\right]\right), \\
\left.\left.\text { ([SDS|Player } 1_{\mathrm{t} 1}\right] ;\left[\text { SDS } \mid \text { Player } 1_{\mathrm{t} 2}\right]\right)\end{array}$ \\
\hline $\begin{array}{l}\text { Player } 2 \\
\text { (POS2 and POS5) }\end{array}$ & $\begin{array}{l}\left(\left[\mathrm{b}_{1} \mid \mathrm{SDS}_{\mathrm{g}}\right] ;\left[\mathrm{b}_{1} \mid \mathrm{SDS}\right]\right)^{28},\left(\left[\mathrm{~b}_{1} \mid \mathrm{SDS}_{\mathrm{g}}\right] ;\left[\mathrm{b}_{2} \mid \mathrm{SDS}\right]\right),\left(\left[\mathrm{b}_{1} \mid \mathrm{SDS}_{\mathrm{g}}\right] ;[\mathrm{nb} \mid \mathrm{SDS}]\right), \\
\left(\left[\mathrm{b}_{2} \mid \mathrm{SDS}_{\mathrm{g}}\right] ;\left[\mathrm{b}_{2} \mid \mathrm{SDS}\right]\right),\left(\left[\mathrm{b}_{2} \mid \mathrm{SDS}_{\mathrm{g}}\right] ;\left[\mathrm{b}_{1} \mid \mathrm{SDS}\right]\right),\left(\left[\mathrm{b}_{2} \mid \mathrm{SDS}_{\mathrm{g}}\right] ;[\mathrm{nb} \mid \mathrm{SDS}]\right), \\
\left(\left[\mathrm{nb} \mid \mathrm{SDS}_{\mathrm{g}}\right] ;[\mathrm{nb} \mid \mathrm{SDS}]\right),\left(\left[\mathrm{nb} \mid \mathrm{SDS}_{\mathrm{g}}\right] ;\left[\mathrm{b}_{1} \mid \mathrm{SDS}\right]\right),\left(\left[\mathrm{nb} \mid \mathrm{SDS}_{\mathrm{g}}\right] ;\left[\mathrm{b}_{2} \mid \mathrm{SDS}\right]\right)\end{array}$ \\
\hline
\end{tabular}

TABLE 4 PURE STRATEGIES OF PLAYER 1 AND PLAYER 2

In the context of the basis game, the PBE may theoretically assume four different shapes: a SDS $\mathrm{g}_{\mathrm{g}}$ pooling equilibrium (both types of player 1 choose $\operatorname{SDS}_{\mathrm{g}}\left[\mathrm{SDS}_{\mathrm{g}}, \mathrm{SDS}_{\mathrm{g}}\right]$ ); a SDS pooling equilibrium (both types of player 1 choose SDS [SDS,SDS]); a separating equilibrium, in the case of which player $1_{\mathrm{t} 1}$ chooses $\operatorname{SDS} \mathrm{g}$ and player $1_{\mathrm{t} 2}$ chooses SDS $\left[\mathrm{SDS}_{\mathrm{g}}, \mathrm{SDS}\right]$; and a separating equilibrium, in the case of which player $1_{\mathrm{t} 1}$ chooses SDS and player $1_{\mathrm{t} 2}$ chooses $\operatorname{SDS}_{\mathrm{g}}\left[\mathrm{SDS}, \mathrm{SDS}_{\mathrm{g}}\right]$. The positions relatively at the beginning (POS1 and POS2) and relatively at the end of the supply chain (POS4 and POS5) are analyzed regarding the presence of PBE.

\subsubsection{Positions relatively at the beginning of the supply chain}

In the basis game relatively at the beginning of the supply chain (see the upper game tree in Figure 3) there is evidence of the existence of two pooling equilibria and one separating equilibrium as PBE in pure strategies. The respective proofs are given in appendix B "Proof of equilibria". The identified equilibria are consecutively numbered and listed in the appendix under the same numeral with the letter B in front of it. Table 5 summarises the structure of equilibria in the basis game relatively at the beginning of the supply chain. The way in which the equilibria are interpreted is elaborated based on three exemplary cases ([SDS $\left.\mathrm{S}_{\mathrm{g}} \mathrm{SDS}_{\mathrm{g}}\right]$, [SDS,SDS] and $\left.\left[\mathrm{SDS}_{\mathrm{g}}, \mathrm{SDS}\right]\right)$ in the footnotes. This reading applies equally to all equilibria that are situated at the end of the supply chain.

\footnotetext{
${ }^{25}$ For the evolution and further developments of Nash equilibrium as concept of solution in game theory see also Myerson 1999and van Damme, Weibull 1995.

${ }^{26}$ The necessary conditions for this solution concept are stated in the appendix B "Proof of equilibria".

${ }^{27}$ Concerning the information in brackets: ([SDS $\mathrm{g} \mid$ Player $\left.1_{\mathrm{t} 1}\right]$; $\left[\mathrm{SDS}_{\mathrm{g}} \mid\right.$ Player $\left.1_{\mathrm{t} 2}\right]$ ) means that player 1 chooses SDS $\mathrm{g}$ under the constraint of being type ${ }_{\mathrm{t} 1}$ and under the constraint of being type ${ }_{\mathrm{t} 2}$, player 1 chooses SDS $_{\mathrm{g}}$ as well.

${ }^{28}$ Concerning the information in brackets: ( $\left.\left[\mathrm{b}_{1} \mid \mathrm{SDS}_{\mathrm{g}}\right] ;\left[\mathrm{b}_{1} \mid \mathrm{SDS}\right]\right)$ means that player 2 chooses $\mathrm{b}_{1}$ under the constraint of observing the signal $\mathrm{SDS}_{\mathrm{g}}$ and under the constraint of observing the signal SDS, player 2 chooses $\mathrm{b}_{1}$ as well.
} 


\begin{tabular}{|c|c|c|}
\hline \multirow{2}{*}{\multicolumn{2}{|c|}{$\begin{array}{c}\text { Positions relatively at the beginning } \\
\text { of the supply chain - } \\
\text { results equilibrium analysis }\end{array}$}} & $\begin{array}{c}\text { Utility components } \\
\text { POS2 (Player 2) }\end{array}$ \\
\hline & & $Y>Z_{\text {rep }}=\left|Z_{\text {lor }}\right|$ with $Y=5, Z_{\text {rep }}=4, Z_{\text {lor }}=-4$ \\
\hline \multirow{3}{*}{$\begin{array}{c}\text { Utility components } \\
\text { POS1 (Player 1) }\end{array}$} & \multirow{3}{*}{$\mathrm{X}_{1}>\mathrm{X}_{2}>\mathrm{W}$} & 1. $\left[\left(\mathrm{SDS}_{\mathrm{g}}, \mathrm{SDS}_{\mathrm{g}}\right),\left(\mathrm{b}_{1}, \mathrm{~b}_{2}\right), \rho>.5, \psi<.5\right]^{29}$ with $\mathrm{X}_{1}>\mathrm{X}_{2}+\mathrm{W}$ \\
\hline & & 2. $\left[(\operatorname{SDS}, S D S),\left(b_{1}, b_{2}\right), \psi>.5, \rho<.5\right]^{30}$ with $X_{1}>X_{2}+W$ \\
\hline & & 3. $\left[\left(\mathrm{SDS}_{\mathrm{g}}, \mathrm{SDS}\right),\left(\mathrm{b}_{1}, \mathrm{~b}_{2}\right), \rho=1, \psi=0\right]^{31}$ with $\mathrm{X}_{1}<\mathrm{X}_{2}+\mathrm{W}$ \\
\hline
\end{tabular}

TABLE 5 RESULTS - EQUILIBRIA RELATIVELY AT THE BEGINNING OF THE SUPPLY CHAIN

\subsubsection{Positions relatively at the end of the supply chain}

In the basis game relatively at the end of the supply chain (see the lower game tree in Figure 3 ) there is evidence of the existence of six pooling equilibria and one separating equilibrium as PBE in pure strategies. The respective proofs are given in appendix B "Proof of equilibria". The identified equilibria are consecutively numbered and listed in the appendix under the same numeral with the letter B in front of it. Table 6 summarises the structure of equilibria in the basis game relatively at the end of the supply chain.

\begin{tabular}{|c|c|c|}
\hline \multirow{2}{*}{\multicolumn{2}{|c|}{$\begin{array}{l}\text { Positions relatively at the end } \\
\text { of the supply chain - } \\
\text { results equilibrium analysis }\end{array}$}} & $\begin{array}{l}\text { Utility components } \\
\text { POS5 (Player 2) }\end{array}$ \\
\hline & & $\left|Z_{\text {lor }}\right|>Z_{\text {rep }}>Y=$ with $Z_{\text {lor }}=-3125, Z_{\text {rep }}=25, Y=5$ \\
\hline \multirow{5}{*}{$\begin{array}{l}\text { Utility components } \\
\text { POS4 } \\
\text { (Player 1) }\end{array}$} & \multirow{5}{*}{$\mathrm{X}_{1}>\mathrm{X}_{2}>\mathrm{W}$} & $\begin{array}{l}\text { 4. }\left[\left(\mathrm{SDS}_{\mathrm{g}}, \mathrm{SDS}_{\mathrm{g}}\right),\left(\mathrm{b}_{1}, \mathrm{~b}_{2}\right), \rho>104 / 105, \psi<1 / 105\right] \text { with } \mathrm{X}_{1}>\mathrm{X}_{2}+\mathrm{W} \\
\text { 5. }\left[\left(\mathrm{SDS}_{\mathrm{g}}, \mathrm{SDS}_{\mathrm{g}}\right),\left(\mathrm{b}_{1}, \mathrm{nb}\right), \rho>104 / 105,1 / 105<\psi<104 / 105\right]\end{array}$ \\
\hline & & 6. $\left[\left(\operatorname{SDS}_{\mathrm{g}}, \mathrm{SDS}_{\mathrm{g}}\right),\left(\mathrm{b}_{2}, \mathrm{nb}\right), \rho<1 / 105,1 / 105<\psi<104 / 105\right]$ \\
\hline & & $\begin{array}{l}\left.\text { 7. [(SDS,SDS), }\left(b_{1}, b_{2}\right), \psi>104 / 105, \rho<1 / 105\right] \text { with } X_{1}>X_{2}+W \\
\left.\text { 8. [(SDS,SDS), }\left(b_{1}, n b\right), \psi>104 / 105,1 / 105<\rho<104 / 105\right]\end{array}$ \\
\hline & & 9. [(SDS,SDS), $\left.\left(\mathrm{b}_{2}, \mathrm{nb}\right), \psi<1 / 105,1 / 105<\rho<104 / 105\right]$ \\
\hline & & 10. $\left[\left(\mathrm{SDS}_{\mathrm{g}}, \mathrm{SDS}\right),\left(\mathrm{b}_{1}, \mathrm{~b}_{2}\right), \rho=1, \psi=0\right]$ with $\mathrm{X}_{1}<\mathrm{X}_{2}+\mathrm{W}$ \\
\hline
\end{tabular}

\subsubsection{Discussion}

The research hypothesis of this paper is: The respective position within a supply chain influences the form of downstream risk communication! The results of the analysis will be discussed against the background of this hypothesis, from both a formal perspective as well as regarding content.

\footnotetext{
${ }^{29}$ Concerning the information in brackets: $\left(\mathrm{SDS}_{\mathrm{g}}, \mathrm{SDS}_{\mathrm{g}}\right)$ means that both types of player 1 choose $\mathrm{SDS}_{\mathrm{g}}$. The corresponding information set of player 2 is on the equilibrium path. The belief $\rho>.5$ equates to the prior distribution of types of player $1(\alpha, 1-\alpha)$ and is in line with Bayesrule. For a perfect Bayesian equilibrium it is necessary, that player 2`s response to the signal $\operatorname{SDS}_{\mathrm{g}}$ is $\mathrm{b}_{1}$ and that player 2 `s response to the signal SDS is $b_{2}$. For this purpose, the belief of player 2 at the corresponding information set of SDS must be $\psi<.5$.

${ }^{30}$ Concerning the information in brackets: (SDS,SDS) means that both types of player 1 choose SDS. The corresponding information set of player 2 is on the equilibrium path. The belief $\psi>.5$ equates to the prior distribution of types of player $1(\alpha, 1-\alpha)$ and is in line with Bayesrule. For a perfect Bayesian equilibrium it is necessary, that player 2 s response to the signal SDS is $b_{1}$ and that player 2 s response to the signal $\mathrm{SDS}_{\mathrm{g}}$ is $\mathrm{b}_{2}$. For this purpose, the belief of player 2 at the corresponding information set of $\operatorname{SDS}_{\mathrm{g}}$ must be $\rho<.5$.

${ }^{31}$ Concerning the information in brackets: $\left(\mathrm{SDS}_{\mathrm{g}}, \mathrm{SDS}\right)$ means that player $1_{1}$ chooses $\mathrm{SDS}_{\mathrm{g}}$ and Player $1_{2}$ chooses SDS. Both corresponding beliefs are on the equilibrium path and determined by Bayes' rule: $\rho=1$ and $\psi=0$. For a perfect Bayesian equilibrium it is necessary, that player 2`s response to the signal $\mathrm{SDS}_{\mathrm{g}}$ is $\mathrm{b}_{1}$ and that player 2`s response to the signal SDS is $\mathrm{b}_{2}$. In this case there is no incentive for player 1
} to deviate. 
From a formal perspective, it can be asserted that there exist stable relations between positions POS1 and POS2 as well as between POS4 and POS5 as PBEs. The PBEs occur in the shape of a pooling equilibrium and a separating equilibrium. This occurs at the beginning and end of the supply chain. Regarding pooling equilibria, it can be said that the structures of equilibria relatively at the beginning are different from those located relatively at the end of the supply chain. This is true regarding the amount as well as the quality (combination of strategies and beliefs) of the pooling PBEs (see Table 5 and Table 6).

The pooling equilibria in Tables 5 and 6 may manifest in two different ways: as $\operatorname{SDS}_{\mathrm{g}}$ pooling equilibrium $\left(\mathrm{SDS}_{\mathrm{g}}, \mathrm{SDS}_{\mathrm{g}}\right)$ and as SDS pooling equilibrium (SDS,SDS). They are also sensitive regarding the positions under observation within the supply chain. Figure 4 contrasts the two types of manifestation of the pooling PBEs in line (a) and in line (b), both relatively at the beginning and relatively at the end of the supply chain. It supplements the results presented in Tables 5 and 6.

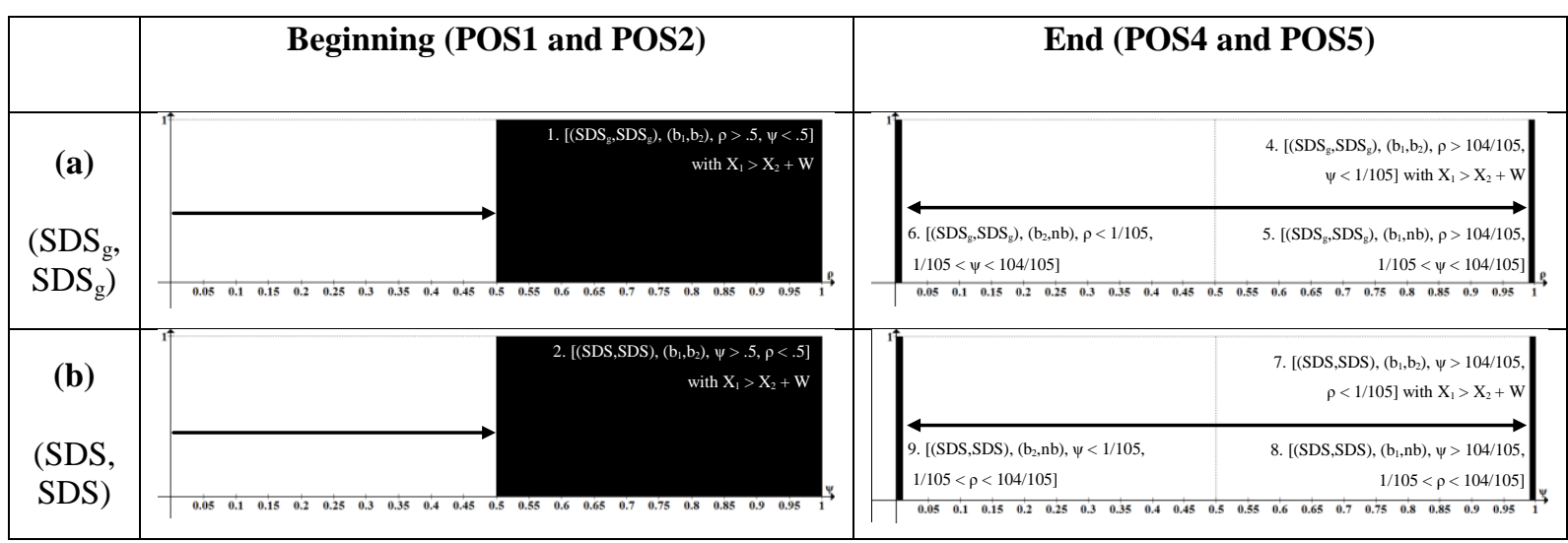

FIGURE 4 RESULTS - GRAPHIC ILLUSTRATION OF POOLING PERFECT BAYESIAN EQUILIBRIA

The diagrams in Figure 4 should be read in the following way. The abscissa represents the respective belief of player 2 in the form of an interval scale, ranging from zero to one. The ordinate is ordinal with one intervalstage. This stage is realised when a combination of beliefs and strategies produces a pooling equilibrium. In the illustration, the realisation corresponds to the black spaces between abscissa and the value 1 on the ordinate. The precise quality of the pooling equilibria (combination of belief and strategy) is stated in brackets inside the black spaces (Beginning (POS1 and POS2)) or immediately next to it (End (POS4 and POS5)). The arrows within the four diagrams represent belief areas that do not lead to stable relationships as in the cases when pooling PBEs occur. From a formal perspective, the pooling equilibria in Figure 4 are discussed column-by-column [Beginning (POS1 and POS2) as well as End (POS4 and POS5)] and line-by-line [line (a) ( SDS $_{\mathrm{g}}, \mathrm{SDS}_{\mathrm{g}}$ ) and line (b) (SDS,SDS)]. When comparing the two manifestations of the pooling PBEs at the beginning (POS1 and POS2) and the end (POS4 and POS5) of the supply chain separately, it appears that apart from the interchange of belief $\psi$ and $\rho$, the equilibria have the same quality. As depicted in the diagrams in Figure 4, the columns Beginning (POS1 and POS2) and End (POS4 and POS5) possess identical shares of black spaces. This can be explained in terms of the internal symmetry of the payoff attribution of players 1 and 2 in the basis game. In the case of choosing the correct level of refinement of the SDS, both types of player 1 realise the utility component $\mathrm{W}$ to an identical extent (i.e. player $1_{t 1}$ chooses the level of refinement $\mathrm{SDS}_{\mathrm{g}}$ while player $1_{\mathrm{t} 2}$ chooses the level SDS). If the players depart from this, they both achieve a payoff of zero. As was the case, both types of player 1 achieve an identical utility increase from entering into business relationships (i.e. the respective business relationships $\mathrm{b}_{1}$ and $b_{2}$ are identical, albeit with differing values for both types). The following applies: $X_{1}>X_{2}$. In turn, player 2 


\section{Part A}

realises the utility component $Z_{\text {rep }}$ to an identical extent when entering into the correct business relationship within a supply chain position ${ }^{32}$ (i.e. player 2 enters into a business relationship $b_{1}$ with player $1_{t 1}$ and into a relationship $b_{2}$ with player $1_{t 2}$ ). All business relationships that deviate from this are equally unconducive to player 2 and he achieves the utility component $Z_{\text {lor }}$ within a supply chain position ${ }^{33}$ to an identical extent (i.e. player 2 enters into a business relationship $b_{2}$ with player $1_{t 1}$ and enters into a business relationship $b_{1}$ with player $\left.1_{\mathrm{t} 2}\right)$.

Comparing the beginning (POS1 and POS2) and end (POS4 and POS5) of the supply chain separately according to the types of manifestations of the pooling PBEs (lines (a) and (b) in Figure 4), it appears that the amount and quality of the pooling PBEs change depending on the position. Depending on the position, the diagrams in Figure 4 exhibit in-between line (a) and line (b) a non-identical number of black spaces as well as black spaces of different sizes. Due to symmetry in the attribution of payoffs of players 1 and 2 in the basis game - which I have explained in the preceding paragraph - the development of both kinds of manifestations of the pooling PBEs is equally different in-between line (a) and line (b) depending on the respective position. This is why at this point the differentiation into different types of manifestation of the pooling PBEs can be neglected and the comparison between positions may be focused upon. What causes the change in amount and quality of the pooling PBEs between the positions beginning and end is the position-dependent dynamic sampling ${ }^{34}$ of the payoffs $\mathrm{Y}, \mathrm{Z}_{\mathrm{rep}}$ and $\mathrm{Z}_{\mathrm{lor}}$ of player 2. This dynamic sampling causes the potential qualities of the pooling PBEs at the end of the supply chain to increase on the one hand. While at the beginning of the supply chain (POS1 and POS2) there is one $\mathrm{SDS}_{\mathrm{g}}$ pooling equilibrium and one SDS pooling equilibrium, at the end of the supply chain (POS4 and POS5) there are three SDS $_{\mathrm{g}}$ pooling equilibria and three SDS pooling equilibria with respectively different qualities. On the other hand, the dynamic sampling of player 2's payoffs prompts the possibility space in which an equilibrium could be generated to narrow down rather rapidly towards the end of the supply chain. In Figure 4, equilibria are realised at the end of the supply chain (POS4 and POS5) on the left and right margin of the belief interval as narrow black spaces.

The separating equilibria identified at the beginning and end of the supply chain correspond in their qualities. They are not position-dependent.

Thus, from a formal perspective, regarding the pooling equilibria the research hypothesis formulated above stands corroborated. However, in terms of the identified separating equilibrium, whose quality and quantity remains unaltered irrespective of position, the research hypothesis must be rejected.

From the perspective of content, the PBEs are discussed here regarding both the kinds of manifestation and their qualities.

Out of the four possible kinds of manifestation of the PBE in the context of this model, three come into effect: a $\mathrm{SDS}_{\mathrm{g}}$ pooling equilibrium $\left[\mathrm{SDS}_{\mathrm{g}}, \mathrm{SDS}_{\mathrm{g}}\right.$, a SDS pooling equilibrium [SDS,SDS] and a separating equilibrium with player $1_{\mathrm{t} 1}$ playing $\mathrm{SDS}_{\mathrm{g}}\left[\mathrm{SDS}_{\mathrm{g}}, \mathrm{SDS}\right]$. These three kinds of manifestation come into effect at the beginning (POS1 and POS2) as well as the end (POS4 and POS5). Depending on the chosen level of refinement of the

\footnotetext{
${ }^{32}$ Among the different positions in the supply chain the utility component $\mathrm{Z}_{\mathrm{rep}}$ varies in accordance with the functional form laid out in chapter 3.2.1. Within a position the value of its realisation is always identical.

${ }^{33}$ Among the different positions in the supply chain the utility component $Z_{\text {lor }}$ varies in accordance with the functional form laid out in chapter 3.2.1. Within a position the value of its realisation is always identical.

${ }^{34}$ With regard to the assumed dynamic sampling of payoffs see above.
} 


\section{Part A}

SDS, these different manifestations are characterised by differences in downstream risk communication inside the respective positions. As explained earlier, forms of downstream risk communication are differentiated here in terms of whether information is transferred inside the supply chain by means of an extensive safety data sheet $\mathrm{SDS}_{\mathrm{g}}$ or a comparatively less extensive safety data sheet SDS. Here, it is assumed that when measured against the normative requirements for downstream risk communication, downstream risk communication conducted by means of a $\mathrm{SDS}_{\mathrm{g}}$ is of better quality than downstream risk communication via a SDS. This assumption is consistent with the idea that risks in handling of substances and preparations are better minimised the more information about that is passed on. ${ }^{35}$ As asserted earlier from a formal perspective, the pooling equilibria change qualitatively and quantitatively depending on the position, while the quantity and quality of the separating equilibrium remain unchanged.

The following considerations refer to the qualities as such. On the one hand, the qualities of the pooling equilibria change because they can be brought into effect in the context of different actions of player $2\left(b_{1}, b_{2}\right)$, $\left(b_{1}, n b\right),\left(b_{2}, n b\right)$. On the other hand, depending on the position, other beliefs $\psi$ and $\rho$ of player 2 are necessary to bring a pooling equilibrium into effect (see Tables 5 and 6). Regarding the different strategies of player 2 which also determine the different qualities of the pooling equilibria - it can be asserted that equilibria are always characterised by the materialisation of a business relationship $b_{1}$ or $b_{2}$. Refraining from entering into a business relationship, nb, is part of the equilibrium strategy, although it is not realised within the equilibrium. ${ }^{36}$ If in the case of an equilibrium player 2 refrained from entering into a business relationship, there would be no downstream risk communication. Obviously, if there was no business relationship, there would be no grounds on which to exchange information and consequently the consideration of a SDS as a means of downstream risk communication would be equally baseless. However, this is not the case here. In the context of the present analysis, downstream risk communication always occurs, albeit with differing qualities of the pooling equilibria in both manifestations $\left(\mathrm{SDS}_{\mathrm{g}}, \mathrm{SDS}_{\mathrm{g}}\right.$ and $\left.\mathrm{SDS}, \mathrm{SDS}\right)$ depending on the position. In terms of the different beliefs of player 2, which - alongside his strategies - also significantly determine the different qualities of the pooling equilibria, it appears that depending on the positions relatively at the beginning (POS1 and POS2) and relatively at the end (POS4 and POS5) the areas of player 2's belief interval - in which a pooling PBE may be realised decrease at the end of the supply chain. Figure 4 (see above) graphically illustrates this insight. For both kinds of manifestation of the pooling equilibria - SDS $_{\mathrm{g}}$ pooling equilibria (line (a)) and SDS pooling equilibria (line (b)) the possible equilibria arise at the left and right margin of player 2's belief interval (depicted as black spaces). Given that in the solution concept of the PBE beliefs are derived from common priors about the distribution of both types of player 1, it appears that maintaining an equilibrium is only possible under very specific distributions. For this reason, relatively at the beginning of the supply chain a share of $\alpha$ of player $1_{\mathrm{t} 1}>50 \%$ is necessary to create a pooling equilibrium. Relatively at the end of the supply chain, the share $\alpha$ of player $1_{\mathrm{t} 1}$ must be either very low $(<1 / 105)$ or very high $(>104 / 105) .{ }^{37}$ In the context of this model, the dynamic sampling of the payoffs of player 2 means that the realisation of stable conditions as equilibria relatively at the end (POS4 and POS5) is only possible under more restrictive assumptions concerning the distribution of both types of player 1 than relatively at the beginning (POS1 and POS2). The quality of the separating PBE remains unchanged throughout all positions of the supply chain, highlighting that a business relationship materialises

\footnotetext{
${ }^{35}$ This is not assumed to be universally valid. There may be situations, when less information leads to more secure handling of substances and preparations. Too much information may be confusing and possibly complicate handling.

${ }^{36}$ See in the appendix B "Proof of equilibria".

${ }^{37}$ The individual qualities of pooling equilibria are fully depicted in Figure 4.
} 


\section{Part A}

according to strategy $\left(\mathrm{b}_{1}, \mathrm{~b}_{2}\right)$ and that downstream risk communication is conducted according to this PBE. Here, player $1_{\mathrm{t} 1}$ chooses $\operatorname{SDS}_{\mathrm{g}}$ as the level of refinement and player $1_{\mathrm{t} 2}$ chooses SDS as the level of refinement.

Thus, regarding content, the research hypothesis for the pooling equilibria is corroborated once more. The qualitative and quantitative changes were correctly interpreted content-wise in their significance for downstream risk communication. In terms of the separating equilibrium, the perspective of content offers the supplementary clue that downstream risk communication occurs, because nb is not part of the quality of this equilibrium. When it comes to the separating equilibrium, the research hypothesis must be rejected, since the identified quality is not contingent upon the positions analyzed.

\section{Concluding remarks}

The previous discussion regarding the structure of the identified equilibria from a formal point of view as well as the perspective of content can now serve as a starting point for some considerations on the regulatory framework of REACH. As described at the beginning of this paper, the REACH-Regulation formulates standard and uniform requirements for downstream risk communication within an abstract supply chain. The fact that this is referred to as a chain of responsibility proves that the approach taken here is based on control theory. This is an approach that partly relies on self-responsible action on part of the norm addressees to achieve the normative requirements of the regulation. By means of theoretical modelling of the characteristics of a supply chain, I have been able to demonstrate that stable communication in the form of equilibria may arise under the condition of rational, utility-maximizing behavior on the part of the actors. I have also been able to prove that the equilibria are characterised by different qualities, which in turn determine the form of downstream risk communication. The changing qualities of the pooling PBEs identified in accordance with the hypothesis underlying this paper that the position within the supply chain has an impact on the form of downstream risk communication exemplify position-dependency. From this perspective, the regulator may now contemplate which of these instances of stable communication are in the interest of the normative aims of REACH and thus may be permitted and which are not. For every instance of stable communication that is not desirable, the regulator needs to think of a supplementary regulation. Nevertheless, even regarding instances of stable communication that are normatively desirable, the regulator must test whether the institutions for the preservation and consolidation of these structures are sufficient and effective. Such kinds of normative considerations are beyond the scope of this paper. However, the results of the analysis and the various considerations from the perspective of game theory may act as a basis for the structured and differentiated inquiry into normative issues of this kind. In this context, it is worth mentioning the disassembling of payoffs into utility components once again. This method enables studying the interaction of different factors of influence within a clear framework. In this respect, this paper also aimed to propagate game theory as a tool for RIA, which has become an established instrument for the designing and implementation of economic policy. 


\section{Appendix}

\section{A Payoff dynamics player 2}

\begin{tabular}{|c|l|c|c|c|c|c|}
\hline \multicolumn{2}{|c|}{} & \multicolumn{5}{c|}{ Position (POS) } \\
\cline { 3 - 7 } & \multicolumn{1}{|c|}{$\mathbf{1}$} & $\mathbf{2}$ & $\mathbf{3}$ & $\mathbf{4}$ & $\mathbf{5}$ \\
\hline \multirow{4}{*}{$\begin{array}{c}\text { Payoff dynamics } \\
\text { player } 2\end{array}$} & $\mathrm{Y}=$ constant $=$ total amount of POS & - & 5 & 5 & 5 & 5 \\
\cline { 2 - 7 } & $\mathrm{Z}_{\mathrm{rep}}\left(\mathrm{POS}_{\mathrm{i}}\right)=(\mathrm{i})^{2}$ & - & 4 & 9 & 16 & 25 \\
\cline { 2 - 6 } & $\mathrm{Z}_{\mathrm{lor}}\left(\mathrm{POS}_{\mathrm{i}}\right)=(\mathrm{i})^{\mathrm{i}} *(-1)$ & - & -4 & -27 & -256 & -3125 \\
\cline { 2 - 7 } & Total $\mathrm{Y}+\mathrm{Z}_{\mathrm{rep}}$ & - & 9 & 14 & 21 & 30 \\
\cline { 2 - 7 } & Total $\mathrm{Y}+\left(\mathrm{Z}_{\mathrm{lor}} *(-1)\right)$ & - & 1 & -22 & -251 & -3120 \\
\hline
\end{tabular}

TABLE A.1 PAYOFF DYNAMICS PLAYER 2 - ABSOLUTE PAYOFFS WITH RESPECT TO THE POSITIONS IN THE SUPPLY CHAIN
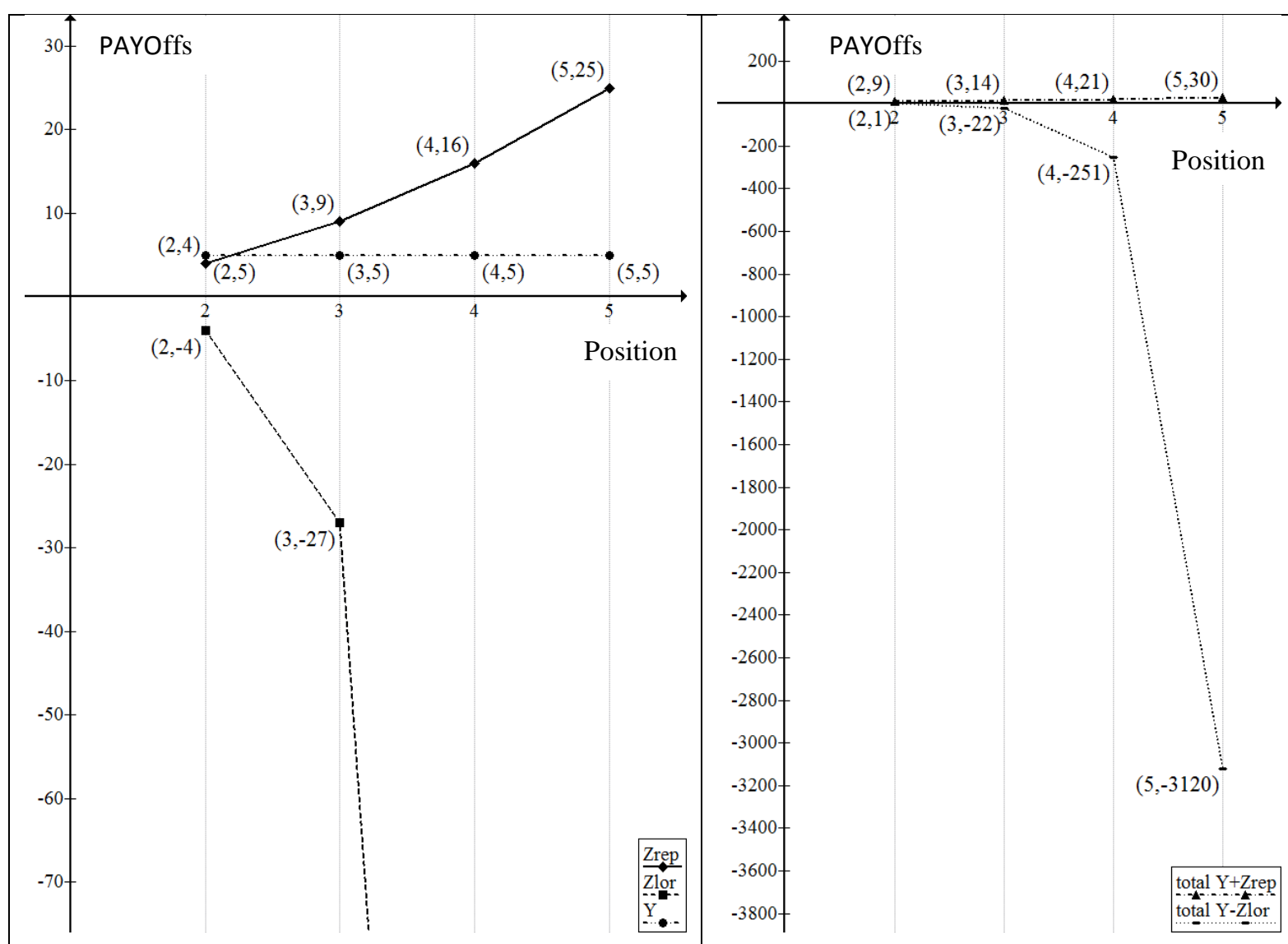

(a) Payoffs player 2 decompiled into utility components

(b) Sum of total Payoff of player 2

FIGURE A.1 PAYOFF DYNAMICS PLAYER 2 - GRAPHIC ILLUSTRATION OF PAYOFF DEVELOPMENT WITH RESPECT TO THE POSITION 


\section{Part A}

\section{B Proof of equilibria}

A perfect Bayesian equilibrium (PBE) in pure strategies exists when there are a pair of strategies and a belief that conform to the following conditions. After having observed a signal $\mathrm{s}_{\mathrm{i}}$ from $\mathrm{S}$, the receiver must develop a belief about the type of sender who originated the signal (condition 1). In due consideration of condition 1, the action chosen by the receiver $a^{*}$ must maximise his expected utility for every $s_{i}$ from $S$ (condition 2 ). The signal $\mathrm{s}^{*}$ from S must - given action $\mathrm{a}^{*}$ on the part of the receiver - maximise the sender's utility (condition 3 ). As far as possible, beliefs are developed in accordance with Bayes’ rule (condition 4).

\section{B.1 Proposition: Pooling on $\operatorname{SDS}_{\mathrm{g}}\left[\left(\mathrm{SDS}_{\mathrm{g}}, \mathrm{SDS}_{\mathrm{g}}\right),\left(\mathbf{b}_{1}, \mathbf{b}_{2}\right), \rho>.5, \psi<.5\right]$ with $\mathbf{X}_{1}>\mathbf{X}_{2}+\mathrm{W}$}

Proof: This pooling equilibrium is characterised by the fact that both types of player 1 send the signal SDS $\mathrm{g}$. This means that player 2 is confronted with uncertainty concerning the respective type of player 1 . All players have the same likelihood estimates $\alpha$ (common priors) about the initial draw of nature and these are known to all of them (common knowledge), here $\alpha>.5$. The deduction of the posterior belief is consistent with Bayes' rule. It leads to $\rho>.5$. In the case of a posterior belief $\rho>.5$, a privileged business relationship $b_{1}$ represents the ideal response of player 2 to the signal $\operatorname{SDS}_{\mathrm{g}}$. The corresponding payoffs are $\mathrm{W}+\mathrm{X}_{1}$ in the case of player $1_{\mathrm{t} 1}$ and $\mathrm{X}_{1}$ in the case of player $1_{\mathrm{t} 2}$. In so far as both types of player 1 decline in their utility position by deviating from their original signal $\left(\mathrm{SDS}_{\mathrm{g}}\right)$, this would not represent an incentive for them to do so. In the case of a belief $\psi<.5$, player 2 chooses as an ideal response the non-privileged business relationship $b_{2}$ if he observes the deviating signal SDS. Under the necessary assumption that $\mathrm{W}+\mathrm{X}_{2}<\mathrm{X}_{1}$ holds, the corresponding payoffs of the senders $\left(\mathrm{X}_{2}\right.$ for player $1_{\mathrm{t} 1}$ and $\mathrm{W}+\mathrm{X}_{2}$ for player $1_{\mathrm{t} 2}$ ) clearly represent a decline in their utility positions. Thus, the assumed existence of a pooling equilibrium is verified in accordance with the aforementioned conditions for PBEs.

\section{B.2 Proposition: Pooling on SDS [(SDS,SDS), $\left.\left(\mathbf{b}_{1}, \mathbf{b}_{2}\right), \psi>.5, \rho<.5\right]$ with $\mathbf{X}_{1}>\mathbf{X}_{2}+\mathbf{W}$}

Proof: This pooling equilibrium is characterised by the fact that both types of player 1 send the signal SDS. This means that player 2 is confronted with uncertainty concerning the respective type of player 1 . All players have the same likelihood estimates $\alpha$ (common priors) about the initial draw of nature and these are known to all of them (common knowledge), here $\alpha>.5$. The deduction of the posterior belief is consistent with Bayes' rule. It leads to $\psi>.5$. In the case of a posterior belief $\psi>.5$, a privileged business relationship $\mathrm{b}_{1}$ represents the ideal response of player 2 to the signal SDS. The corresponding payoffs are $\mathrm{X}_{1}$ in the case of player $1_{\mathrm{t} 1}$ and $\mathrm{W}+\mathrm{X}_{1}$ in the case of player $1_{\mathrm{t} 2}$. In so far as both types of player 1 decline in their utility position by deviating from their original signal (SDS), this would not represent an incentive for them to do so. In the case of a belief $\rho<.5$, player 2 chooses as an ideal response the non-privileged business relationship $b_{2}$ if he observes the deviating signal $\mathrm{SDS}_{\mathrm{g}}$. Under the necessary assumption that $\mathrm{W}+\mathrm{X}_{2}<\mathrm{X}_{1}$ holds, the corresponding payoffs of the senders $\left(\mathrm{W}+\mathrm{X}_{2}\right.$ for player $1_{\mathrm{t} 1}$ and $\mathrm{X}_{2}$ for player $\left.1_{\mathrm{t} 2}\right)$ clearly represent a decline in their utility positions. Thus, the assumed existence of a pooling equilibrium is verified in accordance with the aforementioned conditions for PBEs.

\section{B.3 Proposition: Separation, player $1_{t 1}$ playing $\operatorname{SDS}_{\mathrm{g}}\left[\left(\operatorname{SDS}_{\mathrm{g}}, \mathrm{SDS}\right),\left(\mathrm{b}_{1}, \mathrm{~b}_{2}\right), \rho=1, \psi=0\right]$ with $\mathrm{X}_{1}<\mathrm{X}_{2}+\mathrm{W}$} Proof: In the case of the separating equilibrium suggested here, player $1_{\mathrm{t} 1}$ sends a signal $\mathrm{SDS}_{\mathrm{g}}$ and player $1_{\mathrm{t} 2}$ sends a signal SDS. Both types of player 1 can be clearly identified by reference to the signals. The deduction of posterior beliefs is consistent with Bayes' rule and leads to $\rho=1$ and $\psi=0$. Player 2 chooses as an ideal response a utility-maximizing strategy, namely he chooses $b_{1}$ upon observing SDS $_{\mathrm{g}}$ and $\mathrm{b}_{2}$ upon observing SDS. 


\section{Part A}

In this case, the corresponding payoffs are $\mathrm{W}+\mathrm{X}_{1}$ for player $1_{\mathrm{t} 1}$ and $\mathrm{W}+\mathrm{X}_{2}$ for player $1_{\mathrm{t} 2}$. If player $1_{\mathrm{t} 1}$ deviates and signals SDS, player 2 responds with $b_{2}$ according to his belief $\psi=0$. In this case, the payoff for player $1_{\mathrm{t} 1}$ amounts to $\mathrm{X}_{2}$. If player $1_{\mathrm{t} 2}$ deviates and signals $\mathrm{SDS}_{\mathrm{g}}$, player 2 responds with $\mathrm{b}_{1}$ corresponding to his belief $\rho=$ 1. In this case, the payoff for player $1_{\mathrm{t} 2}$ is $\mathrm{X}_{1}$. The payoff achieved through deviation is clearly smaller in the case of player $1_{\mathrm{t} 1}$. The payoff for player $1_{\mathrm{t} 2}$ is clearly only smaller when inequation $\mathrm{W}+\mathrm{X}_{2}>\mathrm{X}_{1}$ is fulfilled. In this case, both types of player 1 have no incentive to deviate. Thus, the existence of the assumed separating equilibrium is verified in accordance with the aforementioned conditions.

\section{B.4 Proposition: Pooling on $\mathrm{SDS}_{\mathrm{g}}\left[\left(\mathrm{SDS}_{\mathrm{g}}, \mathrm{SDS}_{\mathrm{g}}\right),\left(\mathrm{b}_{1}, \mathrm{~b}_{2}\right), \rho>104 / 105, \psi<1 / 105\right]$ with $\mathrm{X}_{1}>\mathrm{X}_{2}+\mathrm{W}$}

Proof: This pooling equilibrium is characterised by the fact that both types of player 1 send the signal SDS $\mathrm{g}$. This means that player 2 is confronted with uncertainty concerning the respective type of player 1 . All players have the same likelihood estimates $\alpha$ (common priors) about the initial draw of nature and these are known to all of them (common knowledge), here $\alpha>104 / 105$. The deduction of the posterior belief is consistent with Bayes' rule. It leads to $\rho>104 / 105$. In the case of a posterior belief $\rho>104 / 105$, a privileged business relationship $b_{1}$ represents the ideal response of player 2 to the signal $\mathrm{SDS}_{\mathrm{g}}$. The corresponding payoffs are $\mathrm{W}+\mathrm{X}_{1}$ in the case of player $1_{\mathrm{t} 1}$ and $\mathrm{X}_{1}$ in the case of player $1_{\mathrm{t} 2}$. In so far as both types of player 1 decline in their utility position by deviating from their original signal $\left(\mathrm{SDS}_{\mathrm{g}}\right)$, this would not represent an incentive for them to do so. In the case of a belief $\psi<1 / 105$, player 2 chooses as an ideal response the non-privileged business relationship $b_{2}$ if he observes the deviating signal SDS. Under the necessary assumption that $\mathrm{W}+\mathrm{X}_{2}<\mathrm{X}_{1}$ holds, the corresponding payoffs of the senders $\left(X_{2}\right.$ for player $1_{t 1}$ and $W+X_{2}$ for player $\left.1_{t 2}\right)$ clearly represent a decline in their utility positions. Thus, the assumed existence of a pooling equilibrium is verified in accordance with the aforementioned conditions for PBEs.

\section{B.5 Proposition: Pooling on $\mathrm{SDS}_{\mathrm{g}}\left[\left(\mathrm{SDS}_{\mathrm{g}}, \mathrm{SDS}_{\mathrm{g}}\right),\left(\mathrm{b}_{1}, \mathrm{nb}\right), \rho>104 / 105,1 / 105<\psi<104 / 105\right]$}

Proof: This pooling equilibrium is characterised by the fact that both types of player 1 send the signal SDS . This means that player 2 is confronted with uncertainty concerning the respective type of player 1 . All players have the same likelihood estimates $\alpha$ (common priors) about the initial draw of nature and these are known to all of them (common knowledge), here $\alpha>104 / 105$. The deduction of the posterior belief is consistent with Bayes' rule. It leads to $\rho>104 / 105$. In the case of a posterior belief $\rho>104 / 105$, a privileged business relationship $b_{1}$ represents the ideal response of player 2 to the signal $\mathrm{SDS}_{\mathrm{g}}$. The corresponding payoffs are $\mathrm{W}+\mathrm{X}_{1}$ in the case of player $1_{\mathrm{t} 1}$ and $\mathrm{X}_{1}$ in the case of player $1_{\mathrm{t} 2}$. In so far as both types of player 1 decline in their utility position by deviating from their original signal $\left(\mathrm{SDS}_{\mathrm{g}}\right)$, this would not represent an incentive for them to do so. In the case of a belief $1 / 105<\psi<104 / 105$, player 2 chooses the absence of a business relationship, nb, as an ideal response if he observes the deviating signal SDS. The corresponding payoffs of the senders ( 0 for player $1_{t 1}$ and $\mathrm{W}$ for player $1_{\mathrm{t} 2}$ ) clearly represent a decline in their utility positions. Thus, the assumed existence of a pooling equilibrium is verified in accordance with the aforementioned conditions for PBEs.

\section{B.6 Proposition: Pooling on $\operatorname{SDS}_{\mathrm{g}}\left[\left(\mathrm{SDS}_{\mathrm{g}}, \mathrm{SDS}_{\mathrm{g}}\right),\left(\mathrm{b}_{2}, \mathrm{nb}\right), \rho<1 / 105,1 / 105<\psi<104 / 105\right]$}

Proof: This pooling equilibrium is characterised by the fact that both types of player 1 send the signal SDS . This means that player 2 is confronted with uncertainty concerning the respective type of player 1 . All players have the same likelihood estimates $\alpha$ (common priors) about the initial draw of nature and these are known to all of them (common knowledge), here $\alpha<1 / 105$. The deduction of the posterior belief is consistent with Bayes' rule. 
It leads to $\rho<1 / 105$. In the case of a posterior belief $\rho<1 / 105$, a non-privileged business relationship $b_{2}$ represents the ideal response of player 2 to the signal $\mathrm{SDS}_{\mathrm{g}}$. The corresponding payoffs are $\mathrm{W}+\mathrm{X}_{2}$ in the case of player $1_{\mathrm{t} 1}$ and $\mathrm{X}_{2}$ in the case of player $1_{\mathrm{t} 2}$. In so far as both types of player 1 decline in their utility position by deviating from their original signal $\left(\mathrm{SDS}_{\mathrm{g}}\right)$, this would not represent an incentive for them to do so. In the case of a belief $1 / 105<\psi<104 / 105$, player 2 chooses the absence of a business relationship, nb, as an ideal response if he observes the deviating signal SDS. The corresponding payoffs of the senders ( 0 for player $1_{t 1}$ and $\mathrm{W}$ for player $1_{\mathrm{t} 2}$ ) clearly represent a decline in their utility positions. Thus, the assumed existence of a pooling equilibrium is verified in accordance with the aforementioned conditions for PBEs.

\section{B.7 Proposition: Pooling on SDS [(SDS,SDS), $\left.\left(b_{1}, b_{2}\right), \psi>104 / 105, \rho<1 / 105\right]$ with $X_{1}>X_{2}+W$}

Proof: This pooling equilibrium is characterised by the fact that both types of player 1 send the signal SDS. This means that player 2 is confronted with uncertainty concerning the respective type of player 1 . All players have the same likelihood estimates $\alpha$ (common priors) about the initial draw of nature and these are known to all of them (common knowledge), here $\alpha>104 / 105$. The deduction of the posterior belief is consistent with Bayes' rule. It leads to $\psi>104 / 105$. In the case of a posterior belief $\psi>104 / 105$, a privileged business relationship $b_{1}$ represents the ideal response of player 2 to the signal SDS. The corresponding payoffs are $X_{1}$ in the case of player $1_{\mathrm{t} 1}$ and $\mathrm{W}+\mathrm{X}_{1}$ in the case of player $1_{\mathrm{t} 2}$. In so far as both types of player 1 decline in their utility position by deviating from their original signal (SDS), this would not represent an incentive for them to do so. In the case of a belief $\rho<1 / 105$, player 2 chooses as an ideal response the non-privileged business relationship $b_{2}$ if he observes the deviating signal $\mathrm{SDS}_{\mathrm{g}}$. Under the necessary assumption that $\mathrm{W}+\mathrm{X}_{2}<\mathrm{X}_{1}$ holds, the corresponding payoffs of the senders $\left(\mathrm{W}+\mathrm{X}_{2}\right.$ for player $1_{\mathrm{t} 1}$ and $\mathrm{X}_{2}$ for player $\left.1_{\mathrm{t} 2}\right)$ clearly represent a decline in their utility positions. Thus, the assumed existence of a pooling equilibrium is verified in accordance with the aforementioned conditions for PBEs.

\section{B.8 Proposition: Pooling on SDS [(SDS,SDS), $\left.\left(b_{1}, n b\right), \psi>104 / 105,1 / 105<\rho<104 / 105\right]$}

Proof: This pooling equilibrium is characterised by the fact that both types of player 1 send the signal SDS. This means that player 2 is confronted with uncertainty concerning the respective type of player 1 . All players have the same likelihood estimates $\alpha$ (common priors) about the initial draw of nature and these are known to all of them (common knowledge), here $\alpha>104 / 105$. The deduction of the posterior belief is consistent with Bayes' rule. It leads to $\psi>104 / 105$. In the case of a posterior belief $\psi>104 / 105$, a privileged business relationship $b_{1}$ represents the ideal response of player 2 to the signal SDS. The corresponding payoffs are $X_{1}$ in the case of player $1_{\mathrm{t} 1}$ and $\mathrm{W}+\mathrm{X}_{1}$ in the case of player $1_{\mathrm{t} 2}$. In so far as both types of player 1 decline in their utility position by deviating from their original signal (SDS), this would not represent an incentive for them to do so. In the case of a belief $1 / 105<\rho<104 / 105$, player 2 chooses the absence of a business relationship, nb, as an ideal response if he observes the deviating signal $\operatorname{SDS}_{\mathrm{g}}$. The corresponding payoffs of the senders ( $\mathrm{W}$ for player $1_{\mathrm{t} 1}$ and 0 for player $1_{\mathrm{t} 2}$ ) clearly represent a decline in their utility positions. Thus, the assumed existence of a pooling equilibrium is verified in accordance with the aforementioned conditions for PBEs.

\section{B.9 Proposition: Pooling on SDS [(SDS,SDS), $\left.\left(\mathrm{b}_{2}, \mathrm{nb}\right), \psi<1 / 105,1 / 105<\rho<104 / 105\right]$}

Proof: This pooling equilibrium is characterised by the fact that both types of player 1 send the signal SDS. This means that player 2 is confronted with uncertainty concerning the respective type of player 1 . All players have the same likelihood estimates $\alpha$ (common priors) about the initial draw of nature and these are known to all of 


\section{Part A}

them (common knowledge), here $\alpha<1 / 105$. The deduction of the posterior belief is consistent with Bayes' rule. It leads to $\psi<1 / 105$. In the case of a posterior belief $\psi<1 / 105$, a non-privileged business relationship $\mathrm{b}_{2}$ represents the ideal response of player 2 to the signal SDS. The corresponding payoffs are $\mathrm{X}_{2}$ in the case of player $1_{\mathrm{t} 1}$ and $\mathrm{W}+\mathrm{X}_{2}$ in the case of player $1_{\mathrm{t} 2}$. In so far as both types of player 1 decline in their utility position by deviating from their original signal (SDS), this would not represent an incentive for them to do so. In the case of a belief $1 / 105<\rho<104 / 105$, player 2 chooses the absence of a business relationship, nb, as an ideal response if he observes the deviating signal $\mathrm{SDS}_{\mathrm{g}}$. The corresponding payoffs of the senders ( $\mathrm{W}$ for player $1_{\mathrm{t} 1}$ and 0 for player $1_{\mathrm{t} 2}$ ) clearly represent a decline in their utility positions. Thus, the assumed existence of a pooling equilibrium is verified in accordance with the aforementioned conditions for PBEs.

\section{B.10 Proposition: Separation, player $1_{t 1}$ playing $\operatorname{SDS}_{\mathrm{g}}\left[\left(\operatorname{SDS}_{\mathrm{g}}, \mathrm{SDS}\right),\left(\mathrm{b}_{1}, \mathrm{~b}_{2}\right), \rho=1, \psi=0\right]$ with $\mathrm{X}_{1}<\mathrm{X}_{2}+\mathrm{W}$}

Proof: In the case of the separating equilibrium suggested here, player $1_{\mathrm{t} 1}$ sends a signal $\mathrm{SDS}_{\mathrm{g}}$ and player $1_{\mathrm{t} 2}$ sends a signal SDS. Both types of player 1 can be clearly identified by reference to the signals. The deduction of posterior beliefs is consistent with Bayes' rule and leads to $\rho=1$ and $\psi=0$. Player 2 chooses as an ideal response a utility-maximizing strategy, namely he chooses $b_{1}$ upon observing SDS $_{\mathrm{g}}$ and $\mathrm{b}_{2}$ upon observing SDS. In this case the corresponding payoffs are $\mathrm{W}+\mathrm{X}_{1}$ for player $1_{\mathrm{t} 1}$ and $\mathrm{W}+\mathrm{X}_{2}$ for player $1_{\mathrm{t} 2}$. If player $1_{\mathrm{t} 1}$ deviates and signals SDS, player 2 responds with $b_{2}$ according to his belief $\psi=0$. In this case, the payoff for player $1_{t 1}$ amounts to $X_{2}$. If player $1_{t 2}$ deviates and signals $\operatorname{SDS}_{\mathrm{g}}$, player 2 responds with $\mathrm{b}_{1}$ corresponding to his belief $\rho=$ 1. In this case the payoff for player $1_{\mathrm{t} 2}$ is $\mathrm{X}_{1}$. The payoff achieved through deviation is clearly smaller in the case of player $1_{\mathrm{t} 1}$. The payoff for player $1_{\mathrm{t} 2}$ is clearly only smaller when inequation $\mathrm{W}+\mathrm{X}_{2}>\mathrm{X}_{1}$ is fulfilled. In this case, both types of player 1 have no incentive to deviate. Thus, the existence of the assumed separating equilibrium is verified in accordance with the aforementioned conditions. 


\section{Publication bibliography}

Börzel, Tanja A.; Risse, Thomas (2010): Governance without a state: Can it work? In Regulation \& Governance 4, pp. 113-134.

Bundesanstalt für Arbeitsschutz und Arbeitsmedizin (BAuA) (2008): Sicherheitsdatenblätter. Eine Hilfe für den Arbeitgeber. With assistance of Eva Lechtenberg-Auffarth. Edited by Bundesanstalt für Arbeitsschutz und Arbeitsmedizin (BAuA). Bundesanstalt für Arbeitsschutz und Arbeitsmedizin (BAuA). Dortmund. Available online at http://www.baua.de/de/Publikationen/Fachbeitraege/artikel19.html, checked on 2/16/2015.

Bunke, Dirk; Rühl, Reinhold (2011): Das Sicherheitsdatenblatt. Kapitel 20. In Martin Führ (Ed.): Praxishandbuch REACH. Köln: Carl Heymanns, pp. 365-392.

Cecot, Caroline; Hahn, Robert; Renda, Andrea; Schrefler, Lorna (2008): An evaluation of the quality of impact assessment in the European Union with lessons for the US and the EU. In Regulation \& Governance 2, pp. 405424.

European Chemicals Agency (ECHA) (2011): The Operation of REACH and CLP 2011. Edited by European Chemicals Agency (ECHA). European Chemicals Agency (ECHA) (ECHA-11-R-003-EN). Available online at http://echa.europa.eu/documents/10162/13634/operation_reach_clp_2011_en.pdf, checked on 2/23/2015.

European Commission: Glossary: Gold plating. Edited by European Commission. European Commission (Glossary). Available online at http://ec.europa.eu/enterprise/glossary/index_en.htm, checked on 2/22/2015.

European Commission (COM (2013) 49 final) (2013): General Report on REACH. Report from the Commission to the European Parliament, the Council, the European Economic and Social Committee and the Committee of the Regions in accordance with Article 117(4) of REACH and Article 46(2) of CLP, and a review ofcertain elements of REACH in line with Articles 75(2), 138(2), 138(3) and 138(6) of REACH. Edited by European Commission. European Commission. Brussels (COM(2013) 49 final). Available online at http://eurlex.europa.eu/LexUriServ/LexUriServ.do?uri=COM:2013:0049:FIN:EN:PDF, checked on 2/16/2015.

Führ, Martin (2010): Analyse der Anreize und Hemmnisse am Beispiel der europäischen ChemikalienRegulierung REACh. In Stephan Hensel, Kilian Bizer, Martin Führ, Joachim Lange (Eds.): Gesetzesfolgenabschätzung in der Anwendung. Perspektiven und Entwicklungstendenzen. Baden-Baden: Nomos-Verl.-Ges. (Interdisziplinäre Studien zu Recht und Staat, 48), pp. 177-195.

Führ, Martin; Bizer, Kilian (2007): REACh as a paradigm shift in chemical policy - responsive regulation and behavioural models. In Journal of Cleaner Production 15, pp. 327-334.

Gibbons, Robert (1992): A Primer in Game Theory. Nachdr. Harlow u. a.: Prentice Hall Financial Times.

Gibbons, Robert (1997): An Introduction to Applicable Game Theory. In The Journal of Economic Perspectives 11 (1), pp. 127-149.

Hensel, Stephan (2011): Forschungsperspektiven: Erfüllungsaufwand für Normadressaten im Kontext der europäischen Chemikalienregulierung REACh. In Arbeitsgemeinschaft für wirtschaftliche Verwaltung e. V. (AWV) (Ed.): Bürokratieentlastung im europäischen Rechtsrahmen. AWV-Informationen Special (VI), pp. 611.

Hensel, Stephan; Bizer, Kilian; Führ, Martin; Lange, Joachim (Eds.) (2010): Gesetzesfolgenabschätzung in der Anwendung. Perspektiven und Entwicklungstendenzen. Baden-Baden: Nomos-Verl.-Ges. (Interdisziplinäre Studien zu Recht und Staat, 48).

Hey, Christian; Jacob, Klaus; Volkery, Axel (2007): Better regulation by new governance hybrids? Governance models and the reform of European chemicals policy. In Journal of Cleaner Production 15, pp. 1859-1874.

Krarup, Signe (2001): Can voluntary approaches ever be efficient? In Journal of Cleaner Production 9, pp. 135144.

Mayer-Figge, Andrea (2013): Qualität von Sicherheitsdatenblättern - Anspruch und Wirklichkeit: Ergebnisse aus dem Vollzug. In Zeitschrift für Stoffrecht (2), pp. 52-66.

Myerson, Roger B. (1999): Nash Equilibrium and the History of Economic Theory. In Journal of Economic Literature 37 (3), pp. 1067-1082.

Nationaler Normenkontrollrat (2012): Analysis of weak points relating to the registration obligations under the European Chemicals Regulation REACH. A joint project of the Nationaler Normenkontrollrat (NKR), the 


\section{Part A}

Federal Ministry for the Environment, Nature Conservation and Nuclear Safety (BMU), the Federal Institute for Occupational Safety and Health (BAuA), the Federal Environment Agency (UBA), and the German Chemical Industry Association (VCI). Nationaler Normenkontrollrat. Berlin. Available online at http://www.normenkontrollrat.bund.de/Webs/NKR/Content/EN/Publikationen/2013-10-21-englreach.pdf?_blob=publicationFile\&v=1, checked on 2/16/2015.

REACH Regulation: Regulation (EC) No 1907/2006 of the European Parliament and the Council of 18 December 2006 concerning the Registration, Evaluation, Authorisation and Restriction of Chemicals (REACH), establishing a European Chemicals Agency, amending Directive 1999/45/EC and repealing Council Regulation (EEC) No 793/93 and Commission Regulation (EC) No 1488/94 as well as Council Directive 76/769/EEC and Commission Directives 91/155/EEC, 93/67/EEC, 93/105/EC and 2000/21/EC. In Official Journal of the European Union L 136.

van Damme, Eric; Weibull, Jörgen W. (1995): Equilibrium in Strategic Interaction: The Contributions of John C. Harsanyi, John F. Nash and Reinhard Selten. In Scandinavian Journal of Economics 97 (1), pp. 15-40. 
Part B$$
\text { Back to table of contents }
$$
Back to table of contents

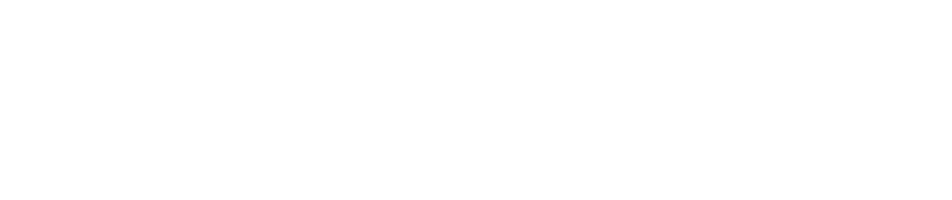

art B 


\title{
The European Community Regulation on Chemicals REACH (EC) No 1907/2006 \\ Incentives for upstream risk communication within supply chains - considerations from the perspective of game theory
}

\author{
Stephan Hensel ${ }^{\text {a, }} \uparrow$ \\ ${ }^{\text {a }}$ Chair of Economic Policy and SME Research, Faculty of Economic Sciences, University of Göttingen, Platz \\ der Göttinger Sieben 3, 37073 Göttingen, Germany
}

\begin{abstract}
This paper is concerned with the European Community Regulation on Chemicals REACH. In order to reach its aims (which include, among other things, a high standard for the protection for humans and the environment as well as the improvement of competition and innovation), the regulation employs an approach based upon control theory, which seeks to combine sovereign regulation with self-responsible action on the part of norm addressees. In this context, passing on information within the supply chain regarding the risks in handling chemicals occupies central importance. For this purpose, information is to be communicated in both directions (downstream risk communication and upstream risk communication). This paper seeks to elucidate upstream risk communication between two protagonists within a supply chain from the perspective of game theory. The conditions under which stable communication structures may emerge are revealed via equilibrium analysis. In consideration of the control theoretical approach adopted by $\mathrm{REACH}$, the results serve as a basis for further inquiry regarding when deviation from the normative requirements set by REACH may constitute a rational choice on the part of the norm addressee. The results of the analysis contribute to focusing on the perspective of the regulator.
\end{abstract}

KEYWORDS: Environmental Law and Economics, Upstream Risk Communication, Regulation and SelfResponsibility, Game Theory, Perfect Bayesian Equilibrium, Regulatory Impact Assessment

JEL classifications C70, K32

\section{Acknowledgements}

The author is grateful for the support of Richard Forsythe and Nikolas Helm who helped to prepare the English version of this paper. The German Federal Ministry of Education and Research (Bundesministerium für Bildung und Forschung (BMBF)) enabled the considerations reported here by funding the research project "Responsive Regulation of Innovation Behavior for Sustainability".

${ }^{\dagger}$ Corresponding author: Stephan Hensel

E-mail address: Stephan.Hensel@ wiwi.uni-goettingen.de; Phone: +49-551-39-4626; Fax: +49-551-39-19558 


\section{Part B}

\section{Introduction}

The regulation (EC) No 1907/2006 on Registration, Evaluation, Authorisation and Restriction of Chemicals which came into effect on June 1, 2007 (REACH-Regulation) - is based on the principle that norm addressees must ensure that the chemicals for whose use and production they are responsible do not affect humans and the environment in negative ways. ${ }^{1}$ In accordance with a chain of responsibility, ${ }^{2}$ norm addressees are obliged to ensure that chemicals are safely handled by transmitting information among one another regarding chemicals along the entire supply chain ${ }^{3}$. This brings into sight the regulation's control theoretical approach, which seeks to combine sovereign regulation with self-responsible ${ }^{4}$ action on the part of norm addressees ${ }^{5}$. From the perspective of the regulator, rational self-responsible communication regarding substance-related risks on the part of the norm addressees - known as risk communication - yields the advantage of emerging in the course of the norm addressees' attempt to maximize their utilities. This can cause risk communication to stabilize in such a way that no norm addressee has an incentive to one-sidedly divert from the status quo. The phrase "throughout the supply chain" implies downstream as well as upstream risk communication and thus the transmission of information from the top to the bottom as well as vice versa. The focus of this paper is on upstream risk communication. REACH sets forth uniform requirements for abstract protagonists involved in upstream risk communication within a supply chain ${ }^{6}$. The requirements to be met mostly concern the kind of information to be communicated upstream. As reports on the functioning of REACH in everyday practice prove, risk communication faces different obstacles (European Commission (COM (2013) 49 final) 2013, European Chemicals Agency (ECHA) 2011 and Nationaler Normenkontrollrat 2012). Therefore, it is not implausible to believe that in everyday practice upstream risk communication does not occur or does not always meet the requirements set forth by REACH.

In this paper, I aim to analyse the incentives of norm addressees to conduct upstream risk communication in compliance with $\mathrm{REACH}^{7}$. In this context, I am chiefly interested in the question of whether rational, selfresponsible upstream risk communication can realistically be put into practice at all. In case upstream risk communication should prove possible, I shall inquire the form of upstream risk communication resulting from it. Different forms of upstream risk communication are distinguished based upon whether information is communicated in compliance with REACH or whether upstream risk communication is being abused to the extent that the self-responsible handling of substances and preparations is not adequately adhered to. This is the cognitive interest behind this paper's hypothesis, namely that there exists no incentive for upstream risk communication in compliance with REACH within the supply chain! To begin with, I briefly recap the requirements of upstream risk communication within a supply chain as set forth by REACH. This chapter

\footnotetext{
1 "This Regulation is based on the principle that it is for manufacturers, importers and downstream users to ensure that they manufacture, place on the market or use substances that do not adversely affect human health or the environment. Its provisions are underpinned by the precautionary principle." Art. 1 (3) REACH-Regulation.

2 "In order to have a chain of responsibilities, downstream users should be responsible for assessing the risks arising from their uses of substances if those uses are not covered by a safety data sheet received from their suppliers, unless the downstream user concerned takes more protective measures than those recommended by his supplier or unless his supplier was not required to assess those risks or provide him with information on those risks". [...]. (Recital 58 REACH-Regulation).

3 “[...]. This important responsibility should also apply throughout the supply chain to enable all actors to meet their responsibility in relation to management of risks arising from the use of substances." (Recital 56 REACH-Regulation).

${ }^{4}$ General considerations on strengths and weaknesses of regulatory approaches including self-responsibility on part of norm addresses are given in Krarup 2001 and Börzel, Risse 2010.

${ }_{5}^{5}$ Further information on this regulatory approach with respect to European chemicals policy can be found in Führ, Bizer 2007 and Hey et al. 2007.

${ }^{6}$ See chapter 2 "Upstream risk communication within a supply chain - requirements according to REACH".

${ }^{7}$ Incentives and constraints with respect to REACH from a broader angle are analyzed by Führ 2010.
} 
subsequently closes with some reflections on an improper form of upstream risk communication, which is used to inadequately adhere to the self-responsible handling of substances and preparations (chapter 2). These reflections are transferred into a proper game theoretical framework in the following chapter. The results of the equilibrium analysis are discussed both formally and content-wise (chapter 3). The paper concludes with some considerations on the practical significance of the results for the regulator (chapter 4). This paper also aims to demonstrate the usefulness of game theory (Gibbons 1997) in the context of norm validation ${ }^{8}$.

\section{Upstream risk communication within a supply chain - requirements according to REACH}

\subsection{The supply chain}

A supply chain is not a static entity; rather, in practice it may take many different shapes, depending on a multitude of factors, such as the kind of product being distributed, the type of process organization and different types of protagonists involved et cetera. The relevant groups of main protagonists in connection with upstream risk communication are "actors in the supply chain" as well as "distributors". In this regard, the REACHRegulation accurately defines that "actors in the supply chain: means all manufacturers ${ }^{9}$ and/or importers ${ }^{10}$ and/or downstream users ${ }^{11}$ in a supply chain" (Art. 3 No. 17 REACH-Regulation) and "distributor: means any natural or legal person established within the Community, including a retailer, who only stores and places on the market a substance, on its own or in a preparation, for third parties" (Art. 3 No. 14 REACH-Regulation). Figure 1 depicts the groups of main protagonists.

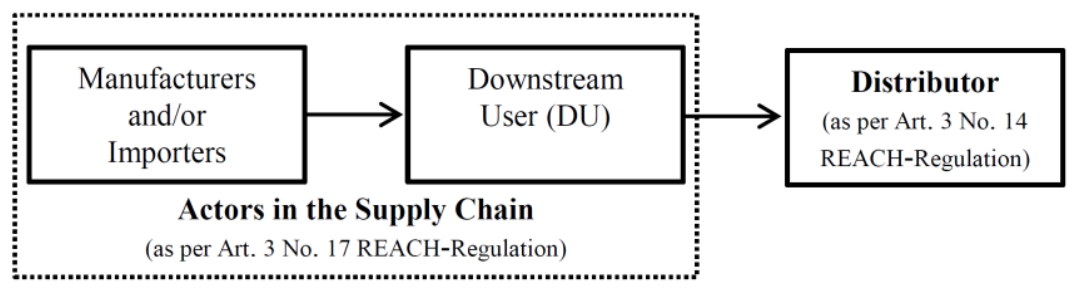

FIGURE 1 SUPPLY CHAIN: MAIN PROTAGONISTS IN CONNECTION WITH UPSTREAM RISK COMMUNICATION AS PER REACH-REGULATION

\subsection{Upstream risk communication according to requirements}

At different points, the REACH-Regulation provides clues concerning how upstream risk communication regarding substance-related risks within the supply chain should be conducted. Among many recitals of the REACH-Regulation, Article 34 REACH-Regulation "Duty to communicate information on substances and preparations up the supply chain" is relevant. ${ }^{12}$ The recitals name self-responsible ${ }^{13}$ action on the part of norm

\footnotetext{
${ }^{8}$ Hensel et al. 2010 contains an actual overview about the application of regulatory impact assessment in practice and recent developments.

9 Accurately defined in Art. 3 No. 9 REACH-Regulation: "manufacturer: means any natural or legal person established within the Community who manufactures a substance within the Community;".

${ }^{10}$ Accurately defined in Art. 3 No. 11 REACH-Regulation: "importer: means any natural or legal person established within the Community who is responsible for import;",

${ }^{11}$ Accurately defined in Art. 3 No. 13 REACH-Regulation: "downstream user: means any natural or legal person established within the Community, other than the manufacturer or the importer, who uses a substance, either on its own or in a preparation, in the course of his industrial or professional activities. A distributor or a consumer is not a downstream user. [...]."

${ }^{12}$ In the synopsis of these passages the control theoretical approach used by REACH, which both imposes duties on norm-addressees as well as using their self-responsible action in pursuit of the regulation's aims, becomes evident.

${ }^{13}$ Amongst others "[...] This Regulation is based on the principle that industry should manufacture, import or use substances or place them on the market with such responsibility and care as may be required to ensure that, under reasonably foreseeable conditions, human health and
} 
addressees as well as the transmission of information in both directions ${ }^{14}$ of a supply chain (downstream and upstream). In connection with upstream risk communication, Article 34 REACH-Regulation accurately defines: "Any actor in the supply chain of a substance or a preparation shall communicate the following information to the next actor or distributor up the supply chain: (a) new information on hazardous properties, regardless of the uses concerned; (b) any other information that might call into question the appropriateness of the risk management measures identified in a safety data sheet supplied to him, which shall be communicated only for identified uses. Distributors shall pass on that information to the next actor or distributor up the supply chain." While Figure 1 in the previous section depicts the supply chain with its various relevant groups of main protagonists for upstream risk communication via the legal definition, the following Figure 2 represents the flow of information from a downstream protagonist to an upstream protagonist according to Article 34 of REACHRegulation.

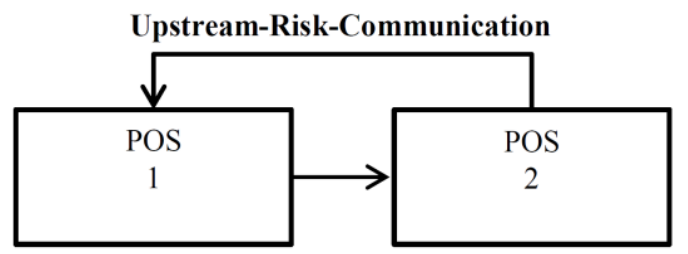

Duty to communicate information to the next actor or distributer up the supply chain (Article 34 REACH-Regulation)

\section{FIGURE 2 UPSTREAM RISK COMMUNICATION WITHIN A SUPPLY CHAIN AS PER REACH-REGULATION}

Against the background of this paper's hypothesis, the differentiation between groups of main protagonists ("actors in the supply chain" and "distributor") will no longer be used. Indeed, given that both groups' incentives to conduct upstream risk communication may be supposed as similar in structure, they may also be analyzed together at a more general level. Therefore, Figure 2 depicts a supply chain that comprises only two elements: an upstream position (POS1) and a downstream position (POS2). The same terminology - which abstracts from the groups of main protagonists - is also used in the game theoretical model in chapter 3.2. Deviation within the everyday practice of upstream risk communication may counteract the aims of REACH. It is possibly a matter of rational choice for a downstream protagonist to pass on part of his self-responsibility in dealing with substances and preparations to the respective upstream protagonist. Even though he could inform himself about the

the environment are not adversely affected.” (Recital 16); “[...] recommendations about risk management measures should systematically be conveyed through supply chains, as reasonably necessary, to prevent adverse effects on human health and the environment. [...]." (Recital 17); "Responsibility for the management of the risks of substances should lie with the natural or legal persons that manufacture, import, place on the market or use these substances. [...]." (Recital 18); "The responsibility to assess the risks and hazards of substances should be given, in the first place, to the natural or legal persons that manufacture or import substances, [...]. Natural or legal persons handling chemicals should take the necessary risk management measures in accordance with the assessment of the risks of substances and pass on relevant recommendations along the supply chain. [...]." (Recital 25); "Part of the responsibility of manufacturers or importers for the management of the risks of substances is the communication of information on these substances to other professionals such as downstream users or distributors. [...]. This important responsibility should also apply throughout the supply chain to enable all actors to meet their responsibility in relation to management of risks arising from the use of substances." (Recital 56); "In order to have a chain of responsibilities, downstream users should be responsible for assessing the risks arising from their uses of substances if those uses are not covered by a safety data sheet received from their suppliers, unless the downstream user concerned takes more protective measures than those recommended by his supplier or unless his supplier was not required to assess those risks or provide him with information on those risks.” [...]. (Recital 58).

${ }^{14}$ Amongst others "[...]. To achieve fair burden sharing with their customers, manufacturers and importers should in their chemical safety assessment address not only their own uses and the uses for which they place their substances on the market, but also all uses which their customers ask them to address." (Recital 30); "Communication up and down the supply chain should be facilitated. The Commission should develop a system categorising brief general descriptions of uses taking into account the outcomes of the RIPs." (Recital 62); "The effective communication of information on chemical risks and how they can be managed is an essential part of the system established by this Regulation. Best practice from the chemicals and other sectors should be considered in the preparation of guidance by the Agency to all stakeholders." (Recital 97). 
necessary measures for adequate handling of substances and preparations - for instance, by means of information that was transmitted downstream beforehand - he lets the respective upstream protagonist recommend or confirm such measures for risk management to himself. In such a scenario, the downstream protagonist engages in a form of reassurance that is not intended by REACH. In this case, the upstream protagonist - provided that he consents to this - is used as a service provider. This conflict between compliant and non-compliant behavior poses as a point of departure for the game theoretical considerations of chapter 3.

\section{Upstream risk communication within a supply chain - a game theoretical point of view}

In this chapter, the aforementioned conditions and incentives for upstream risk communication are transferred to a game theoretical framework. Subsequently, they are analyzed against the background of this paper's hypothesis that "there exists no incentive whatsoever for upstream risk communication in compliance with REACH within the supply chain".

\subsection{The game}

The game under consideration is a dynamic game with pure strategies and incomplete information (Gibbons 1992). There are two protagonists, referred to as players 1 and 2, respectively. Player 1 adopts the role of the downstream protagonist, who may communicate with his respective upstream protagonist player 2 . The game proceeds in stages. Stage 1: An initial draw of nature leads to the selection of a type $t_{i}$ of player 1 for the downstream protagonist in the supply chain from a set $\mathrm{T}=$ (player $1_{\mathrm{t} 1}$; player $1_{\mathrm{t} 2}$ ). This may be a protagonist who is sufficiently competent in his handling of chemicals and preparations and who either meets or even exceeds the aims set out by REACH (player $1_{\mathrm{t} 1}$ ). In this case, exceeding the requirements set out by REACH means that the protagonist himself uses stricter requirements than necessary. Player $1_{\mathrm{t} 2}$ uses relatively less secure measures in handling chemicals in comparison to player $1_{\mathrm{t} 1}{ }^{15}$. Player $1_{\mathrm{t} 1}$ 's share of the population amounts to $\alpha$, while player $1_{\mathrm{t} 2}$ 's share is given by $(1-\alpha)$. After nature's initial draw, the downstream protagonist (player 1) is aware of his type. Furthermore, all players have the same probability estimates regarding nature's initial draw (common priors) and these are common knowledge. Furthermore, the following applies: $0<\alpha<1$. Stage 2: The downstream protagonist (player 1) sends a signal to the upstream protagonist in the supply chain (player 2). In the context of this game, the signals correspond to two different forms of upstream risk communication. $\mathrm{S}=$ (Information; Reassurance) defines the set of signals from which player 1 may choose. The signal "Information" stands for a form of upstream risk communication that is in compliance with $\mathrm{REACH}^{16}$. By contrast, the signal "Reassurance" stands for a form of upstream risk communication in which the downstream protagonist uses the upstream protagonist as a service provider. By passing on part of his responsibility for the secure handling of substances and preparations to the upstream protagonist, the downstream protagonist acts less self-responsibly than he is able to. ${ }^{17}$ Stage 3: The upstream protagonist (player 2) in the supply chain observes the signal sent by player 1 . However, he is unable to recognize the downstream protagonist's type, whereby in this respect player 2 is confronted with uncertainty. This is why player 2 needs to develop beliefs regarding the chances of what type

\footnotetext{
${ }^{15}$ This characterization of player $1_{\mathrm{t} 2}$ does not mean that player $1_{\mathrm{t} 2}$ does not meet the requirements stated by REACH, although the assumption of non-fulfilment of requirements set out by REACH does not run contrary to the characterization made here.

${ }^{16}$ Chapter 2 of this paper contains a closer examination of the conditions REACH requires of upstream risk communication.

${ }^{17}$ This does not mean that the clarification of ambiguities via further inquiries does not conform to REACH requirements, although the assumption of non-fulfilment of requirements set out by REACH does not run contrary to the characterization made here.
} 


\section{Part B}

of player 1 might be sending the signal. This uncertainty is depicted in Figure 3, where the various relevant decision nodes have been assembled into information sets (framed by a dashed line). In correspondence with the number of possible signals $\mathrm{S}=$ (Information;Reassurance), this game features two information sets. The beliefs at the decision nodes in the information sets are defined as $\rho$ and $\psi$. The converse probabilities within the respective information sets are defined as $(1-\rho)$ and $(1-\psi)$. After player 2 has observed a signal, he may react to it with an action. The set of possible actions is defined as $\mathrm{A}=(\mathrm{r} ; \mathrm{i})$. In this context, $\mathrm{r}$ (reacting) stands for a reaction to the signal being sent upstream. However, player 2 may also ignore the signal, thereby choosing the action $\mathrm{i}$ (ignoring). The game finishes after player 2 has made his move.

\subsubsection{Payoffs Player 1 and Player 2}

Player 1: The downstream protagonist derives a utility increase from the utility component "I" when he adheres to his informational duties as set out in Article 34 of $\mathrm{REACH}^{18}$. In the context of the present game, this is the case when both types of player 1 communicate information in a fashion conforming to the requirements of REACH upstream. In this case, the utility increase of player 1 is independent of the following choice of action by player 2. This can be explained in terms of a psychological effect, which behavior that is conformable to law may trigger. The protagonist's conscience - given that it exists - is relieved by the knowledge of norm-compliant behavior. Furthermore, fear of the revelation of non-norm-compliant upstream risk communication may pose as a psychological strain, which is avoided here. Rather than the utility increase from norm-compliant upstream risk communication, player 1 may derive a utility increase " $\mathrm{R}$ " from attempting to infer reassurance from player 2 regarding the secure handling of substances and preparations and player 2 consents to this. In this case, utility arises from player 1 passing on part of his responsibility to the upstream protagonist; for instance, through reassurance for information already communicated downstream regarding the secure handling of substances and preparations. In this case, the utility increase for player $1_{t 2}$ with " $2 R$ " is twice as large as for player $1_{t 1}$ with " $R$ ". This is simply because player $1_{\mathrm{t} 2}$ - who is relatively less competent in his handling of chemicals in comparison with player $1_{\mathrm{t} 1}$ - benefits from reassurance to a higher degree than the latter. Conversely, it is more burdensome to player $1_{\mathrm{t} 2}$ compared with player $1_{\mathrm{t} 1}$ if the requested reassurance is ignored by player 2 . In this case, player $1_{\mathrm{t} 2}$ achieves a utility decrease amounting to “-R", while player $1_{t 1}$ is not negatively affected by this and his payoff amounts to zero. The following applies to the utility components of player $1: \mathrm{R}>0, \mathrm{I}>0,(-\mathrm{R})<0$.

Player 2: The upstream protagonist achieves a utility increase through the utility component " $\mathrm{Z}_{\mathrm{c}}$ "19 when he reacts to information being communicated upstream in compliance with REACH and acts upon this in compliance with the said regulation. As in the case of player 1, his payoff arises from a psychological effect, which behavior that is conformable to law may cause. In practice, the reaction depends upon the content of the transmitted information, whereby different reactions are compatible with Article 34 of REACH. New information pertaining to dangerous characteristics of substances and preparations as well as information questioning the adequacy of his risk management measures should precipitate player 2 to re-evaluate the latter. Player 2 achieves a utility decrease through the utility component " $\mathrm{Z}_{\mathrm{nc}}$ " ${ }^{20}$ Player 2 realizes this utility component when he ignores information transmitted upstream in compliance with REACH and thereby acts in a non-normcompliant manner. In this case, again, a psychological effect is decisive. Conscious non-norm-compliant

\footnotetext{
${ }^{18}$ Article 34 REACH-Regulation is quoted in chapter 2.2 "Upstream risk communication according to requirements".

${ }^{19}$ The index "c" is derived from the word compliance.

${ }^{20}$ The index "nc" is derived from the term non compliance.
} 


\section{Part B}

behavior can be psychologically burdensome, especially through fear of revelation. Both utility components $\mathrm{Z}_{\mathrm{c}}$ and $\mathrm{Z}_{\mathrm{nc}}$ are unaffected by the type of player 1 communicating upstream; rather, they are solely determined by the action of choice of player 2 . The utility component " $\mathrm{Z}_{1}$ " 21 is dependent on the type of player 1 that communicates upstream. Through this, player 2 achieves a utility decrease when he answers player 1's request for reassurance. When player 2 answers a request for reassurance by player $1_{\mathrm{t} 2}$, his utility decrease is twice as high - amounting to " $2 \mathrm{Z}_{\mathrm{l}}$ " - as when he answers a request for reassurance by player $1_{\mathrm{t} 1}$. In the latter case, the utility decrease amounts to merely " $Z_{1}$ ". This weighted dependency is an outcome of player $1_{\mathrm{t} 2}$ being less competent in his handling of chemicals compared with player $1_{\mathrm{t} 1}$. As a result, a request for reassurance by player $1_{\mathrm{t} 2}$ may be assessed as more costly for player 2 . For the utility components of player 2 , the following applies: $Z_{c}>0, Z_{n c}<$ $0, \mathrm{Z}_{1}<0$.

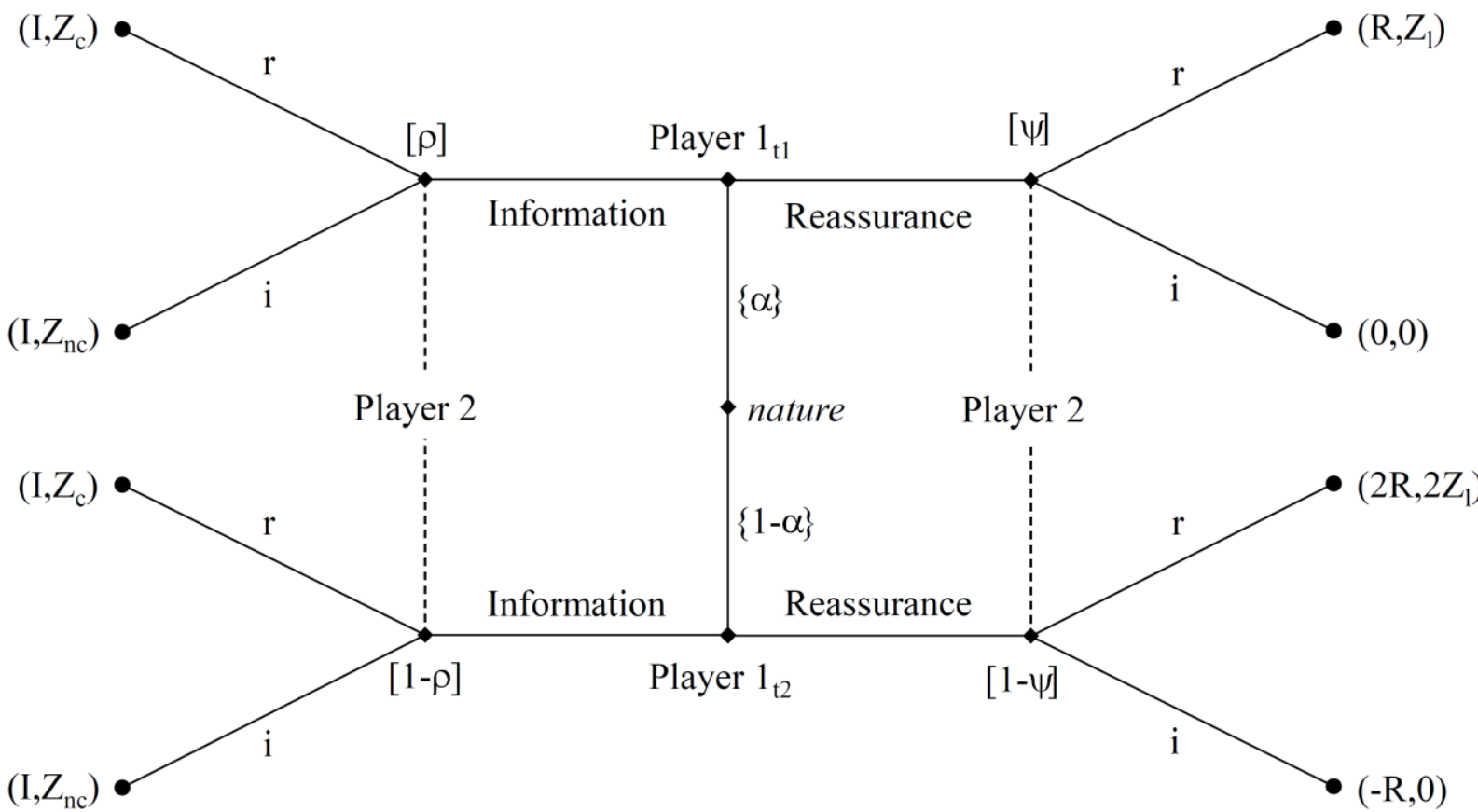

FIGURE 3 THE GAME - UPSTREAM RISK COMMUNICATION WITHIN A SUPPLY CHAIN

\begin{tabular}{|l|l|l|l|l|}
\hline \multicolumn{2}{|l|}{ Player 1 utility components } & \multicolumn{3}{l|}{ Player 2 utility components } \\
\hline $\mathrm{I}:$ & $\begin{array}{l}\text { Upstream risk communication in compliance } \\
\text { with REACH }\end{array}$ & $\mathrm{Z}_{\mathrm{c}}:$ & $\begin{array}{l}\text { REACH-compliant reaction in upstream risk } \\
\text { communication in compliance with REACH }\end{array}$ \\
\hline $\mathrm{R}:$ & $\begin{array}{l}\text { Upstream risk communication that does not } \\
\text { conform to REACH requirements }\end{array}$ & $\mathrm{Z}_{\mathrm{nc}}:$ & $\begin{array}{l}\text { Ignoring upstream risk communication in } \\
\text { compliance with REACH }\end{array}$ \\
\hline & \multicolumn{2}{|l|}{$\mathrm{Z}_{\mathrm{l}}:$} & $\begin{array}{l}\text { Reacting to upstream risk communication that does } \\
\text { not conform to REACH requirements }\end{array}$ \\
\hline
\end{tabular}

TABLE 1 UTILITY COMPONENTS OF PLAYERS 1 AND 2

Figure 3 depicts the aforementioned course of the game in the form of a game tree. ${ }^{22}$ The aforementioned utility components of players 1 and 2 are given in parentheses ${ }^{23}$ at the left- and right-hand side of the game tree. The characterization of players 1 and 2 including their respective utility components are summarized in Table 1.

\footnotetext{
${ }^{21}$ The index "l" is derived from the word loss.

${ }^{22}$ The depiction of the game tree follows the usual established standards for the representation of game trees. The game begins in the middle of the diagram with an initial draw of "nature" and relative to the strategies proceeds along the respective branches of the game tree to the sides.
} 


\section{Part B}

3.2 The game - concretion of incentive structure to communicate up the supply chain

In this section, the game (as introduced in chapter 3.1) will be further concretized against the background of the possibility that upstream risk communication might in practice not always conform to Article 34 of REACH. For this purpose, the utility components of both players are weighted in their respective relations to one another and the utility components of player 2 are assigned numerical values. Both players are conceptualized in terms of the two-element supply chain introduced in chapter 2 (see Figure 2) as protagonists located at positions 1 and 2 and marked accordingly (POS1 and POS2). The content layout is presented in the game tree in Figure 4 and is explained in chapter 3.2.1.

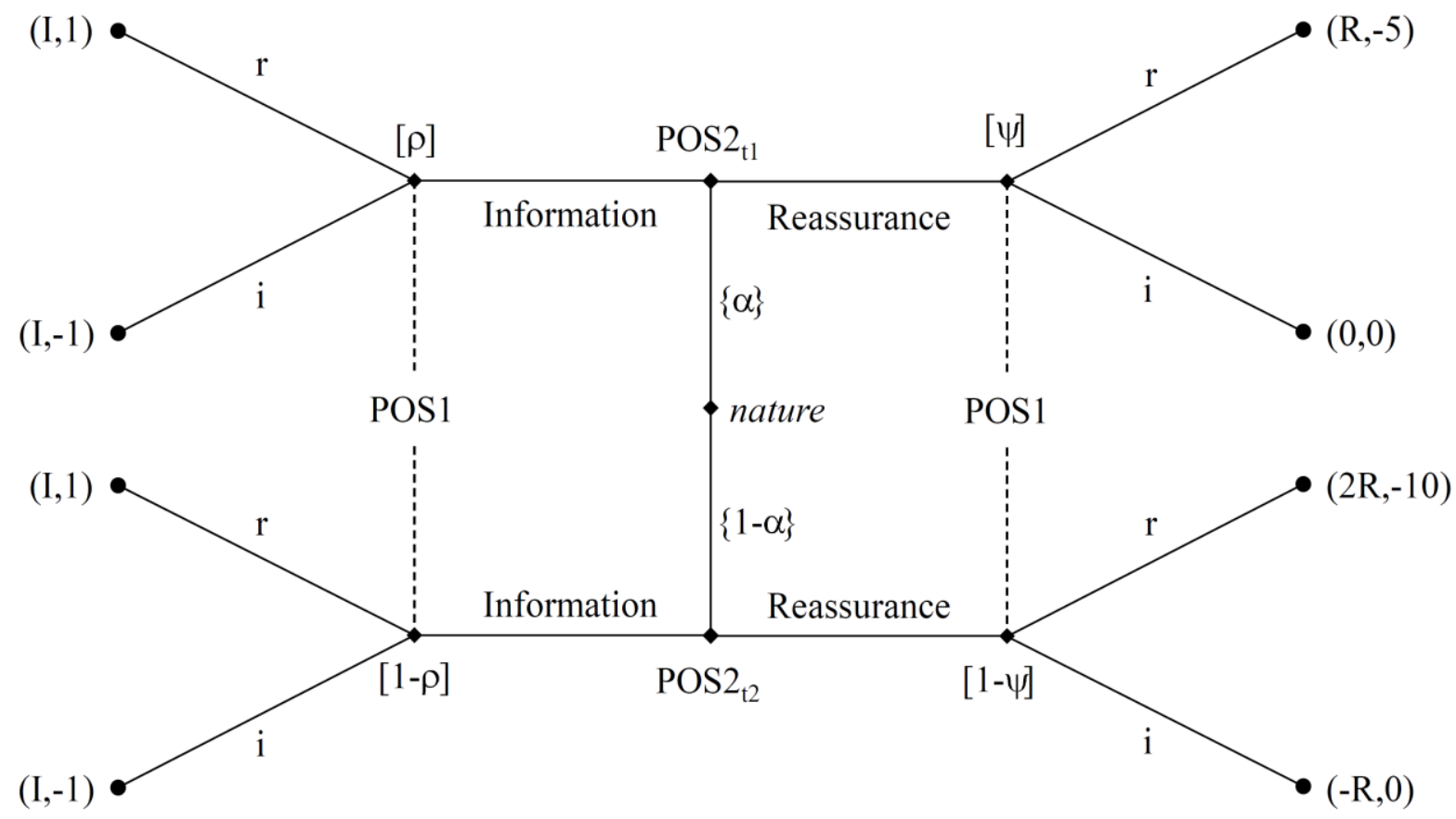

FIGURE 4 THE GAME - CONCRETION OF INCENTIVE STRUCTURE TO COMMUNICATE UP THE SUPPLY CHAIN

\subsubsection{Payoffs of Player 1 and Player 2 against the background of incentive structure concretion to communicate up the supply chain}

Player 1 adopts the role of the downstream protagonist within the supply chain who communicates upstream. He occupies position 2 (POS2) within the supply chain. As mentioned above, player 1 may realize a utility increase via the utility components I or R. This means that player 1 benefits from acting in compliance with Article 34 of REACH (utility component I). If player 1 requests reassurance from player 2 and the latter consents to this, player 1 realizes the utility component R. What may further be specified is that the utility increase R from reassurance is relatively greater than the utility increase from norm-compliant behavior I that is in compliance with Article 34 of REACH. This means that R > I. The justification for this assumption lies in the fact that a clear conscience on part of the protagonist is immediately less beneficial than using another protagonist as a service provider at small costs ${ }^{24}$. Thus, on the whole $\mathrm{R}>\mathrm{I}>0>-\mathrm{R}$.

\footnotetext{
${ }^{23}$ Concerning the information in parentheses: the first utility component represents the payoff of player 1 , the second one depicts the payoff of player 2 .

${ }^{24}$ The phrase 'at small costs' in this context signifies that there arise for the downstream protagonist relatively smaller costs in comparison to a situation in which he would have to explicitly purchase this form of advisory service as, for example, through the conclusion of a commercially available advisory contract.
} 
Player 2 adopts the role of the upstream protagonist within the supply chain who may react to the upstream risk communication of the downstream protagonist (player 1). Within the supply chain, player 2 occupies the position 1 (POS1). The possible utility components for player 2 are " $\mathrm{Z}_{\mathrm{c}}$ ", " $\mathrm{Z}_{\mathrm{nc}}$ " or " $\mathrm{Z}_{\mathrm{l}}$ ". This means that player 2 achieves a utility increase in case of reacting in compliance with REACH to upstream risk communication that is itself conducted in compliance with REACH $\left(\mathrm{Z}_{\mathrm{c}}\right)$. Player 2 derives a utility decrease in case of ignoring upstream risk communication in compliance with $\operatorname{REACH}\left(\mathrm{Z}_{\mathrm{nc}}\right)$ as well as in case of reacting to upstream risk communication that does not conform to the requirements set by REACH $\left(Z_{1}\right)$. What may further be specified is that the utility decrease $Z_{1}$ for player 2 - which arises from his reacting to a request for reassurance - is absolutely greater than the utility decrease that arises from his ignoring REACH-compliant upstream risk communication $\mathrm{Z}_{\mathrm{nc}}$. This may be justified as follows: as explained above, the knowledge of non-compliant reacting may be considered as a kind of psychological pressure. However, what is more immediately burdensome to the protagonist is the cost that arises from his acting as a service provider to another protagonist without being paid for this as customary in the particular market ${ }^{25}$. In the context of this model, the utility increase from REACH-compliant reacting to upstream risk communication conducted according to $\mathrm{REACH}$ requirements $\left(\mathrm{Z}_{\mathrm{c}}\right)$ is absolutely equivalent to the utility decrease from ignoring upstream risk communication conducted according to $\mathrm{REACH}\left(\mathrm{Z}_{\mathrm{nc}}\right)$. What constitutes a minor psychological pressure to one side $\left(Z_{n c}\right)$ represents a minor psychological relief to the other $\left(\mathrm{Z}_{\mathrm{c}}\right)$, for the same reason. Knowledge of REACH-compliant reacting to upstream risk communication conducted in compliance with REACH is seldom immediately beneficial to a single protagonist ${ }^{26}$. In Figure 4 , player 2 is assigned concrete numerical values in accordance with the weighting that is justified in the aforementioned way. Thus, on the whole $\left|Z_{l}\right|>\left|Z_{n c}\right|=Z_{c}$ with $Z_{l}=-5, Z_{n c}=-1, Z_{c}=1$. Table 2 summarizes all concretions made in the game tree in Figure 4 at a glance.

\begin{tabular}{l|l|}
\hline Position & Weighting and concretion utility components \\
\hline POS2 (player 2) & $\mathrm{R}>\mathrm{I}>0>-\mathrm{R}$ \\
\hline POS1 (player 2) & $\left|\mathrm{Z}_{\mathrm{l}}\right|>\left|\mathrm{Z}_{\mathrm{nc}}\right|=\mathrm{Z}_{\mathrm{c}}$ with $\mathrm{Z}_{\mathrm{l}}=-5, \mathrm{Z}_{\mathrm{nc}}=-1, \mathrm{Z}_{\mathrm{c}}=1$. \\
\hline
\end{tabular}
TABLE 2 WEIGHTING AND CONCRETION UTILITY COMPONENTS FOR PLAYER 1 AND PLAYER 2 WITHIN A SUPPLY
CHAIN

\subsection{Equilibrium analysis}

The solution concept ${ }^{27}$ for identifying the equilibrium structure is the perfect Bayesian equilibrium (PBE). A PBE in pure strategies exists when there is an equivalently weighted pair of strategies as well as beliefs that conforms to the following conditions: after the receiver has observed a signal $\mathrm{s}_{\mathrm{i}}$ from $\mathrm{S}$, he must develop a belief regarding what type of player is the originator of the signal (condition 1); the receiver's action of choice $\mathrm{a}^{*}$ must - in consideration of condition 1 - maximize his expected utility for every $\mathrm{s}_{\mathrm{i}}$ from $\mathrm{S}$ (condition 2 ); the sender's signal $\mathrm{s}^{*}$ from $\mathrm{S}$ must - given the receiver's action of choice $\mathrm{a}^{*}$ - maximize his utility (condition 3 ); as far as possible beliefs are developed in accordance with Bayes' theorem (condition 4). Both sender and receiver possess four pure strategies, respectively (see Table 3). The reading of the pure strategies is elaborated based upon two exemplary cases $\quad\left(\left(\left[\right.\right.\right.$ Information|Player $\left.\quad 1_{\mathrm{t} 1}\right] ;$ [Information|Player $\left.\left.\quad 1_{\mathrm{t} 2}\right]\right) \quad$ and

\footnotetext{
25 The phrase 'as customary in the particular market' means the conclusion of an advisory contract with corresponding payment for reassurance as a service.

${ }^{26} \mathrm{I}$ abstract from further considerations as to whether it is possible to build a reputation on the basis of REACH compliant reacting to upstream risk communication that is itself in compliance with REACH.

${ }^{27}$ For the evolution and further developments of Nash equilibrium as concept of solution in game theory see also Myerson 1999 and van Damme, Weibull 1995.
} 
([r|Information]; [r|Reassurance])) in the footnotes. This interpretation applies equally to all strategies listed at table 3 .

\begin{tabular}{|c|c|}
\hline Player & Pure strategies \\
\hline Player 1 (sender) & 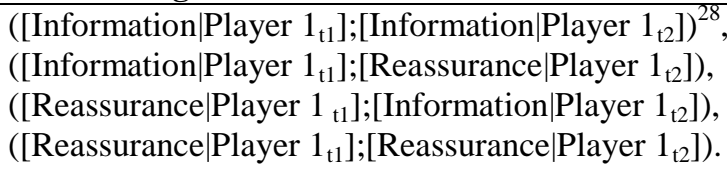 \\
\hline Player 2 (receiver) & $\begin{array}{l}([r \mid \text { Information];[r|Reassurance ]) } \\
\text { ([r| Information];[i|Reassurance]), }^{29} \\
\text { ([i|Information];[r|Reassurance]), } \\
\text { ([i|Information];[i|Reassurance]). }\end{array}$ \\
\hline
\end{tabular}

TABLE 3 PURE STRATEGIES PLAYER 1 AND PLAYER 2

Within the context of the present model, the PBE may theoretically take four different shapes: a pooling equilibrium with both types of player 1 choosing the signal Information [Information,Information], a pooling equilibrium with both types of player 1 choosing the signal Reassurance [Reassurance,Reassurance], a separating equilibrium with player $1_{\mathrm{t} 1}$ choosing the signal Information and player $1_{\mathrm{t} 2}$ choosing the signal Reassurance [Information,Reassurance] and a separating equilibrium with player $1_{\mathrm{tl}}$ choosing the signal Reassurance and player $1_{12}$ choosing the signal Information [Reassurance, Information]. The game tree in Figure 4 is tested for these PBE shapes.

\subsubsection{Results}

The existence of a pooling equilibrium as a PBE in pure strategies in the game tree in Figure 4 can be proven.

Proposition: Pooling on Information [(Information,Information), (r,i), $0<\rho<1,0<\psi<1$ ]

Proof: The pooling equilibrium is characterized by both types of player 1 sending the signal "Information" and thereby conducting upstream risk communication in compliance with REACH. For player 2, there exists uncertainty regarding the type of player 1 . All players have the same likelihood estimates $\alpha$ (common priors) regarding the initial draw of nature and these are common knowledge: $0<\alpha<1$. The deduction of the posterior belief is consistent with Bayes' theorem and leads to $0<\rho<1$. In the case of a posterior belief of $0<\rho<1$, REACH-compliant reacting " $\mathrm{r}$ " to upstream risk communication conducted in compliance with REACH constitutes the ideal answer to the signal "Information". The corresponding payoffs of the senders amount to "I" for player $1_{\mathrm{t} 1}$ and "I" for player $1_{\mathrm{t} 2}$. An equilibrium requires that the sender's strategy likewise represents the ideal response to the action of the receiver. In so far as both types of player 1 would decline in their utility position by deviating from their original signal "Information", they would have no incentive to do so. In the case of a belief of $0<\psi<1$, player 2 chooses ignoring "I" as ideal answer to the signal "Reassurance". The corresponding payoffs of the senders (" 0 " for player $1_{t 1}$ and "- $R$ " for player $1_{t 2}$ ) clearly constitute a decline in their utility positions. Thus, the assumed existence of a pooling equilibrium is verified in accordance with the aforementioned conditions for perfect Bayesian equilibria. Table 4 offers a summary overview of the

\footnotetext{
${ }^{28}$ Concerning the information in brackets: [Information|Player $1_{\mathrm{t} 1}$ ]; [Information|Player $1_{\mathrm{t} 2}$ ] means that player 1 chooses the signal "Information" under the constraint of being type ${ }_{\mathrm{t} 1}$ and under the constraint of being type $\mathrm{t}_{2}$ player 1 chooses the signal "Information" as well.

${ }^{29}$ Concerning the information in brackets: [r|Information]; $[\mathrm{r} \mid$ Reassurance] means that player 2 chooses the action " $r$ " under the constraint of observing the signal "Information" and under the constraint of observing the signal "Reassurance", player 2 chooses the action " $r$ " as well.
} 
characteristics of the pooling equilibrium identified above (the reading of the equilibrium in square brackets is treated in exemplary fashion in a footnote).

\begin{tabular}{|c|c|c|}
\hline \multirow{2}{*}{\multicolumn{2}{|c|}{$\begin{array}{l}\text { Results } \\
\text { equilibrium analysis }\end{array}$}} & $\begin{array}{l}\text { Utility components } \\
\text { POS1 (Player 2) }\end{array}$ \\
\hline & & $\left|Z_{1}\right|>\left|Z_{n c}\right|=Z_{c}$ mit $Z_{1}=-5, Z_{n c}=-1, Z_{c}=1$ \\
\hline $\begin{array}{l}\text { Utility components } \\
\text { POS2 (Player 1) }\end{array}$ & $\mathrm{R}>\mathrm{I}>0>-\mathrm{R}$ & [(Information,Information), (r,i), $0<\rho<1,0<\psi<1]^{30}$ \\
\hline
\end{tabular}

\subsubsection{Discussion}

This paper's hypothesis was that "there exists no incentive whatsoever for upstream risk communication in compliance with REACH within the supply chain". The results from the analysis are discussed here against the background of this hypothesis from both a formal perspective and in terms of content. From a formal perspective, it can be asserted is that there exists a stable form of upstream risk communication within the supply chain in the form of a PBE. This PBE takes the shape of a pooling equilibrium, within which both types of player 1 choose the signal Information (see Table 4). The three other possible shapes cannot be realized. In sole consideration of this conclusion, the part of the hypothesis amounting to "there exists no incentive whatsoever for upstream risk communication [...] within the supply chain" can be rejected from a formal perspective. The $\mathrm{PBE}$ is the result of an incentive structure to conduct upstream risk communication.

Content-wise, the PBE is discussed against the background of both its shape (pooling equilibrium) and its quality (strategy belief combinations). The signal of choice ("Information" or "Reassurance") determines the shape of upstream risk communication. As described in chapter 2, not all shapes of upstream risk communication are in compliance with the requirements set out by Article 34 of REACH. In the context of the present model, the signal "Information" constitutes a form of upstream risk communication that meets the regulatory requirements. However, the signal "Reassurance" constitutes a form of upstream risk communication that is not intended by Article 34 of REACH. In the context of the present model, only the shape of upstream risk communication in compliance with REACH is realized in the equilibrium. The quality of this pooling equilibrium is specifically determined by the following characteristics. Both types of player 1 choose the signal Information and thereby conduct upstream risk communication in compliance with REACH. Therefore, considerations that the type of player 1 influences the form of upstream risk communication cannot be confirmed in this context. From the perspective of content, what holds equal interest are the strategies of player $2(\mathrm{r}, \mathrm{i})$ in which the above-determined equilibrium realizes itself. Player 2 has an incentive to answer the REACH-compliant signal "Information" of player 1 by choosing " $r$ ", which itself enables upstream risk communication in compliance with REACH. The beliefs of player 2 - which alongside the strategies are essential to the pooling equilibrium's quality - may

\footnotetext{
${ }^{30}$ Concerning the information in square brackets: (Information,Information) means that both types of player 1 send the signal Information and are thereby conducting upstream risk communication in compliance with REACH. The corresponding information set of player 2 is on the equilibrium path. The belief $0<\rho<1$ corresponds with the prior distribution of types of player $1(\alpha, 1-\alpha)$ and is determinable via Bayes' theorem. In order for a PBE to exist it is necessary that player 2 react to the signal Information with $r$ and to the signal Reassurance with $i$. This is the case when within the information set of the signal Reassurance the belief of player 2 attains a value $\psi$ between zero and one $(0<$ $\psi<1)$.
} 
assume any value between zero and one $(0<\rho<1$ and $0<\psi<1)$. It becomes obvious that the distribution of both types of player 1 is irrelevant for the realization of an equilibrium as long as the belief interval $(0<$ Belief $<$ 1) is not violated ${ }^{31}$. From the perspective of content, the pooling equilibrium identified above (Information, Information) may thus be taken as evidence of the existence of incentives to conduct upstream risk communication in compliance with REACH. Taken together with the formal perspective, the hypothesis according to which "there exists no incentive whatsoever for upstream risk communication in compliance with REACH within the supply chain" can be completely rejected.

\section{Final considerations}

In the context of the presently modeled conditions and incentives for upstream risk communication, I have been able to demonstrate that a stable form of upstream risk communication in the form of an equilibrium is ultimately possible. Furthermore, I have been able to demonstrate that this equilibrium possesses a quality that does not run contrary to the normative requirements set by REACH. This paper's hypothesis according to which "there exists no incentive whatsoever for upstream risk communication in compliance with REACH within the supply chain" has been rejected both formally and content-wise. Regarding the perspective of the regulator, this result is significant in two ways: first, the control theoretical endeavor to utilize rational self-responsible action on the part of the norm addressees for upstream risk communication in compliance with REACH is deemed practicable from the perspective of game theory; and second, the regulator does not need to consider a basic revision of his kind of regulation; rather, he should analyse the institutions that induce rational, self-responsible upstream risk communication concerning how they may be permanently stabilized.

In this paper, I have demonstrated that a game theoretical framework is adequate for testing a regulation regarding its inherent logic and whether it functions in accordance with its normative design. This has been illustrated based upon a case study of the REACH-Regulation. Alongside the game theoretical framework, regulators nowadays have a number of instruments at their disposal that they may use in testing norms for their practicability, such as the norm check by using methods of experimental economic research. These instruments should be used by the regulator in the context of Regulatory Impact Assessment ${ }^{32}$ to focus his perspective and contribute to better regulation.

\section{Publication bibliography}

Börzel, Tanja A.; Risse, Thomas (2010): Governance without a state: Can it work? In Regulation \& Governance 4, pp. 113-134.

Cecot, Caroline; Hahn, Robert; Renda, Andrea; Schrefler, Lorna (2008): An evaluation of the quality of impact assessment in the European Union with lessons for the US and the EU. In Regulation \& Governance 2, pp. 405-424.

European Chemicals Agency (ECHA) (2011): The Operation of REACH and CLP 2011. Edited by European Chemicals Agency (ECHA). European Chemicals Agency (ECHA) (ECHA-11-R-003-EN). Available online at http://echa.europa.eu/documents/10162/13634/operation_reach_clp_2011_en.pdf, checked on $2 / 23 / 2015$.

\footnotetext{
${ }^{31}$ In order for the beliefs to be economically intelligible they must attain a numerical value between zero and one.

${ }^{32}$ An evaluation of the quality of impact assessment in the European Union is given by Cecot et al. 2008 .
} 
European Commission (COM (2013) 49 final) (2013): General Report on REACH. Report from the Commission to the European Parliament, the Council, the European Economic and Social Committee and the Committee of the Regions in accordance with Article 117(4) of REACH and Article 46(2) of CLP, and a review of certain elements of REACH in line with Articles 75(2), 138(2), 138(3) and 138(6) of REACH. Edited by European Commission. European Commission. Brussels (COM(2013) 49 final). Available online at http://eurlex.europa.eu/LexUriServ/LexUriServ.do?uri=COM:2013:0049:FIN:EN:PDF, checked on 2/16/2015.

Führ, Martin (2010): Analyse der Anreize und Hemmnisse am Beispiel der europäischen Chemikalien-Regulierung REACh. In Stephan Hensel, Kilian Bizer, Martin Führ, Joachim Lange (Eds.): Gesetzesfolgenabschätzung in der Anwendung. Perspektiven und Entwicklungstendenzen. Baden-Baden: Nomos-Verl.-Ges. (Interdisziplinäre Studien zu Recht und Staat, 48), pp. 177-195.

Führ, Martin; Bizer, Kilian (2007): REACh as a paradigm shift in chemical policy - responsive regulation and behavioural models. In Journal of Cleaner Production 15, pp. 327-334.

Gibbons, Robert (1992): A Primer in Game Theory. Nachdr. Harlow u. a.: Prentice Hall Financial Times.

Gibbons, Robert (1997): An Introduction to Applicable Game Theory. In The Journal of Economic Perspectives 11 (1), pp. 127-149.

Hensel, Stephan; Bizer, Kilian; Führ, Martin; Lange, Joachim (Eds.) (2010): Gesetzesfolgenabschätzung in der Anwendung. Perspektiven und Entwicklungstendenzen. BadenBaden: Nomos-Verl.-Ges. (Interdisziplinäre Studien zu Recht und Staat, 48).

Hey, Christian; Jacob, Klaus; Volkery, Axel (2007): Better regulation by new governance hybrids? Governance models and the reform of European chemicals policy. In Journal of Cleaner Production 15, pp. 1859-1874.

Krarup, Signe (2001): Can voluntary approaches ever be efficient? In Journal of Cleaner Production 9, pp. 135-144.

Myerson, Roger B. (1999): Nash Equilibrium and the History of Economic Theory. In Journal of Economic Literature 37 (3), pp. 1067-1082.

Nationaler Normenkontrollrat (2012): Analysis of weak points relating to the registration obligations under the European Chemicals Regulation REACH. A joint project of the Nationaler Normenkontrollrat (NKR), the Federal Ministry for the Environment, Nature Conservation and Nuclear Safety (BMU), the Federal Institute for Occupational Safety and Health (BAuA), the Federal Environment Agency (UBA), and the German Chemical Industry Association (VCI). Nationaler Normenkontrollrat. Berlin. Available online at http://www.normenkontrollrat.bund.de/Webs/NKR/Content/EN/Publikationen/2013-10-21-englreach.pdf?_blob=publicationFile \&v=1, checked on 2/16/2015.

REACH Regulation: Regulation (EC) No 1907/2006 of the European Parliament and the Council of 18 December 2006 concerning the Registration, Evaluation, Authorisation and Restriction of Chemicals (REACH), establishing a European Chemicals Agency, amending Directive 1999/45/EC and repealing Council Regulation (EEC) No $793 / 93$ and Commission Regulation (EC) No 1488/94 as well as Council Directive 76/769/EEC and Commission Directives 91/155/EEC, 93/67/EEC, 93/105/EC and 2000/21/EC. In Official Journal of the European Union L 136.

van Damme, Eric; Weibull, Jörgen W. (1995): Equilibrium in Strategic Interaction: The Contributions of John C. Harsanyi, John F. Nash and Reinhard Selten. In Scandinavian Journal of Economics 97 (1), pp. $15-40$. 
$$
\text { Back to table of contents }
$$

\section{Part C}

Back to table of contents

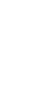

Part C 


\title{
Smart regulation of downstream communication in a supply chain - experimental evidence
}

\author{
Stephan Hensel ${ }^{a, \dagger}$ and Kilian Bizer ${ }^{\mathrm{b}}$ \\ ${ }^{\mathrm{a}, \mathrm{b}}$ Chair of Economic Policy and SME Research, Faculty of Economic Sciences, Universität Göttingen, Platz der \\ Göttinger Sieben 3, D-37073 Göttingen, Germany
}

\begin{abstract}
An approach of control theory that aims at linking autonomous actions by norm addressees with sovereign elements is characteristic of smart regulations. This paper examines the downstream communication in a supply chain against the backdrop of certain norms. By using the method of experimental economic research, two aspects of behavior are examined here: first, we investigate how legal compliance during downstream communication in a supply chain is affected by the non-existence of a mechanism of sanctions; and second, we examine whether legal compliance or non-compliance influences the cooperative behavior between two norm addressees during downstream communication. The results are discussed in consideration of the approach of control theory as established in the European regulation on chemicals (REACH), which aims at linking autonomous actions by norm addressees with sovereign elements. Our findings are supposed to serve the regulator as a basis for further ideas when designing concepts of control theory.
\end{abstract}

KEYWORDS: Downstream Communication in Supply Chains, Environmental Law and Economics, Experimental Economics, Regulation and Self-Responsibility, Regulatory Impact Assessment

JEL classifications C91, K32

Acknowledgements

We thank Tonia Sauerwald, Lisa Fiedler, Juliette Irretier and Richard Forsythe for having supported us in conducting and analyzing the experiments and in composing this paper. The German Federal Ministry of Education and Research (Bundesministerium für Bildung und Forschung (BMBF)) enabled the experiments reported here by funding the research project "Responsive Regulation of Innovation Behavior for Sustainability".

${ }^{\dagger}$ Correspondence:

Stephan Hensel, Chair of Economic Policy and SME Research, Faculty of Economic Sciences, Universität Göttingen, Platz der Göttinger Sieben 3, D-37073 Göttingen, Germany,

Email: Stephan.Hensel@wiwi.uni-goettingen.de, Phone: +49-551-39-4626, Fax: +49-551-39-19558 


\section{Introduction}

A common characteristic of smart regulations is that to reach regulatory aims, they no longer focus on sovereign elements alone but rather the autonomous conduct of the involved actors ${ }^{1}$. Such an approach of control theory is pursued by REACH ${ }^{2}$ (REACH Regulation), the European regulation on the use of chemicals, ${ }^{3}$ which came into effect on June 1,2007 . It places the duty on norm addressees to ensure that human health or the environment are not adversely affected when producing and using chemicals. ${ }^{4}$ In this respect, a central role is occupied by the norm addressees' autonomous downstream communication in supply chains. From the perspective of the regulator, autonomous communication is advantageous given that it evolves if norm addressees act economically rationally and thereby maximize utility. For autonomous downstream communication to happen, it is necessary that the actors in a supply chain profit through their communication. In this paper, this benefit will be termed as 'gain from cooperation' or 'cooperation gain'. A mechanism of sanctions is mostly dispensable if the norm addressees' behavior - as desired by the regulator - is identical to economically rational behavior. If the norm addressees strived to maximize utility, the goals of a regulation could be reached. By using the method of experimental economic research and basing it on the context of REACH, in this paper we investigate two aspects of behavior relating to economically rational downstream communication between two norm addressees. ${ }^{5}$ We express our scientific interest in two hypotheses. Hypothesis 1: If they are not sanctioned for noncompliant behavior, the actors will choose the form of downstream communication that brings them the highest cooperation gain possible, even if this form is not conformable to law. Hypothesis 2: If noncompliant behavior is not sanctioned, the way of dividing the cooperation gain made through a form of downstream communication between two norm addressees is independent of whether this form is conformable to law.

The remainder of this paper is structured as follows. First, the current practice of downstream communication in supply chains by use of data sheets as means of communication is briefly illustrated. Second, we present the theoretical framework for the design of our experiment (chapter 2), before the experiment design, our predictions, the results as well as the discussion of the latter follow in chapter 3 . We finish this paper with concluding remarks on the importance of the results for the regulator's perspective, which develops concepts of control theory such as REACH.

\section{Downstream communication in a supply chain}

\subsection{Downstream communication by data sheet}

In supply chains of the chemical industry, the Safety Data Sheet (SDS) has established itself as a means of communication about risks induced by chemicals. The purpose of this data sheet is to provide actors with safe and adequate control over materials (Bundesanstalt für Arbeitsschutz und Arbeitsmedizin (BAuA) 2008). Always structured uniformly, the data sheet contains information relating to materials. Upon the delivery of his material, in most $\operatorname{cases}^{6}$ the upstream actor is obliged to provide the downstream 
actor with a corresponding data sheet. Although the categories indicating risks posed by chemical substances are uniformly prescribed by the data sheet's structure, the quality of the indications themselves and thus the quality of the data sheet often depends on various factors. The degree of detail can influence the quality of the data sheet; for instance, as can the specialized knowledge of the person issuing the sheet. Are the requirements for the quality of the data sheet well-known to this person? Are there any incentives ${ }^{7}$ to willingly ignoring these requirements? This short notice on factors that may affect the quality of the data sheet renders the assumption plausible that data sheets in downstream communication can vary in quality. Studies investigating the quality of SDSs in practice support these considerations ((European Commission (COM (2013) 49 final) 2013), European Chemicals Agency (ECHA) 2011, Nationaler Normenkontrollrat 2012, Mayer-Figge 2013 and Bunke, Rühl 2011). In relation to the European Chemicals Directive REACH, upon which the investigations explained in this paper are textually based, but the context of which is not explicitly mentioned in the experiment ${ }^{8}$, the actors in the supply chain play an essential role regarding downstream communication by the use of data sheets. The concept of control theory as presented in REACH grants the actors a high level of autonomy in implementing the communicative requirements in a supply chain. In this case, ascribing economic rationality (behavior to maximize utility) to the actors would mean that they will use their autonomy to maximize utility. Therefore, for downstream communication to happen autonomously, both the upstream and downstream actor in the supply chain must be able to obtain a benefit in the form of a cooperation gain from the downstream communication by data sheet. In the following chapter 2.2 , we explain our considerations to put the aspects illustrated in this chapter in a theoretical context, which will subsequently provide the basis for the experimental design created to examine hypotheses 1 and 2 .

\subsection{Lemon Market Game or Bargaining Game?}

The aspects from practice depicted in chapter 2.1 show characteristics of two classes of games known in the literature, namely Lemon Market Games and Bargaining Games.

The classic Lemon Market Game has been explained using the example of a market for used cars (Akerlof 1970). Since the information about the quality of the used cars has been distributed asymmetrically between the seller and the buyer, the classic Lemon Market will fail. Given that the buyers are unable to register the quality level of a car before they buy it, they build up expectations about the average quality of the cars on offer, which in turn form the basis for their maximum willingness to pay. Vendors of used cars that have a good level of quality are unwilling to offer their cars for the price of a used car of average quality and thus they leave the market, whereas used cars with lower quality levels remain in the market. Subsequently, the maximum willingness to pay on the part of buyers continues to deteriorate and the vendors of used cars with higher quality levels successively retreat from the market, before eventually the market collapses. Lemon Market Games have been part of experimental economics for quite some time. They are analyzed regarding various questions, mostly with the aim of overcoming the market failure that is theoretically predicted. In this context, we are primarily interested in the common way of implementation and portrayal of several quality grades within an experimental design. ${ }^{9}$ 
In the process, we do not allow informational asymmetries, which can be perceived as an exception of the classic Lemon Market Game.

The classic Bargaining Game describes a situation in which two (or more) actors negotiate how they will divide the gain from their cooperation. This sort of game has also long been a subject of experimental economics (Güth, Tietz 1990). With respect to Bargaining Games, we are interested in the common way of implementation and portrayal of negotiations about the division of the gain from cooperation between two actors within an experimental design. ${ }^{10}$

In both categories of games and their experimental application, characteristics can be discovered that are easily transferrable to the context of our study. In our experimental design, the seller of a substance is given the opportunity to decide upon the quality grade of the data sheet to be handed out to the buyer when purchasing the substance. The design is analogous to the Lemon Market Game in so far as the seller decides whether to offer a substance with an appropriate data sheet or not and - if he/she does so chooses the quality grade of the data sheet. With our experimental design, we also offer the seller and buyer the opportunity to realize a cooperative gain whereby autonomous downstream communication by data sheet can be reproduced. The design is analogous to the Bargaining Game regarding the potential cooperation gain that can be divided between seller and buyer and concerning the manner in which this division is made.

\section{Experimental evidence}

In order to investigate our two hypotheses, we conducted an economic experiment in February 2013 at the Laboratory of Behavioral Economics at the University of Göttingen, which is equipped with 24 individual cubicles, each with one personal computer. All 24 computers are connected to the laboratory's network and can be operated and monitored by a controlling computer. The participants came from diverse subjects of study at the University of Göttingen and were recruited by the online recruiting system ORSEE (Greiner 2004). Z-Tree software (Fischbacher 2007) was used for programming the experiment. Overall, 160 students participated in the experiment, which was administered in nine sessions. In addition to a fixed show-up fee of $€ 3.00$ for arriving on time, the participants had the chance to earn further money in the course of the experiment, which comprised multiple rounds.

\subsection{Design}

The experimental design was inspired by the reflections of the realistic depiction of downstream communication in a supply chain, as proposed in chapter 2. We deliberately chose a clear design to keep the number of influencing factors as small as possible and adequately examine our hypotheses. The experiment contained two treatments and was conducted in the between-subjects design. Hypotheses 1 and 2 are examined here in respect of both treatments. Before elaborating upon the differences between treatment $1^{11}$ and $2^{12}$, we describe the procedure of the experiment, which was identical for both treatments. Subsequently, we briefly illustrate the structure and contents of the instructions. 


\subsubsection{Procedure}

The instructions were presented to the participants in hard copy, which each of them found in their cubicle. In the first instance, they were asked to read them completely, because they would not come to know which role they would play before the beginning of the experiment. ${ }^{13}$ To ensure that the instructions had been understood, the participants were asked to complete some exercises at the computer in their cubicle after having read the instructions. These exercises contained yes/no questions concerning the procedure and the roles characterized in the instructions of the experiment. Concerning the composition of possible additional earnings during the experiment, short mathematical tasks subsequently had to be completed. After all participants had successfully accomplished the tasks the experiment began, which comprises ten rounds. The participants did not know the number of rounds in advance and they were not allowed to communicate verbally with each other during the entire experiment.

\subsubsection{Instructions}

The instructions comprised three parts: background of the experiment, characterization of the "seller" role and characterization of the "buyer" role.

The participants were given an understanding of the background to the experiment as follows ${ }^{14}$ : "This experiment approaches the communication between two actors. One actor is the seller and the other is the buyer. According to legal standards, the seller is obliged to provide the buyer with information about the product that is to be sold. For this purpose, a data sheet has to be used, listing product-related characteristics and information. Over time, legal standards have been adjusted to the content and the length of the data sheet. In this experiment, a distinction is made between: 'old' legal requirements and 'new' legal requirements. Of course, the 'new' legal requirements are binding. However, you will not be penalized for not complying with the "new' legal requirements.", 15

Characterization of the seller ${ }^{16}$ : The seller sells a product with a corresponding data sheet. The quality and the price of the product - for which the data sheet has to be issued - are not important here and remain steady for the duration of the experiment. The data sheet can be issued in four quality grades. The seller stays in this role in all rounds and makes contact with the same buyer throughout the entire experiment. In each round, the seller may decide whether to offer one product with the corresponding data sheet. If the seller does so, the buyer will then decide whether to accept or decline the offer. If the seller offers a product, two steps have to be taken: first, the seller decides on one quality grade of the data sheet; and second, the seller decides on a price to demand from the buyer for the data sheet. The price may be chosen as exactly as two decimal places. The seller is fully informed, which means: the seller knows the costs incurring when issuing the data sheet for the different quality levels; the seller knows that the quality grade of the data sheet is identifiable by the buyer before the contract is completed; the seller knows the buyer's maximum willingness to pay for each quality grade; and the seller knows that the buyer is aware of the expenses of issuing the data sheet. In each round in which the seller participates in the market, the seller may decide anew on the quality grade of the data sheet, which has to be attached to the product. The seller will not be penalized for not complying with the 'new' legal requirements when 
compiling the data sheet. When the experiment begins, the seller is not in funds, i.e. the seller does not have any money to start with. In each round, the seller can earn the difference between the expenses of issuing the data sheet and the price paid by the buyer. If a deal is not completed for some reason (the seller does not make an offer or the buyer declines the offer), there will be no additional earnings (€ 0.00) for the seller in that round. No costs will arise for the seller. To conclude the characterization of the seller, the instructions contained explained screenshots ${ }^{17}$, provided in the order in which they would chronologically appear during the experiment.

Characterization of the buyer ${ }^{18}$ : The buyer decides on the purchase of a product with a corresponding data sheet that is offered to him/her. The data sheet issued by the seller may have four different quality grades. The buyer stays in this role in all rounds and makes contact with the same seller throughout the entire experiment. The buyer is fully informed, which means: the buyer can identify the quality grade of the data sheet offered before the contract is completed; the buyer knows the seller's expenses of issuing the data sheet; and the buyer knows that the seller is aware of the buyer's varying maximum willingness to pay regarding the different quality grades. In each round in which the seller participates in the market, the buyer may decide whether to accept or decline the offer. The buyer is not sanctioned for purchasing a product with a corresponding data sheet that does not comply with the 'new' legal requirements. The buyer also does not have any money to start with. In each round, the buyer can earn the difference between the maximum willingness to pay for the particular quality grade of the data sheet and the price actually paid to the seller. If a deal is not completed for some reason (the seller does not make an offer or the buyer declines the offer), there will be no additional earnings $(€ 0.00)$ for the buyer in that round. No costs will arise for the buyer. Finally, a screenshot ${ }^{19}$ with written explanations was presented to the participants.

\subsubsection{Treatments}

Treatments 1 and 2 differ in the respect that the buyer's maximum willingness to pay varies for two of the four possible quality grades of the data sheet. The following table 1 lists all four quality grades that the data sheet may have, each with a brief description. Data sheets with the quality grade of 1 are generally inadequate and do not comply with any legal regulations. Those with a quality grade of 2 at least fulfill the 'old' legal requirements but do not meet the 'new' requirements, which are valid and binding in the context of the experiment. ${ }^{20}$ Quality grade 3 meets the 'new' legal requirements without any constrictions and quality grade 4 over-achieves these prerequisites. Table 1 further contains the seller's costs for issuing the data sheet and the buyer's maximum willingness to pay with reference to treatment 1 and 2. 


\begin{tabular}{|c|c|c|c|c|c|}
\hline \multirow[b]{2}{*}{$\begin{array}{l}\text { Quality } \\
\text { Grade } \\
\text { of Data } \\
\text { Sheet: }\end{array}$} & \multirow[b]{2}{*}{$\begin{array}{l}\text { Characteristics of } \\
\text { Quality Grade: }\end{array}$} & \multicolumn{2}{|c|}{$\begin{array}{l}\text { Treatment } 1 \\
\text { Econ. Maximum = Compliance } \\
\text { (74 participants, } 4 \text { sessions) }\end{array}$} & \multicolumn{2}{|c|}{$\begin{array}{l}\text { Treatment } 2 \\
\text { Econ. } \text { Maximum = Non-Compliance } \\
(86 \text { participants, } 5 \text { sessions })\end{array}$} \\
\hline & & $\begin{array}{l}\text { Seller: } \\
\text { Costs of Creating } \\
\text { Quality Grade } \\
\text { (in EUR) }\end{array}$ & $\begin{array}{l}\text { Buyer: } \\
\text { Max Willingness } \\
\text { to Pay (WTP) } \\
\text { (in EUR) }\end{array}$ & $\begin{array}{l}\text { Seller: } \\
\text { Costs of Creating } \\
\text { Quality Grade } \\
\text { (in EUR) } \\
\end{array}$ & $\begin{array}{l}\text { Buyer: } \\
\text { Max Willingness } \\
\text { to Pay (WTP) } \\
\text { (in EUR) }\end{array}$ \\
\hline 1 & $\begin{array}{l}\text { - Generally inadequate; } \\
\text { does not comply with any } \\
\text { legal requirements. }\end{array}$ & 0.50 & 0.70 & 0.50 & 2.50 \\
\hline 2 & $\begin{array}{l}\text { In compliance with legal } \\
\text { requirements 'old'; } \\
\text { - does not comply with legal } \\
\text { requirements 'new'. }\end{array}$ & 2 & 3 & 2 & 3 \\
\hline 3 & $\begin{array}{l}\text { In compliance with legal } \\
\text { requirements 'new'. }\end{array}$ & 3 & | & 3 & (3.20 \\
\hline 4 & $\begin{array}{l}\text { Goes beyond legal } \\
\text { requirements 'new'; } \\
\text { - in compliance with legal } \\
\text { requirements 'new'. }\end{array}$ & 4.10 & 4.80 & 4.10 & 4.80 \\
\hline
\end{tabular}

\section{TABLE 1 COMPARISON OF TREATMENT 1 AND TREATMENT 2}

In comparison, the buyers' maximum willingness to pay does not change regarding the quality grades 2 and 4 in both treatments. However, they do so in respect of the quality grades 1 and 3. For quality grade 1 , the maximum willingness to pay amounted to $€ 0.70$ in treatment 1 and $€ 2.50$ in treatment 2 , thereby increasing by $€ 1.80$. Conversely, the maximum willingness to pay for a data sheet of quality grade 3 decreased by $€ 1.80$ from treatment 1 to 2 , declining from $€ 5.00$ in treatment 1 to $€ 3.20$ in treatment 2 . The fields used in table 1 are supposed to highlight the effect of these changes on the participants. In the "treatment 1" column, a field with a dotted frame is included in a field with a drawn-through frame. This is supposed to illustrate that two aspects are congruent in this case: on the one hand, quality grade 3 is compliant with the legal requirements of the new regulation, as shown by the inner field with the dotted frame; on the other hand, quality grade 3 offers the highest additional gain possible to the participants if a deal is concluded. Here, the cooperation gain for both parties is the largest. This aspect is visualized by the outer field with the drawn-through line. In this case, the participants have the opportunity to share $€$ 2.00. In the "treatment 2" column, the fields are no longer congruent because the aforementioned two factors diverge. The realizable highest cooperation gain - in this case also $€ 2.00$ - can be made by quality grade 1, as illustrated by the field with the drawn-through line. However, this quality grade does not comply with the legal requirements of the new regulation. These 'new' legal requirements are still complied with by quality grade 3 , as shown by the field with the dotted line. However, at $€ 0.20$, the attainable cooperation gain for the participants is the smallest of all in this case.

\subsection{Predictions}

Prediction hypothesis 1: "If they are not sanctioned for non-compliant behavior, the actors will choose the form of downstream communication that brings them the highest cooperation gain possible, even if this form is not conformable to law." We assume economically rational behavior on behalf of the participants, 
meaning that they maximize utility. Since a missing mechanism of sanctions for non-compliant behavior should not affect the economically rational behavior here, we can plausibly predict that the study participants choose the form of downstream communication that brings them the highest gain possible.

Prediction hypothesis 2: "If non-compliant behavior is not sanctioned, the way of dividing the cooperation gain made by a form of downstream communication between two norm addressees is independent of whether this form is conformable to law." Again, economically rational (utilitymaximizing) behavior is assumed. Similar to the prediction for hypothesis 1 , it seems plausible here to predict that a missing mechanism of sanctions for non-compliant behavior should not affect the economically rational behavior regarding the division of a possible cooperation gain, independent of whether the form of downstream communication is conformable to law.

\subsection{Results}

Figure 1 summarizes and emphasizes the structure of the investigations as previously described.

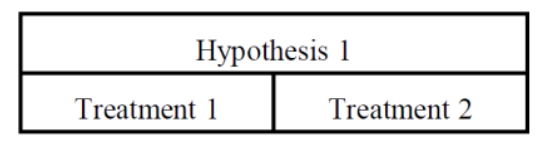

\begin{tabular}{|c|c|}
\hline \multicolumn{2}{|c|}{ Hypothesis 2 } \\
\hline Treatment 1 & Treatment 2 \\
\hline
\end{tabular}

\section{FIGURE 1 STRUCTURE OF INVESTIGATIONS}

In the following sub-chapter 3.3.1, an overview of the results is presented by analogy with figure 1. The results will subsequently be discussed in sub-chapter 3.3.2.

\subsubsection{Overview}

Table 4 summarizes the results from the examination of hypothesis 1 and will be briefly explained here. It contains the tables 2 and 3 as well as figures 2 and 3. Table 2 shows the results concerning treatment 1 , whereas table 3 shows those regarding treatment 2 . Itemizing each round, both tables depict which of the four quality grades were chosen by the sellers, from now onwards also named as 'proposers'. In addition to the quality grades 1 to 4 , the tables also contain a quality grade 0 . The latter was put into effect every time the proposers refrained from participating in the market and thus did not choose among the quality grades 1 to 4 . For every quality grade, each line contains two numbers on top of each other, with the upper number indicating the absolute frequency and the lower number the relative frequency in percent. As a check, the right columns of the tables contain the totalized frequencies as distributed among the quality grades. The corresponding figures 2 and 3 visualize the relative frequencies. 


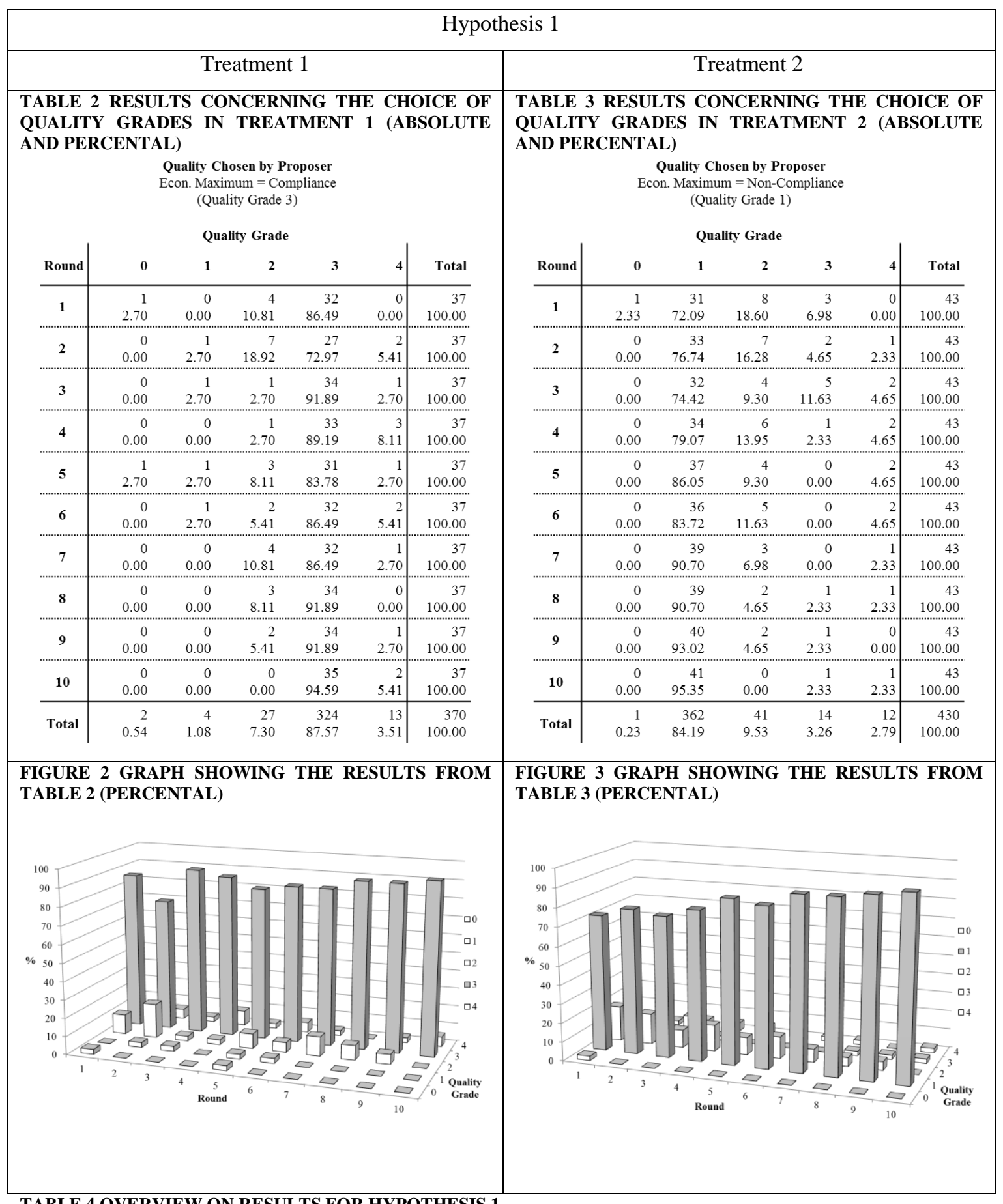

\section{TABLE 4 OVERVIEW ON RESULTS FOR HYPOTHESIS 1}

Table 7 sums up the results of the study regarding hypothesis 2 and will likewise be briefly explained here. It contains tables 5 and 6 as well as figures 4 and 5. Table 5 shows the results of treatment 1 and table 6 those of treatment 2. For each round, both tables list the division of the possible cooperation gain as suggested by the proposers. In both tables, only the quality grade that enables the highest cooperation gain possible and constitutes the economic maximum in each treatment is highlighted. In treatment 1 , this is quality grade 3, which is compliant with the new legal requirements, whereas in treatment 2 it is quality grade 1 , which is non-compliant with the new legal requirements. As described before, a cooperation gain 
of $€ 2.00$ can be divided in each treatment. The middle column - "profit split demanded by proposer" - is divided into the categories "under half", "exact half" and "above half". For both treatments, these categories show whether the proposers claim for themselves an amount that is less than half of the cooperation gain (under half, less than $€ 1.00$ ), whether they propose to split the cooperation gain by half (exact half, exact $€ 1.00$ ) or whether they demand more than half of the cooperation gain (above half, more than $€ 1.00) .{ }^{21}$ For all three categories, each line contains two numbers on top of each other, with the upper number indicating the absolute frequency and the lower number the relative frequency in percent. As a check, the right columns of the tables contain the totalized frequencies as distributed among the categories. The corresponding figures 4 and 5 visualize the relative frequencies.

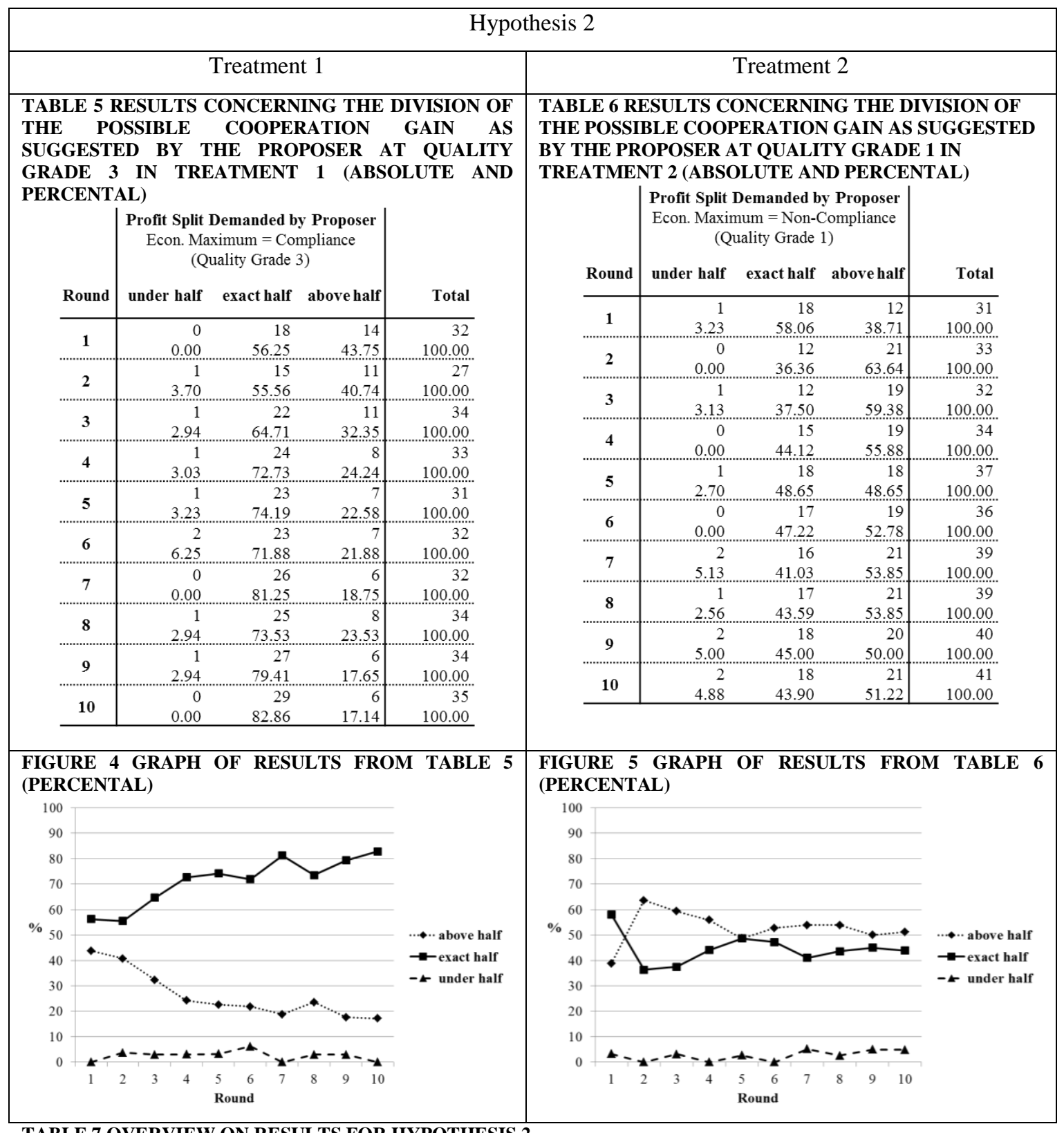

TABLE 7 OVERVIEW ON RESULTS FOR HYPOTHESIS 2 


\subsubsection{Discussion}

In this sub-chapter, the results for hypotheses 1 and 2 will be discussed against the backdrop of the predictions made in chapter 3.2 .

Hypothesis 1: In this experiment, the forms of downstream communication were distinguished from each other according to the quality grade of the data sheet issued and used for this purpose. The results presented in table 4 affirm this hypothesis. In treatment 1 (see table 2), the highest cooperation gain possible can be realized in quality grade 3 , which is conformable to law. In all ten rounds, about 88 percent of the proposers chose this quality grade. The deviations between each round are negligibly meager. In the last round, even 95 percent chose quality grade 3 . In treatment 2 (see table 3 ), the maximum cooperation gain could be realized in quality grade 1, which is not conformable to law. In all ten rounds, about 84 percent of the proposers chose this quality grade. As compared to treatment 1 , the deviations between each round are more profound but still negligibly small. In rounds 1 to 3 in particular, a small number of proposers chose the compliant quality grade 3 and quality grade 2, which is consistent with the 'old' regulation, being no longer valid in this experiment. In treatment 2, from rounds 1 to 4 (except round 2) and as compared to treatment 1, notably fewer proposers chose the quality grade that brings them the highest cooperation gain possible. It can be concluded that some participants adopted a wait-and-see attitude in the early stage of the experiment. This seems plausible against the backdrop of the situation generated in treatment 2, which forced the participants to decide between compliant behavior on the one hand (quality grade 3) and maximum cooperation gain on the other (quality grade 1). Concerning the proposers' behavior from round 5 onwards, the variations between treatments are negligibly small. A similarly high number of participants decided for the form of downstream communication that brings them the highest cooperation gain possible. Like in treatment 1, approximately 95 percent in treatment 2 chose the quality grade with the maximum benefit in the last round. The number of participants who acted correspondent to our prediction is clearly predominant. Utility-maximizing behavior could be detected, which is rational from an economic perspective. Therefore, we can confirm hypothesis 1 .

Hypothesis 2: The results presented in table 7 are divided with respect to this hypothesis and require individual analysis. When comparing treatments 1 and 2, the entries in the "under half" column in tables 5 and 6 show virtually the same results. Looking at the entries in the "exact half" and "above half" columns in the corresponding tables, noticeable differences can be detected between the two treatments. The following discussion treats the direct comparison of these two forms concerning the division of the cooperation gain (exact half and above half). Although the results for the first round of both treatments are very similar, they strongly differ for the last round. In both treatments in round 1, slightly more than 50 percent of the proposers suggested an equal division of the cooperation gain and somewhat less than 50 percent of the proposers claimed more than half of the cooperation gain. In round 10 and treatment 1 , more than 80 percent of the proposers recommended an equal division of the cooperation gain, whereas just under 44 percent suggested this form of division in treatment 2 . The results for round 10 are a mirror image concerning the form of an 'above half' division in favor of the proposers. In treatment 1, slightly 
less than 20 percent of the proposers claimed more than half of the cooperation gain, while in treatment 2 , more than 50 percent suggested this form of division. Looking at how the experiment developed, we can observe that in treatment 1 , the number of proposers who suggested an equal division of the cooperation gain steadily increased, whereas those claiming more than half of the cooperation gain steadily decreased in number by tendency. Figure 4 illustrates these findings. The graphs showing the data for 'exact half' and 'above half' steadily diverge by tendency. In treatment 2, the share of proposers who suggested an equal division of the cooperation gain oscillated about all rounds around 45 percent on average, while the share of proposers who demanded more than half of the cooperation gain oscillated about all rounds around 53 percent on average. Figure 5 depicts these findings. The graphs corresponding to the data for 'exact half' and 'above half' varyingly center about an average value, with the graph for 'above half' being above that for 'exact half' in most cases. Regarding hypothesis 2, only a small number of participants acted according to our prediction, whereas the majority did not. The number of proposers who claimed less than half of the cooperation gain varies to a very small extent between treatments 1 and 2. For these participants, we can confirm our hypothesis. The shares of proposers who claimed half or more of the cooperation gain for themselves clearly vary between treatments 1 and 2 . In this respect, we have to discard hypothesis 2 . We consider two possible explanations for the differences between the treatments leading to this result. First: The participants' perception concerning their income opportunities can be influenced by both the differing expenses of issuing the data sheet and the differing maximum willingness to pay in both treatments, which might result in a form of 'monetary illusion'. According to table 1 , the maximum cooperation gain that is divisible in the treatments is $€ 2.00 .^{22}$ Therefore, there is no difference between treatments 1 and 2 regarding the income opportunities for the participants. The absolute amounts that constitute the interval in which the $€ 2.00$ can be divided significantly differ. In treatment 1 , the proposers can divide this amount by fixing the price between $€ 3.00$ and $€ 5.00$, whereas in treatment 2 , they can trigger the division by determining the price between $€ 0.50$ and $€ 2.50$. According to the instructions ${ }^{23}$, the proposers' possible additional earnings in both treatments are calculated from the difference between the suggested prices minus the expenses of creating the data sheet. Based upon these small absolute amounts in treatment 2, the participants possibly expected their additional earnings to only slowly increase. To maximize their benefit more quickly, the proposers tried to reserve a larger share of the cooperation gain for themselves, which can be a strategy of individual rationality triggered by the framing in treatment 2. Second: Although the participants knew that they would not be penalized for non-compliant behavior, they still knew that they did not act conformably to law. The considerably higher number of proposers in treatment 2 who demanded for themselves more than half of the cooperation gain could be interpreted as an expression of 'compensation for possible cognitive dissonances'. On the one hand, these cognitive dissonances could exist here in their natural form whereby the knowledge about non-compliant behavior is conceived of differently, namely more negatively than behavior that is conformable to law. On the other hand, these cognitive dissonances could be invented by the proposers according to the previous argument to faster maximize their benefit. This can also be a strategy of individual rationality triggered by the framing in treatment 2 . 


\section{Concluding remarks}

Within the scope of our experiment, we have examined two behavioral aspects regarding the economically rational downstream communication between two norm addressees. The experiment was framed according to the European regulation on the use of chemicals REACH and the requirements for downstream communication in supply chains worded therein. However, this background was not mentioned to the participants. At this point, we try to refer our results to this context to support the regulator's discussion about the design of a concept of control theory that raises the claim to link sovereign elements with norm addressees' autonomous behavior.

Essentially, for autonomous downstream communication to generally happen, both the upstream and downstream actor in the supply chain have to be able to realize a benefit in the form of a cooperation gain when communicating downstream by the using a data sheet. Regarding the first aspect of behavior - "If they are not sanctioned for non-compliant behavior, the actors will choose the form of downstream communication that brings them the highest cooperation gain possible, even if this form is not conformable to law" (hypothesis 1) - our results clearly confirm this assumption. The regulator can thus conclude to refrain from imposing a mechanism of sanctions if the behavior of the norm addressees as desired by the regulator matches their economically rational behavior. Based upon this understanding, the aims of the regulation can be achieved if the norm addressees seek to maximize utility. However, if this precondition is not met, autonomous downstream communication works in the form that is not conformable to law, which brings the highest cooperation gain possible. In this case, further regulation in the form of a mechanism of sanctions - for instance - is to be considered. In relation to the second aspect of behavior - "If non-compliant behavior is not sanctioned, the way of dividing the cooperation gain made by a form of downstream communication between two norm addressees is independent of whether this form is conformable to law" (hypothesis 2) - the results of our study do not support this hypothesis in many respects. The suggestions concerning how the cooperation gain could be divided seem unaffected by the legal conformity of the form of downstream communication. For the regulator, the discoveries are complex. The arguments presented in chapter 3 to explain the participants' behavior during the experiment allude to two points for discussion, which can also matter regarding autonomous downstream communication in supply chains. First: The actual benefit from downstream communication by data sheet has to be clearly recognizable by the norm addressees in the form of a cooperation gain. Every illusion in this respect might lead to an incorrect perception of this benefit and thus might be under-estimated or over-estimated. There are many reasons that might induce such an illusion concerning the actual benefit from downstream communication by data sheet and they must be subject to further scientific analysis. However, based upon our results, we can generally ascertain that 'illusions' can influence downstream communication and thus are significant to its form and for the regulatory goals. In cases where the actual benefit from downstream communication by data sheet might not be or only distortedly perceived by the norm addressees, the regulator should reflect upon establishing adequate means for transparency based upon the reasons that might be responsible for the illusion. Second: Provided that autonomous downstream communication that is not conformable to law triggers 'cognitive dissonances' on the part of 
Back to table of contents
the norm addressees, the regulator should consider establishing
addressees from dissolving these dissonances by compensational
Referring the results to the European Union regulation REACH, v
the actual behavior of norm addressees is crucial in terms of dev
aims at linking their rational, autonomous actions with sovereign
checking norms for their efficiency and functionality
is able to make a valuable contribution to the scientific discussion

Back to table of contents
the norm addressees, the regulator should consider establishing certain measures that prevent the norm
addressees from dissolving these dissonances by compensational behavior.
Referring the results to the European Union regulation REACH, we have shown that the knowledge about
the actual behavior of norm addressees is crucial in terms of developing a concept of control theory that
aims at linking their rational, autonomous actions with sovereign elements. In this context and regarding
checking norms for their efficiency and functionality ${ }^{24}$, the method of experimental economics ${ }^{25}$ research
is able to make a valuable contribution to the scientific discussion.

Back to table of contents
the norm addressees, the regulator should consider establishing certain m
addressees from dissolving these dissonances by compensational behavior.
Referring the results to the European Union regulation REACH, we have sh
the actual behavior of norm addressees is crucial in terms of developing a
aims at linking their rational, autonomous actions with sovereign elements
checking norms for their efficiency and functionality ${ }^{24}$, the method of expe
is able to make a valuable contribution to the scientific discussion.

Back to table of contents
the norm addressees, the regulator should consider establishing certain measures that prevent the norm
addressees from dissolving these dissonances by compensational behavior.
Referring the results to the European Union regulation REACH, we have shown that the knowledge about
the actual behavior of norm addressees is crucial in terms of developing a concept of control theory that
aims at linking their rational, autonomous actions with sovereign elements. In this context and regarding
checking norms for their efficiency and functionality ${ }^{24}$, the method of experimental economics ${ }^{25}$ research
is able to make a valuable contribution to the scientific discussion.

Back to table of contents
the norm addressees, the regulator should consider establishing certain measures that prevent the norm
addressees from dissolving these dissonances by compensational behavior.
Referring the results to the European Union regulation REACH, we have shown that the knowledge about
the actual behavior of norm addressees is crucial in terms of developing a concept of control theory that
aims at linking their rational, autonomous actions with sovereign elements. In this context and regarding
checking norms for their efficiency and functionality ${ }^{24}$, the method of experimental economics ${ }^{25}$ research
is able to make a valuable contribution to the scientific discussion.

Back to table of contents
the norm addressees, the regulator should consider establishing certain measures that prevent the norm
addressees from dissolving these dissonances by compensational behavior.
Referring the results to the European Union regulation REACH, we have shown that the knowledge about
the actual behavior of norm addressees is crucial in terms of developing a concept of control theory that
aims at linking their rational, autonomous actions with sovereign elements. In this context and regarding
checking norms for their efficiency and functionality ${ }^{24}$, the method of experimental economics ${ }^{25}$ research
is able to make a valuable contribution to the scientific discussion.

Back to table of contents
the norm addressees, the regulator should consider establishing certain measures that prevent the norm
addressees from dissolving these dissonances by compensational behavior.
Referring the results to the European Union regulation REACH, we have shown that the knowledge about
the actual behavior of norm addressees is crucial in terms of developing a concept of control theory that
aims at linking their rational, autonomous actions with sovereign elements. In this context and regarding
checking norms for their efficiency and functionality ${ }^{24}$, the method of experimental economics ${ }^{25}$ research
is able to make a valuable contribution to the scientific discussion.

Back to table of contents
the norm addressees, the regulator should consider establishing ce
addressees from dissolving these dissonances by compensational be
Referring the results to the European Union regulation REACH, we
the actual behavior of norm addressees is crucial in terms of devel
aims at linking their rational, autonomous actions with sovereign e
checking norms for their efficiency and functionality ${ }^{24}$, the method
is able to make a valuable contribution to the scientific discussion. 


\section{Appendices: Instructions}

i. Instructions treatment 1 (original text in German)

EXPERIMENT_SU

\section{Instructions}

You are now taking part in an economic experiment. Whatever the results, you are going to receive a show-up fee of $€ 3.00$. During the experiment, you can earn extra money.

Please read the following instructions carefully. They will inform you about everything you need to know to participate in the experiment. In case you do not understand something, please put your hand up. Your question will then be answered at your seat.

The experiment is divided into several rounds. In each round, you will be asked to make decisions and enter them into the computer.

Please note that it is strictly prohibited to communicate with each other during the experiment. Furthermore, we would like to inform you that you may only use those technical functions at your computer that are designed for the experiment. You will be banned from participating in the experiment if you do not follow these rules. If you have any questions, please do not hesitate to contact us.

\section{Important advice:}

Please read the instructions COMPLETELY. They describe TWO roles (seller and buyer).

\section{You will be informed about your role once the experiment begins!}

\section{Contents}

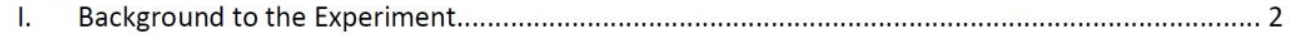

II. Characterisation of the Seller .................................................................................................. 2

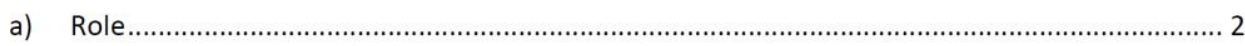

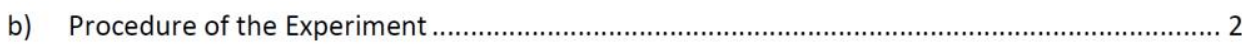

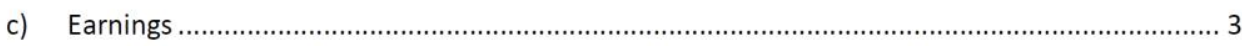

d) Screenshots: Input Screens in Chronological Order ............................................................ 3

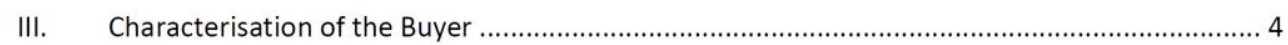

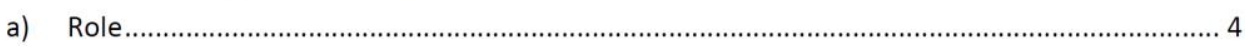

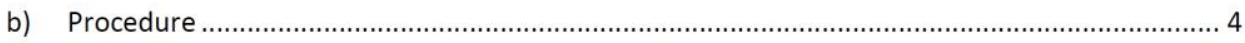

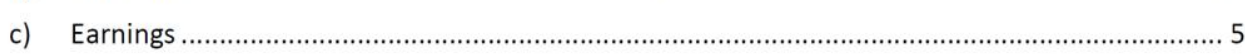

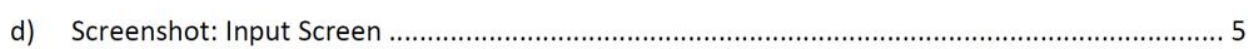




\section{Background to the Experiment}

This experiment approaches the communication between two actors. One actor is the seller and the other the buyer. According to legal standards, the seller is obliged to provide the buyer with information about the product which is to be sold. For this purpose, a data sheet has to be used, listing product-related characteristics and information. As time went by, legal standards have been adjusted to the content and to the length of the data sheet. In this experiment, it is distinguished between: legal requirements 'old' and legal requirements 'new'. The legal requirements 'new' are, of course, binding.

HOWEVER: You will not be penalised for not complying with the legal requirements 'new'.

\section{Characterisation of the Seller}

a) Role

$\checkmark$ The 'seller' sells a product with a corresponding data sheet.

$\checkmark$ The data sheet can be issued in four quality grades.

$\checkmark$ The quality and the price of the product, for which the data sheet has to be issued, are not important here and remain steady for the duration of the experiment.

b) Procedure of the Experiment

$\checkmark$ The experiment consists of several rounds. One round contains one action performed by the seller and a reaction carried out by the buyer. The number of rounds is unknown.

$\checkmark$ The seller stays in this role in all rounds and makes contact with the same buyer throughout the entire experiment.

$\checkmark$ In each round, the seller may decide whether to offer one product with the corresponding data sheet at the market or not. If so, the buyer will then decide whether to accept or decline the offer.

$\checkmark \quad$ If the seller offers a product, two steps have to be taken:

STEP 1: The seller decides for one quality grade of the data sheet. There are four quality grades to choose from.

STEP 2: $\quad$ The seller decides on a price to demand from the buyer. The price may be chosen as exactly as two decimal places.

$\checkmark$ The seller is fully informed. This means (see the following table):

- The seller knows the costs for the different quality grades when issuing the data sheet;

- the seller knows that the quality grade of the data sheet is identifiable by the buyer before the contract is completed;

- the seller knows the buyer's maximum willingness to pay for each quality grade;

- the seller knows that the buyer is aware of the expenses of issuing the data sheet.

Table: Overview on seller's costs and buyer's maximum willingness to pay

\begin{tabular}{|c|l|c|c|}
\hline $\begin{array}{c}\text { Quality Grade } \\
\text { of Data Sheet: }\end{array}$ & $\begin{array}{l}\text { Characteristics of } \\
\text { Quality Grade: }\end{array}$ & $\begin{array}{l}\text { Seller: Costs of Creating } \\
\text { Quality Grade (in EUR) }\end{array}$ & $\begin{array}{l}\text { Buyer: Max Willingness } \\
\text { to Pay (WTP) (in EUR) }\end{array}$ \\
\hline $\mathbf{1}$ & $\begin{array}{l}\text { Generally inadequate; } \\
\text { does not comply with any } \\
\text { legal requirements. }\end{array}$ & 0.5 & 0.7 \\
\hline $\mathbf{2}$ & $\begin{array}{l}\text { In compliance with legal } \\
\text { requirements 'old'; } \\
\text { does not comply with legal } \\
\text { requirements 'new' }\end{array}$ & 2 & 3 \\
\hline 3 & $\begin{array}{l}\text { In compliance with legal } \\
\text { requirements 'new'. }\end{array}$ & 3 & 5 \\
\hline 4 & $\begin{array}{l}\text { Goes beyond legal } \\
\text { requirements 'new'; } \\
\text { in compliance with legal } \\
\text { requirements 'new' }\end{array}$ & 4.1 & 4.8 \\
\hline
\end{tabular}


In each round in which the seller participates in the market by offering a product, the seller may decide anew on the quality grade of the corresponding data sheet.

$\checkmark$ The seller will not be penalised for not complying with the legal requirements 'new' when compiling the data sheet.

$\checkmark$ When the experiment begins, the seller is not in funds, i.e. the seller does not have any money to start with.

\section{c) Earnings}

Additional Earnings

- In each round, the seller can earn the difference between the expenses of issuing the data sheet and the price paid by the buyer:

\section{EARNINGS = PRICE PAID minUs EXPENSES FOR ISSUE OF DATA SHEET}

- INDEPENDENT of the result achieved in the experiment, each participant receives $€ 3.00$ for having attended the experiment.

\section{NO Additional Earnings}

- INDEPENDENT of the reason: If a deal is not completed (the seller does not make an offer or the buyer declines the offer), there will be NO additional earnings ( $€ 0.00)$ for neither the seller nor the buyer in THAT round. No costs will arise for the seller.

\section{d) Screenshots: Input Screens in Chronological Order}

Figure 1: FIRST Step: You choose a quality grade.

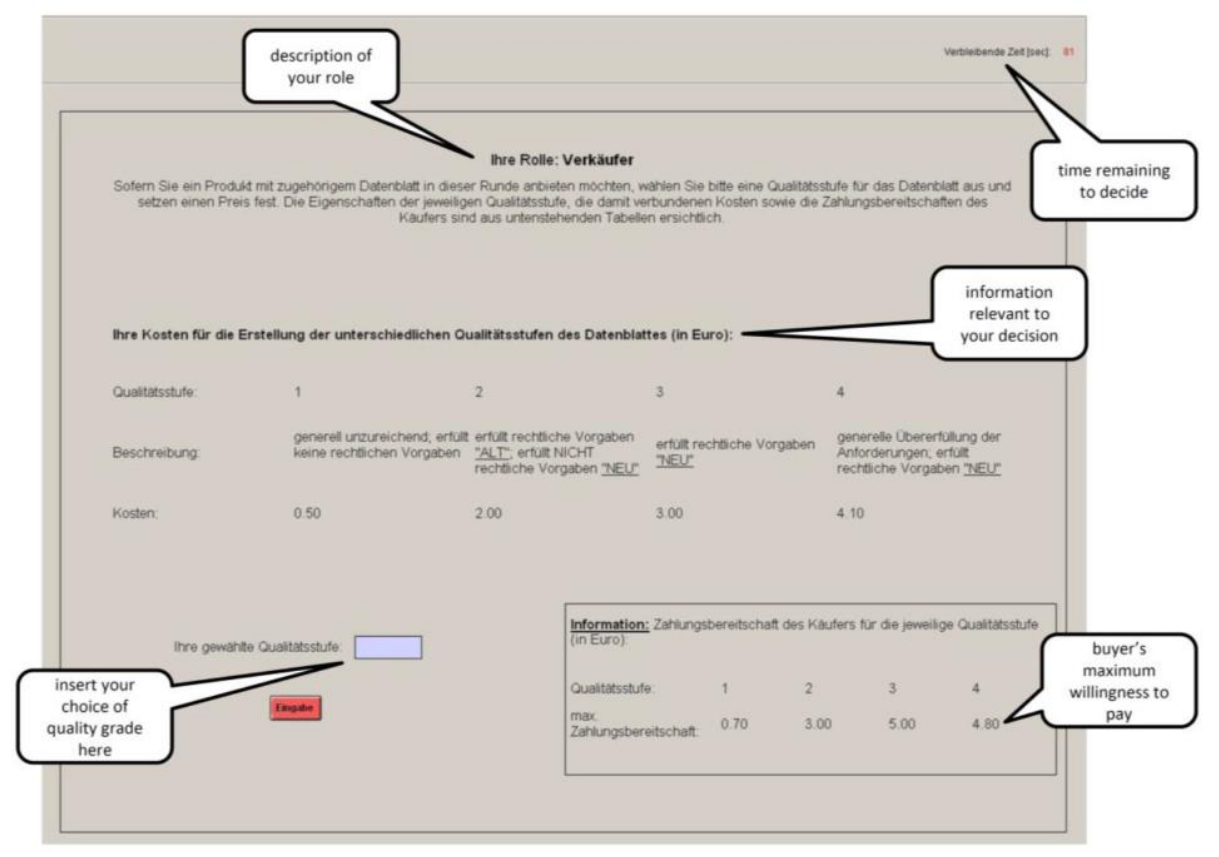


Figure 2: SECOND step: You decide on the price for the chosen quality grade.

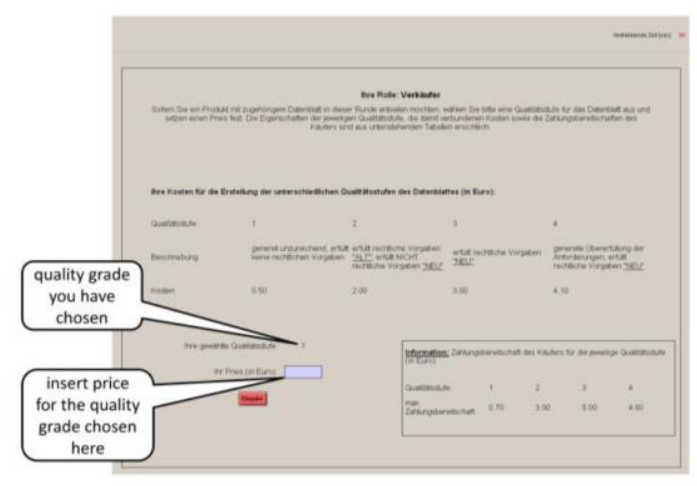

\section{Characterisation of the Buyer}

a) Role

$\checkmark$ The 'buyer' is offered a product with a corresponding data sheet and decides whether to purchase the product or not.

$\checkmark$ The data sheet may have four different quality grades.

$\checkmark$ The quality and the price of the product, for which the data sheet has to be issued, are not important here and remain steady for the duration of the experiment.

\section{b) Procedure}

$\checkmark$ The experiment consists of several rounds. One round contains one action performed by the seller and a reaction carried out by the buyer. The number of rounds is unknown.

$\checkmark$ The buyer stays in this role in all rounds and makes contact with the same seller throughout the entire experiment.

$\checkmark$ If the seller offers a product with a corresponding data sheet, the buyer decides whether to accept or decline the offer.

$\checkmark$ The buyer is fully informed. This means (see the following table):

- The buyer can identify the quality grade of the data sheet offered by the seller before the contract is completed;

- the buyer has a different willingness to pay for each quality grade;

- the buyer knows the seller's expenses for issuing the data sheet;

- the buyer knows that the seller is aware of his varying maximum willingness to pay.

Table: Overview on seller's costs and buyer's maximum willingness to pay

\begin{tabular}{|c|l|c|c|}
\hline $\begin{array}{l}\text { Quality Grade } \\
\text { of Data Sheet: }\end{array}$ & $\begin{array}{l}\text { Characteristics of } \\
\text { Quality Grade: }\end{array}$ & $\begin{array}{l}\text { Seller: Costs of Creating } \\
\text { Quality Grade (in EUR) }\end{array}$ & $\begin{array}{l}\text { Buyer: Max Willingness } \\
\text { to Pay (WTP) (in EUR) }\end{array}$ \\
\hline $\mathbf{1}$ & $\begin{array}{l}\text { Generally inadequate; } \\
\text { does not comply with any } \\
\text { legal requirements. }\end{array}$ & 0.5 & 0.7 \\
\hline $\mathbf{2}$ & $\begin{array}{l}\text { In compliance with legal } \\
\text { requirements 'old'; } \\
\text { does not comply with legal } \\
\text { requirements 'new' }\end{array}$ & 2 & 3 \\
\hline $\mathbf{3}$ & $\begin{array}{l}\text { In compliance with legal } \\
\text { requirements 'new' }\end{array}$ & 3 & 5 \\
\hline $\mathbf{4}$ & $\begin{array}{l}\text { Goes beyond legal } \\
\text { requirements 'new'; } \\
\text { in compliance with legal } \\
\text { requirements 'new' }\end{array}$ & 4.1 & 4.8 \\
\hline
\end{tabular}


In each round in which the seller participates in the market, the buyer may decide whether to accept or decline the offer.

$\checkmark$ The buyer is not penalised for purchasing a product with a corresponding data sheet that does not comply with the legal requirements 'new'.

$\checkmark$ When the experiment begins, the buyer is not in funds, i.e. the buyer does not have any money to start with.

\section{c) Earnings}

Additional Earnings

- In each round, the buyer can earn the difference between the maximum willingness to pay for the particular quality grade of the data sheet and the price actually paid to the seller:

\section{EARNINGS = MAXIMUM WILLINGNESS TO PAY minus PRICE PAID}

- INDEPENDENT of the result achieved in the experiment, each participant receives $€ 3.00$ for having attended the experiment.

\section{NO Additional Earnings}

- INDEPENDENT of the reason: If a deal is not completed (the seller does not make an offer or the buyer declines the offer), there will be NO additional earnings ( $€ 0.00)$ for neither the seller nor the buyer in THAT round. No costs will arise for the buyer.

\section{d) Screenshot: Input Screen}

Figure 3: You decide whether to accept or decline the offer made by the seller

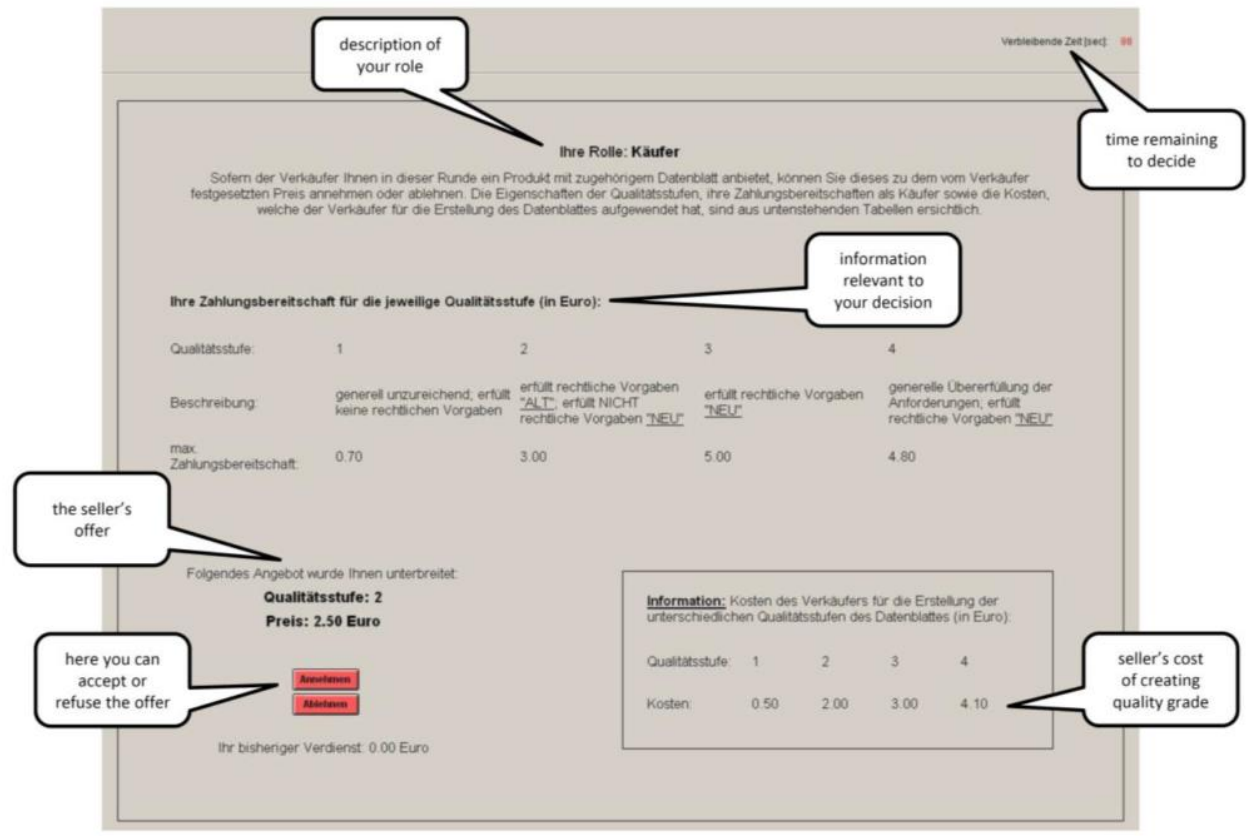


ii. Instructions treatment 2 (original text in German)

EXPERIMENT_SurE

\section{Instructions}

You are now taking part in an economic experiment. Whatever the results, you are going to receive a show-up fee of $€ 3.00$. During the experiment, you can earn extra money.

Please read the following instructions carefully. They will inform you about everything you need to know to participate in the experiment. In case you do not understand something, please put your hand up. Your question will then be answered at your seat.

The experiment is divided into several rounds. In each round, you will be asked to make decisions and enter them into the computer.

Please note that it is strictly prohibited to communicate with each other during the experiment. Furthermore, we would like to inform you that you may only use those technical functions at your computer that are designed for the experiment. You will be banned from participating in the experiment if you do not follow these rules. If you have any questions, please do not hesitate to contact us.

\section{Important advice:}

Please read the instructions COMPLETELY. They describe TWO roles (seller and buyer).

\section{You will be informed about your role once the experiment begins!}

\section{Contents}

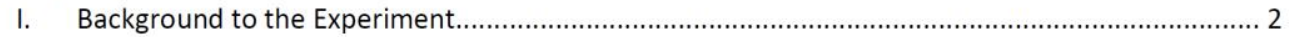

II. Characterisation of the Seller .............................................................................................. 2

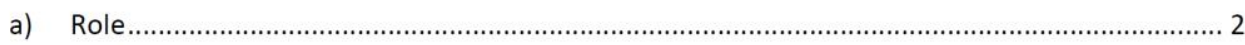

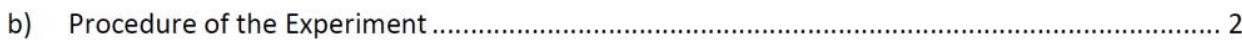

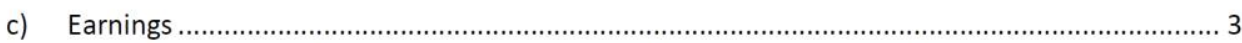

d) Screenshots: Input Screens in Chronological Order ............................................................ 3

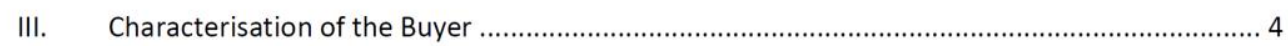

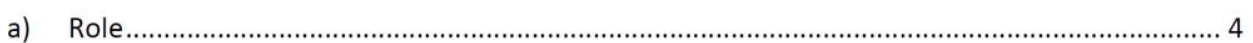

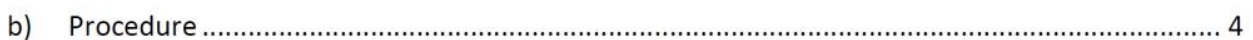

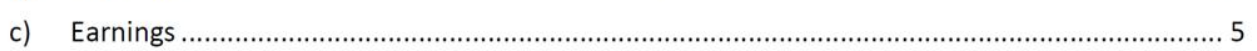

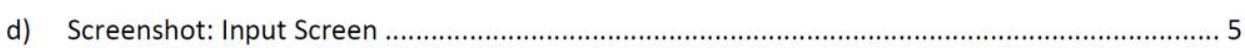




\section{Background to the Experiment}

This experiment approaches the communication between two actors. One actor is the seller and the other the buyer. According to legal standards, the seller is obliged to provide the buyer with information about the product which is to be sold. For this purpose, a data sheet has to be used, listing product-related characteristics and information. As time went by, legal standards have been adjusted to the content and to the length of the data sheet. In this experiment, it is distinguished between: legal requirements 'old' and legal requirements 'new'. The legal requirements 'new' are, of course, binding.

HOWEVER: You will not be penalised for not complying with the legal requirements 'new'.

\section{Characterisation of the Seller}

a) Role

$\checkmark$ The 'seller' sells a product with a corresponding data sheet.

$\checkmark$ The data sheet can be issued in four quality grades.

$\checkmark$ The quality and the price of the product, for which the data sheet has to be issued, are not important here and remain steady for the duration of the experiment.

\section{b) Procedure of the Experiment}

$\checkmark$ The experiment consists of several rounds. One round contains one action performed by the seller and a reaction carried out by the buyer. The number of rounds is unknown.

$\checkmark$ The seller stays in this role in all rounds and makes contact with the same buyer throughout the entire experiment.

$\checkmark$ In each round, the seller may decide whether to offer one product with the corresponding data sheet at the market or not. If so, the buyer will then decide whether to accept or decline the offer.

$\checkmark \quad$ If the seller offers a product, two steps have to be taken:

STEP 1: The seller decides for one quality grade of the data sheet. There are four quality grades to choose from.

STEP 2: The seller decides on a price to demand from the buyer. The price may be chosen as exactly as two decimal places.

$\checkmark$ The seller is fully informed. This means (see the following table):

- The seller knows the costs for the different quality grades when issuing the data sheet;

- the seller knows that the quality grade of the data sheet is identifiable by the buyer before the contract is completed;

- the seller knows the buyer's maximum willingness to pay for each quality grade;

- the seller knows that the buyer is aware of the expenses of issuing the data sheet.

Table: Overview on seller's costs and buyer's maximum willingness to pay

\begin{tabular}{|c|l|c|c|}
\hline $\begin{array}{l}\text { Quality Grade } \\
\text { of Data Sheet: }\end{array}$ & $\begin{array}{l}\text { Characteristics of } \\
\text { Quality Grade: }\end{array}$ & $\begin{array}{l}\text { Seller: Costs of Creating } \\
\text { Quality Grade (in EUR) }\end{array}$ & $\begin{array}{l}\text { Buyer: Max Willingness } \\
\text { to Pay (WTP) (in EUR) }\end{array}$ \\
\hline $\mathbf{1}$ & $\begin{array}{l}\text { Generally inadequate; } \\
\text { does not comply with any } \\
\text { legal requirements. }\end{array}$ & 0.5 & 2.50 \\
\hline $\mathbf{2}$ & $\begin{array}{l}\text { In compliance with legal } \\
\text { requirements 'old'; } \\
\text { does not comply with legal } \\
\text { requirements 'new' }\end{array}$ & 2 & 3 \\
\hline $\mathbf{3}$ & $\begin{array}{l}\text { In compliance with legal } \\
\text { requirements 'new' }\end{array}$ & 3 & 3.20 \\
\hline $\mathbf{4}$ & $\begin{array}{l}\text { Goes beyond legal } \\
\text { requirements 'new'; } \\
\text { in compliance with legal } \\
\text { requirements 'new' }\end{array}$ & 4.1 & 4.8 \\
\hline
\end{tabular}


In each round in which the seller participates in the market by offering a product, the seller may decide anew on the quality grade of the corresponding data sheet.

$\checkmark$ The seller will not be penalised for not complying with the legal requirements 'new' when compiling the data sheet.

$\checkmark$ When the experiment begins, the seller is not in funds, i.e. the seller does not have any money to start with.

\section{c) Earnings}

$\checkmark$ Additional Earnings

- In each round, the seller can earn the difference between the expenses of issuing the data sheet and the price paid by the buyer:

EARNINGS $=$ PRICE PAID minus EXPENSES FOR ISSUE OF DATA SHEET

- INDEPENDENT of the result achieved in the experiment, each participant receives $€ 3.00$ for having attended the experiment.

\section{NO Additional Earnings}

- INDEPENDENT of the reason: If a deal is not completed (the seller does not make an offer or the buyer declines the offer), there will be NO additional earnings ( $€ 0.00)$ for neither the seller nor the buyer in THAT round. No costs will arise for the seller.

\section{d) Screenshots: Input Screens in Chronological Order}

\section{Figure 1: FIRST Step: You choose a quality grade.}

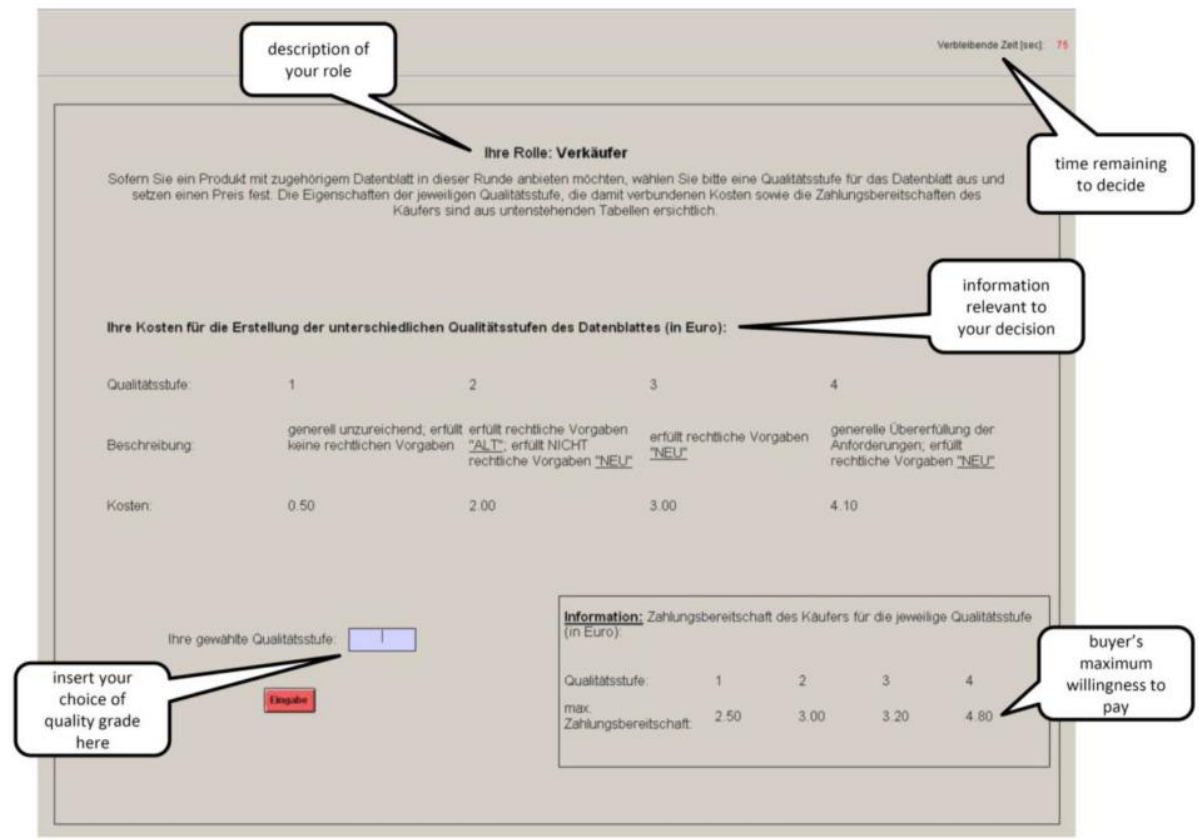


Figure 2: SECOND step: You decide on the price for the chosen quality grade.

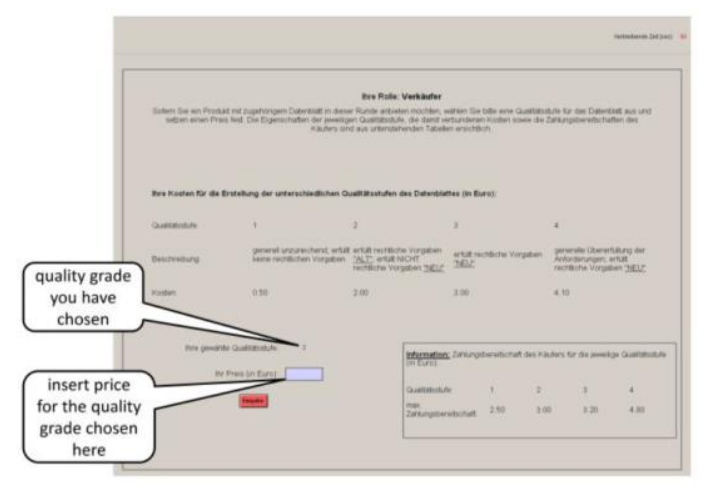

\section{Characterisation of the Buyer}

a) Role

$\checkmark$ The 'buyer' is offered a product with a corresponding data sheet and decides whether to purchase the product or not.

$\checkmark$ The data sheet may have four different quality grades.

$\checkmark$ The quality and the price of the product, for which the data sheet has to be issued, are not important here and remain steady for the duration of the experiment.

\section{b) Procedure}

$\checkmark$ The experiment consists of several rounds. One round contains one action performed by the seller and a reaction carried out by the buyer. The number of rounds is unknown.

$\checkmark$ The buyer stays in this role in all rounds and makes contact with the same seller throughout the entire experiment.

$\checkmark$ If the seller offers a product with a corresponding data sheet, the buyer decides whether to accept or decline the offer.

$\checkmark$ The buyer is fully informed. This means (see the following table):

- He can identify the quality grade of the data sheet offered to him before the contract is completed;

- the buyer has a different willingness to pay for each quality grade;

- the buyer knows the seller's expenses for issuing the data sheet;

- the buyer knows that the seller is aware of his varying maximum willingness to pay.

Table: Overview on seller's costs and buyer's maximum willingness to pay

\begin{tabular}{|c|l|c|c|}
\hline $\begin{array}{l}\text { Quality Grade } \\
\text { of Data Sheet: }\end{array}$ & $\begin{array}{l}\text { Characteristics of } \\
\text { Quality Grade: }\end{array}$ & $\begin{array}{l}\text { Seller: Costs of Creating } \\
\text { Quality Grade (in EUR) }\end{array}$ & $\begin{array}{l}\text { Buyer: Max Willingness } \\
\text { to Pay (WTP) (in EUR) }\end{array}$ \\
\hline $\mathbf{1}$ & $\begin{array}{l}\text { Generally inadequate; } \\
\text { does not comply with any } \\
\text { legal requirements. }\end{array}$ & 0.5 & 2.50 \\
\hline $\mathbf{2}$ & $\begin{array}{l}\text { - In compliance with legal } \\
\text { requirements 'old'; } \\
\text { does not comply with legal } \\
\text { requirements 'new'. }\end{array}$ & 2 & 3 \\
\hline $\mathbf{3}$ & $\begin{array}{l}\text { In compliance with legal } \\
\text { requirements 'new'. }\end{array}$ & 3 & 3.20 \\
\hline $\mathbf{4}$ & $\begin{array}{l}\text { Goes beyond legal } \\
\text { requirements 'new'; } \\
\text { in compliance with legal } \\
\text { requirements 'new'. }\end{array}$ & 4.1 & 4.8 \\
\hline
\end{tabular}


In each round in which the seller participates in the market, the buyer may decide whether to accept or decline the offer.

$\checkmark$ The buyer is not penalised for purchasing a product with a corresponding data sheet that does not comply with the legal requirements 'new'.

$\checkmark$ When the experiment begins, the buyer is not in funds, i.e. the buyer does not have any money to start with.

\section{c) Earnings}

$\checkmark$ Additional Earnings

- In each round, the buyer can earn the difference between the maximum willingness to pay for the particular quality grade of the data sheet and the price actually paid to the seller:

\section{EARNINGS = MAXIMUM WILLINGNESS TO PAY minUS PRICE PAID}

- INDEPENDENT of the result achieved in the experiment, each participant receives $€ 3.00$ for having attended the experiment.

\section{NO Additional Earnings}

- INDEPENDENT of the reason: If a deal is not completed (the seller does not make an offer or the buyer declines the offer), there will be NO additional earnings ( $€ 0.00)$ for neither the seller nor the buyer in THAT round. No costs will arise for the buyer.

\section{d) Screenshot: Input Screen}

Figure 3: You decide whether to accept or decline the offer made by the seller

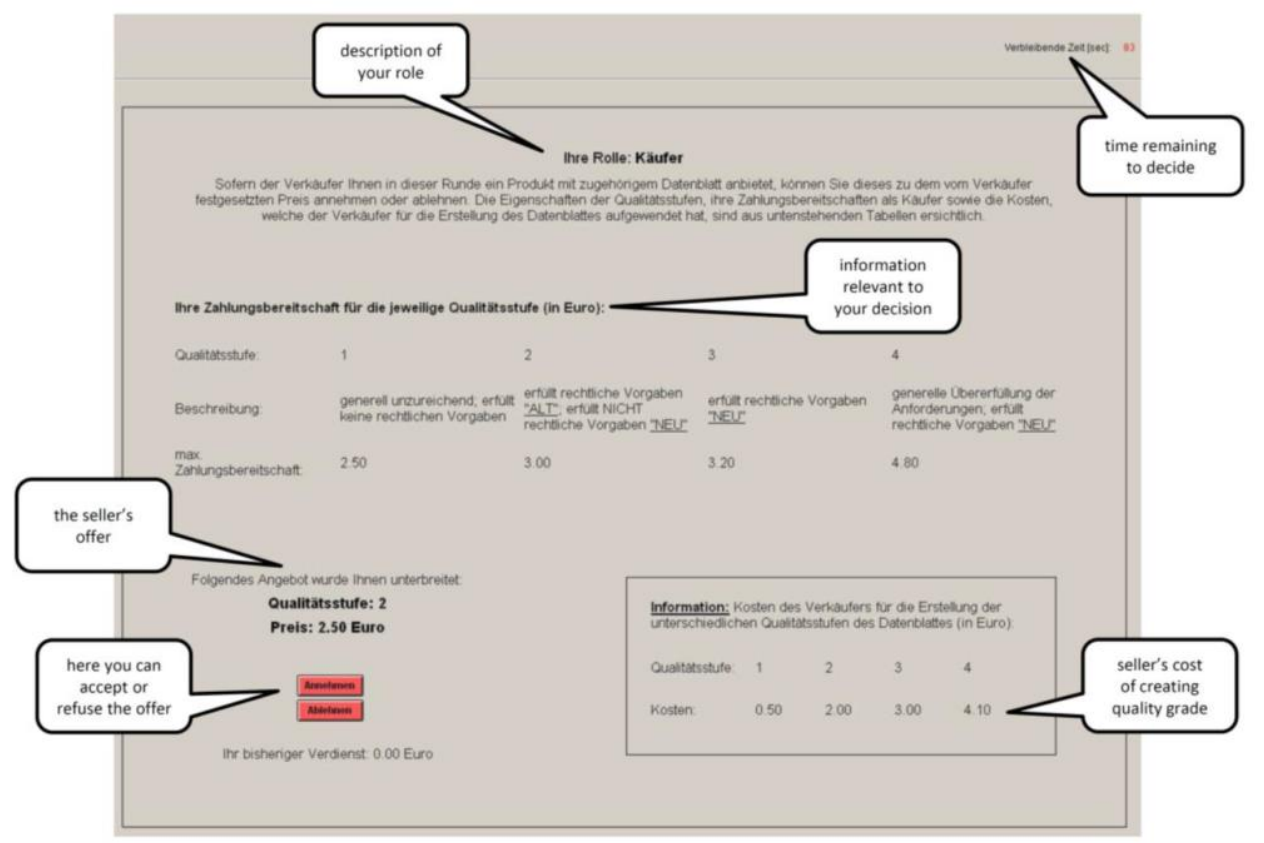




\section{Notes}

1 General considerations on strengths and weaknesses of regulatory approaches including selfresponsibility on part of norm addresses are given in Krarup 2001and Börzel, Risse 2010.

2 The acronym REACH stands for Registration, Evaluation, Authorisation and Restriction of Chemicals.

3 Further information on this regulatory approach with respect to European chemicals policy can be found in Führ, Bizer 2007 and Hey et al. 2007.

4 "This Regulation is based on the principle that it is for manufacturers, importers and downstream users to ensure that they manufacture, place on the market or use such substances that do not adversely affect human health or the environment. Its provisions are underpinned by the precautionary principle." Article 1 (3) REACH Regulation.

5 Within the frame of REACH, the group of norm addressees knows different groups of actors that are legally definable. Since the content of the present paper just roughly follows the context of $\mathrm{REACH}$, two ideal-typical norm addressees will be assumed in a supply chain, which are one upstream seller and one downstream buyer.

6 The term "in most cases" highlights the fact that exceptions from this obligation are known within corresponding regulations. It is not necessary to be explained further at this point with respect to our research goals.

7 Incentives and constraints with respect to REACH are analyzed by Führ 2010.

8 By doing so, we aim at precluding unwanted framing that might result from terms used in the handling of chemicals.

9 For the usual state of the art of implementation see for example Holt, Sherman 1999.

10 For the usual state of the art of implementation see for example Güth et al. 1982.

11 The original instructions for treatment 1 can be found in the appendix of this paper under " $\mathrm{i}$ ".

12 The original instructions for treatment 2 can be found in the appendix of this paper under "ii".

13 By informing them about both roles possible in the experiment, we intended to ensure that the structure of the experiment had been understood by the participants best possible.

14 We present the wording verbatim to show the neutrality of our experimental context. Implementing the original terminology used in the chemicals regulation might otherwise have triggered unwanted framing at this point.

15 Wording of original instructions, see appendix of this paper.

16 See similar wording in the original instructions in the appendix of this paper.

17 See the original instructions in the appendix of this paper.

18 See similar wording in the original instructions in the appendix of this paper.

19 See the original instructions in the appendix of this paper.

20 See the details on the background to the experiment in subchapter 3.1.2. 
21 Regarding the calculation and realisation of the cooperation gain see the explanations in subchapter 3.1.2, "instructions".

22 The fields with drawn-through lines in table 1 denote the respective quality grades and expenses of issuing the data sheet as well as the maximum willingness to pay at which the divisible cooperation gain is the highest possible.

23 See also the explanations about the instructions in subchapter 3.1.2.

24 An overview about the state of the art on regulatory impact assessment in practice is given in Hensel et al. 2010.

25 For a broader reflection on how experimental economics can contribute to the design of institutions which are able to reach a superior goal by explicitly taking into account incentives and behavior of norm addressees, see also Santos 2011 and Ockenfels 2009.

\section{Publication bibliography}

Akerlof, George A. (1970): The Market for "Lemons": Quality Uncertainty and the Market Mechanism. In Quarterly Journal of Economics 84 (3), pp. 488-500.

Börzel, Tanja A.; Risse, Thomas (2010): Governance without a state: Can it work? In Regulation \& Governance 4, pp. 113-134.

Bundesanstalt für Arbeitsschutz und Arbeitsmedizin (BAuA) (2008): Sicherheitsdatenblätter. Eine Hilfe für den Arbeitgeber. With assistance of Eva Lechtenberg-Auffarth. Edited by Bundesanstalt für Arbeitsschutz und Arbeitsmedizin (BAuA). Bundesanstalt für Arbeitsschutz und Arbeitsmedizin (BAuA). Dortmund. Available online at http://www.baua.de/de/Publikationen/Fachbeitraege/artikel19.html, checked on $2 / 16 / 2015$.

Bunke, Dirk; Rühl, Reinhold (2011): Das Sicherheitsdatenblatt. Kapitel 20. In Martin Führ (Ed.): Praxishandbuch REACH. Köln: Carl Heymanns, pp. 365-392.

European Chemicals Agency (ECHA) (2011): The Operation of REACH and CLP 2011. Edited by European Chemicals Agency (ECHA). European Chemicals Agency (ECHA) (ECHA-11-R-003-EN). Available online at http://echa.europa.eu/documents/10162/13634/operation_reach_clp_2011_en.pdf, checked on $2 / 23 / 2015$.

European Commission (COM (2013) 49 final) (2013): General Report on REACH. Report from the Commission to the European Parliament, the Council, the European Economic and Social Committee and the Committee of the Regions in accordance with Article 117(4) of REACH and Article 46(2) of CLP, and a review of certain elements of REACH in line with Articles 75(2), 138(2), 138(3) and 138(6) of REACH. Edited by European Commission. European Commission. Brussels (COM(2013) 49 final). Available online http://eurlex.europa.eu/LexUriServ/LexUriServ.do?uri=COM:2013:0049:FIN:EN:PDF, checked on 2/16/2015.

Fischbacher, Urs (2007). z-Tree: Zurich toolbox for ready-made economic experiments. In Experimental Economics 10, pp. 171-178.

Führ, Martin (2010): Analyse der Anreize und Hemmnisse am Beispiel der europäischen ChemikalienRegulierung REACh. In Stephan Hensel, Kilian Bizer, Martin Führ, Joachim Lange (Eds.): Gesetzesfolgenabschätzung in der Anwendung. Perspektiven und Entwicklungstendenzen. Baden-Baden: Nomos-Verl.-Ges. (Interdisziplinäre Studien zu Recht und Staat, 48), pp. 177-195.

Führ, Martin; Bizer, Kilian (2007): REACh as a paradigm shift in chemical policy - responsive regulation and behavioural models. In Journal of Cleaner Production 15, pp. 327-334. 
Greiner, Ben (2004): The Online Recruitment System ORSEE - A Guide for the Organization of Experiments in Economics. Max Planck Institute of Economics, Strategic Interaction Group (Papers on Strategic Interaction, 2003-10).

Güth, Werner; Schmittberger, Rolf; Schwarze, Bernd (1982): An experimental analysis of ultimatum bargaining. In Journal of Economic Behavior and Organization 3, pp. 367-388.

Güth, Werner; Tietz, Reinhard (1990): Ultimatum bargaining behavior. A survey and comparison of experimental results. In Journal of Economic Psychology 11, pp. 417-449.

Hensel, Stephan; Bizer, Kilian; Führ, Martin; Lange, Joachim (Eds.) (2010): Gesetzesfolgenabschätzung in der Anwendung. Perspektiven und Entwicklungstendenzen. Baden-Baden: Nomos-Verl.-Ges. (Interdisziplinäre Studien zu Recht und Staat, 48).

Hey, Christian; Jacob, Klaus; Volkery, Axel (2007): Better regulation by new governance hybrids? Governance models and the reform of European chemicals policy. In Journal of Cleaner Production 15, pp. 1859-1874.

Holt, Charles A.; Sherman, Roger (1999): Classroom Games: A Market for Lemons. In Journal of Economic Perspectives 13 (1), pp. 205-214.

Krarup, Signe (2001): Can voluntary approaches ever be efficient? In Journal of Cleaner Production 9 , pp. 135-144.

Mayer-Figge, Andrea (2013): Qualität von Sicherheitsdatenblättern - Anspruch und Wirklichkeit: Ergebnisse aus dem Vollzug. In Zeitschrift für Stoffrecht (2), pp. 52-66.

Nationaler Normenkontrollrat (2012): Analysis of weak points relating to the registration obligations under the European Chemicals Regulation REACH. A joint project of the Nationaler Normenkontrollrat (NKR), the Federal Ministry for the Environment, Nature Conservation and Nuclear Safety (BMU), the Federal Institute for Occupational Safety and Health (BAuA), the Federal Environment Agency (UBA), and the German Chemical Industry Association (VCI). Nationaler Normenkontrollrat. Berlin. Available online at http://www.normenkontrollrat.bund.de/Webs/NKR/Content/EN/Publikationen/2013-10-21-englreach.pdf?_blob=publicationFile\&v=1, checked on 2/16/2015.

Ockenfels, Axel (2009): Marktdesign und Experimentelle Wirtschaftsforschung. In Perspektiven der Wirtschaftspolitik 10 (Special Issue), pp. 31-53.

REACH Regulation: Regulation (EC) No 1907/2006 of the European Parliament and the Council of 18 December 2006 concerning the Registration, Evaluation, Authorisation and Restriction of Chemicals (REACH), establishing a European Chemicals Agency, amending Directive 1999/45/EC and repealing Council Regulation (EEC) No 793/93 and Commission Regulation (EC) No 1488/94 as well as Council Directive 76/769/EEC and Commission Directives 91/155/EEC, 93/67/EEC, 93/105/EC and 2000/21/EC. In Official Journal of the European Union L 136.

Santos, Ana C. (2011): Behavioural and experimental economics: are they really transforming economics? In Cambridge Journal of Economics 35, pp. 705-728. 


\section{Affirmation in lieu of an oath}

(Versicherung an Eides Statt)

Ich versichere an Eides Statt, dass ich die eingereichte Dissertation „Essays about Prerequisites for the Regulation of Risk Communication in Supply Chains with Respect to the European Community Regulation on Chemicals REACH (EC) No 1907/2006“ selbstständig verfasst habe. Anderer als der von mir angegebenen Hilfsmittel und Schriften habe ich mich nicht bedient. Alle wörtlich oder sinngemäß den Schriften anderer Autorinnen und/oder Autoren entnommenen Stellen habe ich kenntlich gemacht.

Stephan Hensel 